University of Wisconsin Milwaukee UWM Digital Commons

Theses and Dissertations

May 2017

\title{
Do Exchange Rate Changes Have Symmetric or Asymmetric Effects on Stock Prices?
}

Sujata Saha

University of Wisconsin-Milwaukee

Follow this and additional works at: https://dc.uwm.edu/etd

Part of the Economics Commons

\section{Recommended Citation}

Saha, Sujata, "Do Exchange Rate Changes Have Symmetric or Asymmetric Effects on Stock Prices?" (2017). Theses and Dissertations. 1535.

https://dc.uwm.edu/etd/1535

This Dissertation is brought to you for free and open access by UWM Digital Commons. It has been accepted for inclusion in Theses and Dissertations by an authorized administrator of UWM Digital Commons. For more information, please contact open-access@uwm.edu. 


\title{
DO EXCHANGE RATE CHANGES HAVE SYMMETRIC OR ASYMMETRIC EFFECTS ON STOCK PRICES?
}

by

Sujata Saha

\begin{abstract}
A Dissertation Submitted in
Partial Fulfilment of the

Requirements for the Degree of
\end{abstract}

Doctor of Philosophy

in Economics

at

The University of Wisconsin-Milwaukee

May 2017 


\begin{abstract}
DO EXCHANGE RATE CHANGES HAVE SYMMETRIC OR ASYMMETRIC EFFECTS ON STOCK PRICES?
\end{abstract}

by

Sujata Saha

The University of Wisconsin-Milwaukee, 2017

Under the Supervision of Professor Mohsen Bahmani-Oskooee

This study employs the bounds testing approach to cointegration to examine the short run and long run dynamics between stock prices and exchange rates, accounting for few other macroeconomic variables such as Consumer Price Index, Industrial Production Index, nominal money supply (M2) which are known to have effects on stock prices as well. The main contribution of this paper which is absent in the literature is that the change in nominal effective exchange rate is decomposed into partial sum of positive changes and negative changes to determine whether the changes in exchange rates have symmetric or asymmetric effects on stock prices. The analysis is applied to both developed and developing countries over the period of 1973-2015. The results show that the effect of exchange rate changes is asymmetric on stock prices. Furthermore, I disaggregate data at the sectoral level for the U.S. stock market to investigate the performance of different sectors due to changes in macroeconomic variables and results show that different sectors react differently to changes in macroeconomic variables and exchange rate changes have asymmetric effects on the stock price indices of different sectors in the U.S. 
my parents 


\section{TABLE OF CONTENTS}

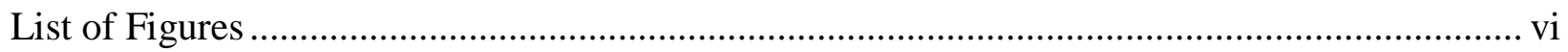

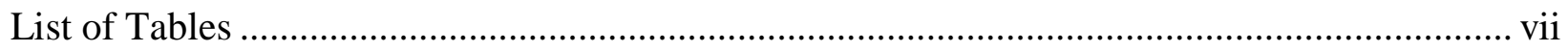

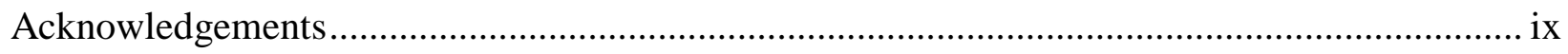

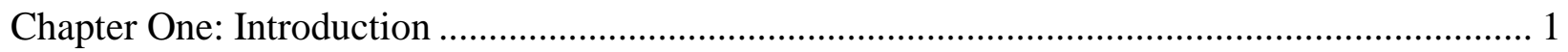

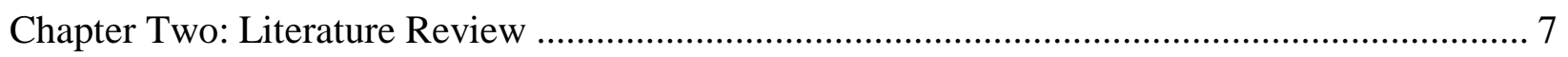

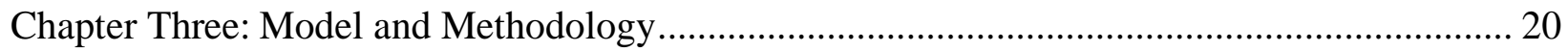

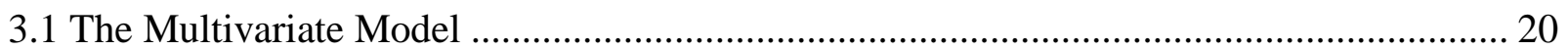

3.1.1 The Linear Model: EX, IPI, CPI and M2 as independent variables .......................... 20

3.1.2 The Non-Linear Model: POS, NEG, IPI, CPI and $M 2$ as independent variables ........ 24

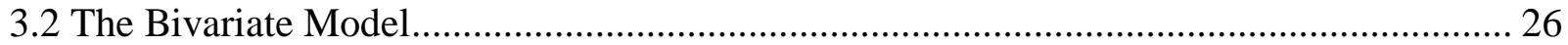

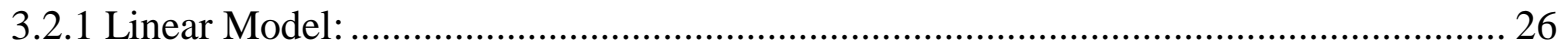

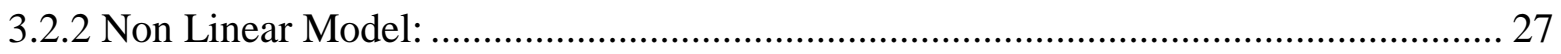

Chapter Four: Empirical Results........................................................................................ 28

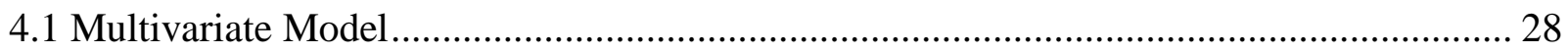

4.2 The Bivariate Model: ............................................................................................ 33

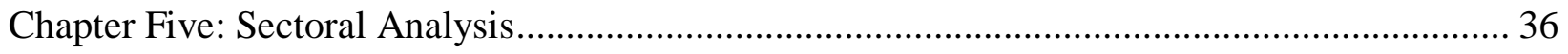

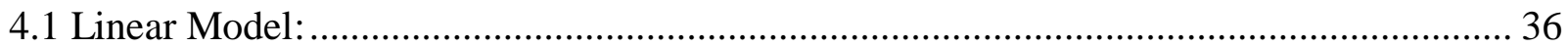

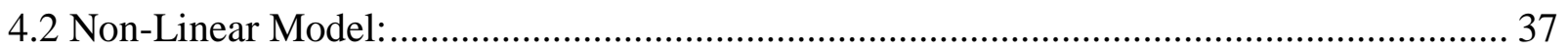

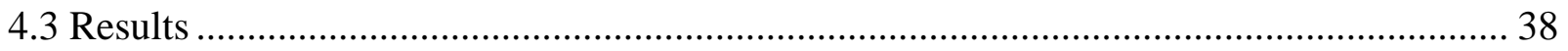

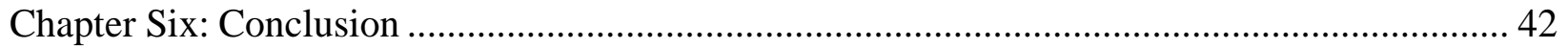

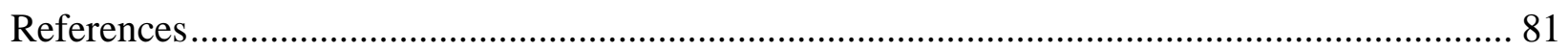

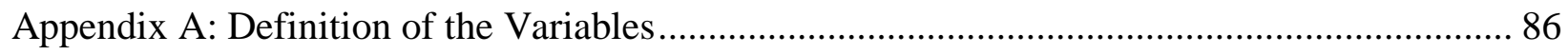

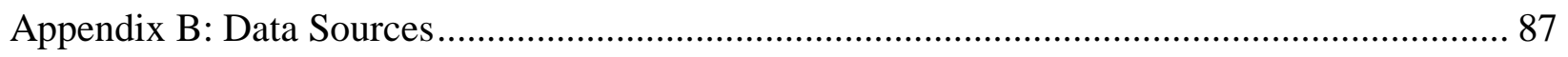

Appendix C.1: Data period for the Multivariate Model .............................................................. 88

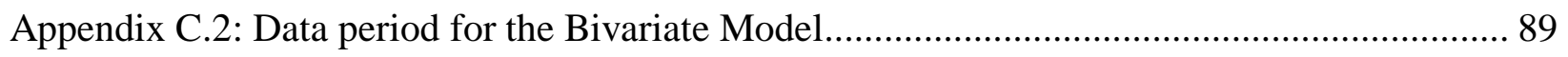

Appendix C.3: Data period for the Sectoral Analysis for the U.S. ............................................. 90 


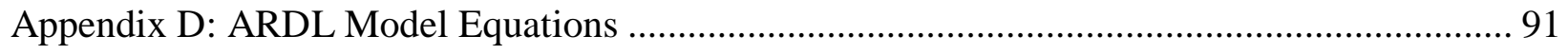

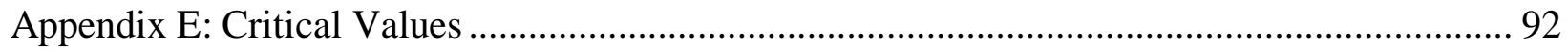

Appendix F: Natural Log of LEX, POS, NEG, LIPI, LCPI, LM2 and LSP Graphs .................. 93

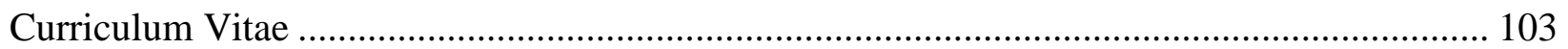




\section{LIST OF FIGURES}

Figure 1: CUSUSM and CUSUSM Square plots for the multivariate model ............... 70-74

Figure 2: CUSUSM and CUSUSM Square plots for the sectoral analysis ............... 75-80 


\section{LIST OF TABLES}

Table 1: The ADF Test Results for variables in level 45

Table 2: The ADF Test Results for first differenced variables 46

Table 3: Estimates of Linear and Non-linear Models for Brazil (multivariate model) 47

Table 4: Estimates of Linear and Non-linear Models for Canada (multivariate model) 48

Table 5: Estimates of Linear and Non-linear Models for Chile (multivariate model)

Table 6: Estimates of Linear and Non-linear Models for Indonesia (multivariate model) 50

Table 7: Estimates of Linear and Non-linear Models for Japan (multivariate model) 51

Table 8: Estimates of Linear and Non-linear Models for Korea (multivariate model) 52

Table 9: Estimates of Linear and Non-linear Models for Malaysia (multivariate model) 53

Table 10: Estimates of Linear and Non-linear Models for Mexico (multivariate model) 54

Table 11: Estimates of Linear and Non-linear Models for U.K. (multivariate model) 55

Table 12: Estimates of Linear and Non-linear Models for U.S. (multivariate model) 56

Table 13.1: Estimates of the Linear Model for the bivariate model 57

Table 13.2: Estimates of the Linear Model for the bivariate model 58

Table 13.3: Estimates of the Linear Model for the bivariate model 59

Table 13.4: Estimates of the Linear Model for the bivariate model 60 
Table 14.1: Estimates of the Non Linear Model for the bivariate model

Table 14.2: Estimates of the Non Linear Model for the bivariate model 62

Table 14.3: Estimates of the Non Linear Model for the bivariate model 63

Table 14.4: Estimates of the Non Linear Model for the bivariate model 64

Table 15: The ADF Test Results for the sectoral analysis 65

Table 16.1: Estimates of Both Linear and Nonlinear ARDL Models (sectoral analysis) 66

Table 16.2: Estimates of Both Linear and Nonlinear ARDL Models (sectoral analysis) 67

Table 16.3: Estimates of Both Linear and Nonlinear ARDL Models (sectoral analysis) 68

Table 16.4: Estimates of Both Linear and Nonlinear ARDL Models (sectoral analysis) 69 


\section{ACKNOWLEDGEMENTS}

This thesis represents my work at the University of Wisconsin-Milwaukee for the last five years and is the result of many unique experiences and opportunities - it has indeed been amazing. This would not have been a success without the support and help of many remarkable individuals whom I wish to thank and express my sincere appreciation.

First and foremost, I would like to thank God. Throughout this process, I have grown to realize the impact of his blessings and how they have caused wonders. He has given me the courage, strength and patience to work through problems faced in order to achieve my dreams.

I express my sincere gratitude and thanks to my advisor, Professor Mohsen Bahmani-Oskooee for encouraging me during this process. His unwavering support and faith in me and my abilities are most appreciated. His guidance, patience and immense knowledge have always been a source of great comfort, has steered me through difficult and uncertain times and have allowed me to grow as an economist. He has been a great mentor and I owe a lot of my success to him.

I would also like to thank my dissertation committee members, Professor Kundan Kishor, Professor Rebecca Neumann and Professor Swarnjit Arora. Words truly are not enough to express my gratitude for all the things they have done for me. Their brilliant comments, suggestions, direction and co-operation have helped me achieve my goals. I thank all of them for sparing their valuable time whenever I approached them for guidance.

I thank all the Professors at the Department of Economics whose teaching has helped to develop the economist in me: Professors Scott Drewianka, Kundan Kishor, Suyong Song, Matthew McGinty, Filip Vesley, Chuan Goh, Antu Murshid, Avik Chakrabarti and Rebecca Neumann. I would also like to thank Professors Mohsen Bahmani-Oskooee, Scott Adams, John Heywood, 
Matthew McGinty, Scott Drewianka, Niloy Bose, James Peoples and Itziar Lazkano for their helpful advice on the job market. I am grateful to all of them for ensuring that good times keep flowing.

I would have been lost without the support from Brenda and Vickey, the "soul" of the Department of Economics. Their help and motivation have kept me going. A "tight" hug from Brenda was all that I needed during tough times.

My professors back in India: Professors Samik Ray, Joydeep Ghosh, Somen Sikdar and Samir Ghosh, who discovered and nurtured the talent in me while pursuing my Bachelor's and Master's degrees. I express my gratitude and thank them all immensely.

I owe special thanks to my husband, Kastur for being so supportive since day one. I am thankful as he has always been there to push me when I was ready to give up. Thanks for not just believing, but knowing that I could do this. I greatly value his contributions and continued patience. He is the one who has pushed me to pursue my career. I thank him for everything.

I acknowledge the people who mean a lot to me, my parents, Ma and Baba for bringing me into this wonderful world and for giving me the opportunity to learn. I thank them for believing in me and for giving me the freedom to choose what I desired. They both are now half the world apart, but this journey would have not been possible without their love and support. I thank them for all the pain they took to shape up my life. Their priceless prayers have helped me sail through hard times.

My special thanks and regard go to my parents-in-law for their moral support. Thanks to my brothers-in-law, Kaushik and Kuntal and my sister-in-law Pradipta and Debjani (special thanks to Debjani for being such a nice friend to me). 
I thank all my classmates, Uche, Linh, Hesam, Gabe, Majid, Amirhossein, Kristin and Anni for all the help during the coursework phase, whether with exams or assignments. They have always encouraged me and have brought out the best in me.

A special thanks to my friend Uche (my DPOP). I am falling short of words to express my gratitude to him. I do not know how would have I survived this doctoral journey without his help, support, guidance, weird jokes and facial expressions. I thank him for listening to all my chit-chats.

I thank Hesam for all his support, encouragement and for motivating me to take the driving test. I owe special thanks to Amirhossein for helping me with software stuff. Linh has helped me a lot during my first semester of $\mathrm{PhD}$ with coursework, I thank her for that. I would also like to thank my friend Sugato, who has helped me with several software tips (his help in Microsoft excel is unparalleled), motivated me to become a licensed driver and for the jokes he shared with me to keep me sane during stressful times.

My little sister that I never had, Raktima. I thank her for not letting me get bored, for cheering me up all the time. I relive my childhood when I spend time with her.

I thank my friends both in India and here, Payal, Priyanka, Nupur, Shalini, Mansi, Chandra, Siri, Amid, Venky, Martin, Eduard, Mehdi and Hadis, they all have helped me in one way or the other. Also I thank Sarah for making my last few months at UWM more cheerful and fun-filled.

Thank you for all the help, support and motivation. 


\section{Chapter One: Introduction}

The link between foreign exchange markets and stock markets has captured the interest of both policy makers and investors as it plays an important role in the development of an economy through investment decisions. The relationship between exchange rates and stock prices is bidirectional. There are two approaches to explain the relationship between stock prices and exchange rates. According to the goods market approach (traditional approach/flow-orientated approach) changes in exchange rates affect stock prices. A depreciation of the home currency makes exports cheaper, leading to an increase in both competiveness and the earnings of the export-oriented firm, hence the firm benefits from a depreciation of the home currency (exchange rates affect stock prices- a positive relationship). However, according to the portfolio approach (stock orientated approach), stock prices affect exchange rates via portfolio adjustments. A decline in stock prices will lead to a reduction of the wealth of the domestic investors and thus, demand for money will fall and interest rates will decline, causing capital outflows leading to depreciation of the home currency (stock prices affect exchange rates- a negative relationship). There are a few other macroeconomic variables such as money supply, inflation, economic activity, interest rates, oil prices, etc. which might affect stock prices. Theoretically, the value of a firm's stock should equal the expected present value of the firm's future cash flow, and the future cash flow is dependent on the performance of the firm. Furthermore, the performance of the firm is dependent on the changes in different macroeconomic variables of a country. Hence a change in any macroeconomic variables could potentially affect stock prices.

Several studies have been carried out to explore the relationship between stock prices and exchange rates. Perhaps the first to explore the relationship between stock prices and exchange rates was by Aggarwal (1981). He considered monthly data from 1974 to 1978 for U.S.A. and by using an 
aggregate index of stock prices and effective exchange rate of the U.S. dollar, he argued that a change in exchange rates causes change in stock prices and both the variables have a positive correlation such that the decrease in the value of U.S. dollar is associated with a decrease in stock prices. Soenen and Hennigar (1988) found a strong negative relationship between the stock prices and the changes in the U.S. dollar exchange rate, a conclusion opposite to the findings by Aggarwal (1981). They selected seven sectors such as automobile, computer, machinery, paper, textile, steel and chemical in the belief that each of these sectors are strongly affected by international trade. Their finding implied that depreciation of U.S. dollar boosts the economy. Neither Aggarwal (1981) nor Soenen and Hennigar (1988) considered the integrating properties of the variables, thus their results might suffer from spurious regression. To account for the integrating properties of the two variables and to check for cointegration between the two variables, Bahmani-Oskooee and Sohrabian (1992) used monthly data for the period of 1973-1988 and applied the Granger causality test and cointegration method. They found evidence of two way Granger causality between stock prices measured by S\&P 500 price index and the effective rate of the U.S. dollar in the short run and no relationship between the variables in the long run. Application of Engle and Granger (1987) cointegration method also revealed that there is no long-run relationship between these two variables.

In the field of empirical research, many studies have focused on the two variable models using exchange rates and stock prices. But there are other studies which have focused on analyzing the effects of different macroeconomic variables such as money supply, inflation, interest rates, industrial production index, GDP, oil prices, exchange rates, etc. on stock prices. Chen, Roll and Ross (1986) examined the effects of different macroeconomic variables (industrial production, inflation, risk premia, etc.) on the stock returns of the U.S. and found that macroeconomic variables 
have significant effects on expected stock returns. Fama (1981) found a positive correlation between stock returns and different macroeconomic variables. Mukherjee and Naka (1995) found that the Japanese stock market is cointegrated with six macroeconomic variables (exchange rate, money supply, inflation, industrial production, long-term government bond rate and call money rate). The relationship between stock prices and exchange rates is dependent on the data period and also on the countries studied but most of the papers concluded that there is a short run relationship between the two variables and no long run relationship between them. Most of the studies also concluded that the relationship runs from exchange rates to stock prices and stock prices are affected by few other macroeconomic variables such as GDP, Industrial Production Index, money supply, CPI, interest rates, etc.

This dissertation is primarily motivated by two factors. First, the existing literature has focused on the symmetric effect of exchange rate changes on stock prices, which assumes that both depreciation and appreciation of the currency of a country will have a symmetric effect on stock prices, which means, assuming a positive relationship, if appreciation of home currency hurts the country's stock prices, then depreciation of the home currency will improve stock prices (with the magnitude of change remaining the same in both cases). But this might not be true always, as appreciation and depreciation will not have similar effects in terms of magnitude and sign on stock prices. This is because the amount of increase in stock prices due to depreciation of currency might not match the amount of decrease in stock prices due to appreciation of the currency hence, the effect of changes in exchange rates on stock prices can be asymmetric. Asymmetry in the exchange rate - stock price relationship implies that exchange rate changes affect stock prices differently depending on whether currencies appreciate or depreciate. The asymmetry can arise in two forms: asymmetry in terms of the sign; which means that different countries or industries might respond 
to depreciations and appreciations differently and asymmetry in terms of magnitude; which means that different countries or industries respond differently to the degree of changes (large or small) in exchange rates. For example, for a firm, cost of imported inputs decline when home currency appreciates which leads to increase in profit and thus stock prices increase. However, for the same firm, when domestic currency depreciates, the cost of imported inputs increases. But in order to maintain their market share, they can either keep the price of the goods the same and absorb the increased cost by lowering their profit margin, or they can increase the price of the goods by a fraction of the increase in the cost of the input goods, thereby transferring a little bit of the cost to the consumer, without significantly decreasing their market share. In both of the cases, profits will decline but the decline in magnitude will not be the same as that of the increase in magnitude as was the case of currency appreciation.

The work contributes to the literature by filling this gap and by investigating the effect of appreciation of currency and depreciation of currency separately, while correcting for industrial production index (IPI), consumer price index (CPI) and money supply (M2) on aggregate stock price indices (the multivariate model). Monthly data over the period of 1973 to $2014^{1}$ is used for Brazil, Canada, Chile, Indonesia, Japan, Korea, Malaysia, Mexico, U.K. and U.S.A. Due to data unavailability, only ten countries are considered in the multivariate model. To extend the range of this study, a model with exchange rate as the only determinant of stock prices (the bivariate model) is considered so that more countries can be added to our study. Since exchange rate is exogenously determined and not correlated with the other macroeconomic variables (IPI, CPI, M2) so it can be assumed that the other determinants are contained in the error term. This helps to establish the fact of dropping the other variables because of data unavailability. The countries considered now are

\footnotetext{
${ }^{1}$ A detailed description on the data period and data source is provided in Appendices B and C.1.
} 
Argentina, Australia, Austria, Belgium, Brazil, Canada, Chile, China, France, Germany, Greece, Hong Kong, India, Indonesia, Japan, Korea, Malaysia, Mexico, Netherlands, New Zealand, Singapore, Switzerland, United Kingdom and United States of America. Second, the effect of exchange rate changes on different industries of a particular country, the U.S., is examined in order to investigate asymmetry within a country's different microeconomic units. The existing literature has considered composite stock price indices which capture the aggregate effect on the industries/sectors. As composite data might suffer from aggregation bias due to the fact that these measures do not reflect how the stock price of each individual sectors in a particular country is affected by changes in different macroeconomic variables. In a particular country, there are different industrial sectors which will react differently to changes in macroeconomic variables, for example, following a depreciation of home currency, an export oriented industry will benefit from it, while any import orientated industry might be hurt. In order to capture the effect of changes in macroeconomic variables on different industries, stock price index data at the sectoral level (sectoral stock price indices) for the U.S. are considered. More recent tests for cointegration, Nonlinear Autoregressive Distributive Lag (NARDL) approach (Shin et al. 2014) and Autoregressive Distributive Lag (ARDL) approach to cointegration (Pesaran et al. 2001) are employed to analyze the relationship. Other tests for cointegration such as Engle-Granger (1987) and Johansen-Juselius (1990) require that all the variables should be cointegrated of the same order. So if one of the variables is $\mathrm{I}(1)$ and the other one is $\mathrm{I}(0)$, the methods will give inaccurate results. This implies that both the methods need some pre-testing for unit roots for the variables. The autoregressive distributed lag (ARDL) model by Pesaran et al. (2001) helps to analyze data that have variables with different order of integration. Following Brown et al. (1975), the CUSUM and CUSUMQ tests are employed to check the stability of the estimated coefficients. 
What remains is organized as follows: chapter two reviews the literature, chapter three introduces the model and explains the methodology, chapter four reports the empirical findings and chapter five presents the sectoral analysis. Chapter six concludes the thesis. 


\section{Chapter Two: Literature Review}

The literature can be broadly categorized into two sub-groups: bivariate studies- the ones that considered exchange rate as the only determinant of stock prices and multivariate studies- which considered exchange rate and other macroeconomic variables such as GDP, money supply, inflation, interest rates, industrial production index, oil prices, etc. as the explanatory variables for changes in stock prices.

With the Asian financial crisis of 1997, there was a renewed interest in the study of this relationship in developing countries. Granger et al. (2000) used daily data for the period 1986-1997 for nine Asian countries; Hong Kong, Indonesia, Japan, South Korea, Malaysia, the Philippines, Singapore, Thailand and Taiwan to study the relationship between stock prices and exchange rates. They found that exchange rates affect stock prices in Japan and Thailand whereas for Taiwan, the relationship was reversed. Bi-directional relationship existed between the variables in Indonesia, South Korea, Malaysia and the Philippines. However, Singapore failed to show any relationship between the two variables.

Nieh and Lee (2001) used daily data from the period 1993-1996 for the G-7 countries (Canada, France, Germany, Italy, Japan, UK and USA) and concluded that in the long run, there was no relationship between the two variables, a conclusion similar to the long run findings of BahmaniOskooee and Sohrabian (1992). Their results also suggest that the two variables do not have predictive power for more than two consecutive days. Hence a short-run significant relationship lasted only for one day for certain G-7 counties. Following the same path, Smyth and Nandha (2003) considered daily data for Bangladesh, India, Pakistan and Sri Lanka for the period of 19952001. Using Engle-Granger and Johansen's cointegration methodologies, they found no long-run 
equilibrium relationship between the two variables in any of the four countries. Granger causality test concluded that exchange rates Granger cause stock prices in India and Sri Lanka but for Bangladesh and Pakistan they found no evidence of causality running in either direction. Phylaktis and Ravazzolo (2005) used monthly data from 1980 to 1998 for Hong Kong, Indonesia, Malaysia, the Philippines, Singapore and Thailand. They analyzed the short run and the long run relationships between exchange rates and stock prices and the avenues through which exogenous shocks affect these two variables. They found channels through which exogenous shocks affect the two variables, so there is an external factor that moves the two variables together. It might not be reverse causality between the two variables. They found that exchange rates and stock prices are positively related using the method of cointegration and Granger causality tests. U.S. stock price is the causing variable which acts as a channel that links the exchange rates of the five countries to their stock market indices. Lean et al. (2005) used weekly data from 1991 to 2002 for Hong Kong, Indonesia, Singapore, Malaysia, South Korea, the Philippines and Thailand to study the preand post-crisis scenario and the effect of 9-11 terrorist attack. Japan was used as a control and they applied both cointegration and bivariate causality technique. For all of the countries except for the Philippines and Malaysia, they found no evidence of Granger causality between stock prices and exchange rates in the period before the Asian financial crisis. During the crisis period, they found evidence of causality between the two variables. Results show that there exists no cointegration between the variables before or during the Asian crisis of 1997 but after the 9-11 terrorist attack, weaker cointegration relationship between the variables was found.

Using a cointegrating VAR approach, Obben and Shakur (2006) analyzed the relationship between the performance of the share market and the exchange rates in New Zealand using weekly data 
from 1999 to 2005 . They concluded that both in the short run and in the long run there is bidirectional causality between the five exchange rates and a couple of share price indices.

For seven Asian countries (Hong Kong, Japan, Korea, Malaysia, Singapore, Taiwan and Thailand), Pan et al. (2007) applied the methods of Granger causality and Johansen cointegration test using daily data from 1988 to 1998 . They concluded that during the Asian financial crisis period there is no long-run equilibrium relationship between exchange rates and stock prices. For Hong Kong, Japan, Malaysia and Thailand, they found a significant causal relationship from exchange rates to stock prices before the financial crisis and during the financial crisis period there was causal relationship from exchange rates to stock prices for all the countries except for Malaysia. However, Yau and Nieh (2009) found evidence of a long-run equilibrium relationship between New Taiwan Dollar and Japanese Yen and the stock prices of Japan and Taiwan using monthly data from 1991 to 2008 but found no short-run causal relationship between the two countries' financial assets (but earlier, Yau and Nieh (2006) found bi-directional causality between the stock prices of Taiwan and Japan and no significant causal relationship between the NTD/Yen exchange rate and the stock prices of Japan and Taiwan).

Ismail and Isa (2009) assumed a non-linear relationship between exchange rates and stock prices in Malaysia using monthly data from 1990 to 2005. They found evidence of no cointegration between the variables and their analysis showed that a non-linear model is more appropriate to model the series than a linear model. Using monthly data for the period 2003-2008 for Bangladesh, India and Pakistan, Rahman and Uddin (2009), found evidence of no long-run relationship between stock prices and exchange rates, they also found no causal relationship in either direction between the variables. The implication is that market participants cannot use information of one market to forecast the other market. For Australia, Richards et al. (2009) used daily data from 2003 to 2006 
and using Johansen cointegration test they showed that stock prices and exchange rates are cointegrated in the long run. Granger causality test also supported that changes in stock prices affect exchange rates. However, using weekly data from 1989 to 2006, Kutty (2010) was unable to support cointegration in Mexico, though some evidence of short run Granger causality was found. Using monthly data from 1991 to 2009 for China, Zhao (2010) applied the Johansen method of cointegration and found no stable long-run equilibrium relationship between the real effective exchange rate and the stock price. The source and the magnitude of the spillovers were identified through vector auto-regression and multivariate generalized autoregressive conditional heteroskedasticity models. From the foreign exchange market to the stock market there was no mean spillover effect but there was bi-directional volatility spillover effects.

Among the recent studies, Alagidebe et al. (2011) used monthly data from 1992 to 2005 for Australia, Canada, Japan, Switzerland and the U.K. Again, they found no long-run relationship between the variables. Through Granger causality test it was found that in Canada, Switzerland and U.K., there is a causal linkage from exchange rates to stock prices and in Japan the causality runs from stock prices to exchange rates. Following the same line of research, Harjito and McGowan (2011) used weekly data from 1993 to 2002 for Indonesia, the Philippines, Singapore and Thailand and reported evidence of bi-directional causality in Thailand and Singapore. They also found cointegration between exchange rates and stock prices and cointegration among the stock markets of all the four countries. By using weekly data from 1999 to 2010 for the countries of Australia, New Zealand, Japan, Switzerland, USA, UK and Euro Zone, Katechos (2011) examined the relationship between stock markets and exchange rates in the light of the global equity market returns. The method of maximum likelihood regression with GARCH was applied and results showed that there is a link between the exchange rates and the global stock market 
returns but the characteristics of the currencies determine the sign of the relationship. The value of currencies with higher rates of interest is positively related to global equity returns and the value of currencies with lower rates of interest is negatively related to global equity returns. Larger is the interest rate differential more is the explanatory power of the model. By allowing for structural breaks, Lean et al. (2011) used weekly data for the period 1990-2005 for Hong Kong, Indonesia, Japan, Korea, Malaysia, the Philippines, Singapore and Thailand and by applying the methods of panel Lagrange Multiplier (LM) cointegration, Gregory-Hansen test for cointegration and Granger causality test, found little evidence of long-run equilibrium relationship between exchange rates and stock prices. Only in Korea, exchange rates and stock prices were cointegrated. The predictive power of the two variables is limited only to short run, though not for all countries. Again, using weekly data for the period of 2000-2008 for Indonesia, Korea, Malaysia, the Philippines, Taiwan and Thailand, Lee et al. (2011) examined the relationship between the two variables and the effect on their correlation due to stock market volatility. They used the method of Smooth Transition Conditional Correlation GARCH model and found that in Indonesia, Korea, Malaysia, Thailand and Taiwan there are significant prices spillovers from stock market to foreign exchange market. Stock market volatility does affect the correlation between the stock and the foreign exchange markets. For all the countries except for the Philippines, the correlation becomes higher when the stock market becomes more volatile. Using rolling regression analysis, Kollias et al. (2012) studied the link between the two variables. The advantage of using rolling regression is, with the sample size remaining same, at a time, the sample period moves forward by one observation. Hence it takes into account of the new information available. They used daily data from 2002 to 2008 for European countries and showed that there is no long-run relationship between the two variables and the direction of causality depends on the condition of the market. 
Using the method of quantile regression, Tsai (2012) found that exchange rates and stock prices are negatively related when the exchange rates are extremely high or low for Singapore, Thailand, Malaysia, the Philippines, South Korea and Taiwan for the period of 1992-2009. The method of quantile regression helps to study the relationship under different market conditions ("different quantiles of exchange rates"). Wickremasinghe (2012) examined the relationship between stock prices and the Sri Lankan exchange rates against the Indian rupee, the Japanese yen, the British pound and the U.S. dollar. The results showed no evidence of any long-run relationship between any of the four exchange rates and stock prices in Sri Lanka. There was only evidence of unidirectional causality running from stock prices to Sri Lankan exchange rate against U.S. dollar. Through variance decomposition analysis it was inferred that most of the variance of the stock price is explained by Indian rupee. Abidin (2013) employed Engle-Granger cointegration test and used daily data from 2006 to 2008 for Australia, Hong Kong, Indonesia, Japan, New Zealand, South Korea and Thailand to examine the relationship between the two variables. Results showed no long run cointegration relationship between stock markets and exchange rates.

Most of the papers reviewed so far concentrated either on developed or on developing countries. However, Buberkoku (2013) considered both developed and developing countries and used monthly data from 1998 to 2008 for countries such as Australia, Canada, England, Germany, Japan, Singapore, South Korea, Switzerland and Turkey. Results showed that except for Singapore there is no relationship between the variables in the long run. In the short run, stock prices affect exchange rates in Canada, Switzerland and Turkey.

Tsagkanos and Siriopoulos (2013) used both daily and monthly data (to test for sensitivity of the results to data frequency) from 2008 to 2012 for the European Union and the U.S.A. to study the relationship between the two variables during the financial crisis of 2008 to 2012. They applied 
methods of structural non-parametric cointegrating regression, Johansen cointegration test and Granger causality test and found that movements in stock prices affect movements in exchange rates in the E.U. in the long run and in the U.S.A. in the short run. Caporale et al. (2014) used data for the period 2003-2011 and found that in the short run, there is unidirectional Granger causality from stock returns to exchange rate in the U.S. and the U.K.; in the opposite direction in Canada and bidirectional causality in the Euro area and Switzerland. Causality-in-variance from stock returns to exchange rate fluctuations is found in the U.S. and in the Euro area, while in Japan, it is in opposite direction. There is also evidence of bidirectional feedback effect in Switzerland and Canada and dependence between the two variables has increased during the recent financial crisis. Using daily data from 1997 to 2010 for India, Indonesia, Japan, Korea, Malaysia, the Philippines, Singapore, Taiwan and Thailand, Yang et al. (2014) applied Granger causality test in quantiles and found that during the Asian financial crisis, all the countries except for Thailand there are feedback relations between exchange rates and stock prices and in Thailand, stock returns affect exchange rates.

There are other empirical studies which have focused on analyzing the effects of different macroeconomic variables such as money supply, inflation, interest rates, industrial production index, GDP, oil prices, exchange rates, etc. on stock prices. The analysis of the effects of different macroeconomic variables are important because they can help policy makers to better formulate policies and investors find it important to see how and which variables cause the stock prices to fluctuate. Using an APM model, Chen et al. (1986) examined the effects of different macroeconomic variables (industrial production, inflation, risk premia, etc.) on the stock returns of the U.S. and found that macroeconomic variables have significant effects on expected stock returns. Fama (1981) found a positive correlation between stock returns and different 
macroeconomic variables. Using data from Japan, Mukherjee and Naka (1995) found that the Japanese stock market is cointegrated with six macroeconomic variables (exchange rate, money supply, inflation, industrial production, long-term government bond rate and call money rate).

Under recent studies, Tian and Ma (2010) studied the relationship among stock prices and exchange rates, money supply, industrial production and consumer price index using monthly data from 1995 to 2009 for China. They employed the ARDL method of cointegration and found that prior to financial liberalization of 2005 , no cointegration exists between the major foreign exchange rates and the Shanghai stock price index but after the liberalization, cointegration exists. Money supply and exchange rates affect stock prices with positive correlation in China and also previous month CPI Granger causes stock prices. Using Johansen method of cointegration, Chortareas et al. (2011), for countries such as Egypt, Kuwait, Oman and Saudi Arabia examined the role of oil prices on the link between the stock markets and exchange rates. They used monthly data from 1994 to 2006 and results showed that when oil price is not considered, there is no long run cointegration between exchange rates and stock prices. Inclusion of oil prices show no cointegration between exchange rates and stock prices when full sample period is considered. Before the oil price shock of 1999, no cointegration exists among the variables. After the shock, exchange rates, stock prices and oil prices are cointegrated in Egypt, Oman and Saudi Arabia. But for Kuwait, there is long run relationship only between stock prices and oil prices. Real exchange rates are positively related to stock prices in Egypt and Oman and in Saudi Arabia they are negatively related. Oil prices have long run positive effect on stock prices. Liu and Tu (2011) used daily data from 2001 to 2007 for Taiwan to study the relationship among stock price index, exchange rate and foreign capital and to analyze whether in these markets the properties of asymmetric volatility switching and mean-reverting exists or not. They found that the movements 
of the exchange rate and the stock price index are affected by overbuy and oversell rates of foreign capital affect. All of the three conditional means exhibit asymmetric mean-reverting behavior (negative returns reverting quicker than positive returns). The volatility of the three markets exhibits GARCH effects.

The model employed by Parsva and Lean (2011) included variables such as interest rates, inflation rates and oil prices as the main determinants of stock prices in Egypt, Iran, Jordan, Kuwait, Oman and Saudi Arabia. Using monthly data from 2004 to 2010 they estimated the model using Johansen method of cointegration and Granger causality test. They found that in the long run, all variables are cointegrated. Both in the short run and in the long run there is bi-directional causality between stock prices and exchange rates for Egypt, Iran and Oman before the crisis. In Kuwait causality runs from exchange rates to stock prices in the short run. Comparing the pre-crisis and post-crisis periods, there was not much distinction in the behavior of exchange rates and stock returns. Basher et al. (2012) used monthly global data from 1988 to 2008 to examine the relationship among stock prices in emerging markets. Additionally, they included global real economic activity as one of the variable which affects oil prices. Using a structural VAR model and through the analysis of impulse response function they found that positive shock to oil prices decreases the emerging markets' stock prices and U.S. dollar exchange rates in the short run. Exchange rates respond to changes in oil prices in the short run, a positive shock to oil prices leads to decrease in tradeweighted exchange rates. In the same light, Eita (2012) employed Johansen's method of cointegration and quarterly data from 1998 to 2009 for Namibia to examine the determinants of stock prices. The results showed that stock prices are affected by economic activity, exchange rates, inflation, interest rates and money supply. Stock prices increase with increase in economic activity and money supply and stock prices decrease with increase in inflation and interest rates. 
Exchange rates, GDP, money supply and inflation move stock market away from equilibrium. By applying Cochran-Orcutt Autoregressive Model, Inegbedion (2012) found that exchange rates and stock prices are negatively related for Nigeria. The relationship of stock prices with interest rates and inflation, respectively are not significant. But the joint effect of all the variables on stock prices is significant. For emerging Asian countries such as India, Indonesia, Korea, Philippines, Taiwan and Thailand, Lin (2012), used monthly data from 1986 to 2010 to study the co-movement of stock prices and exchange rates in the light of market liberalization and financial crisis. To deal with structural breaks, the ARDL method of cointegration was applied and interest rates and foreign reserves were added as additional variables to explore the effect of portfolio adjustment. During crises periods, in terms of long run cointegration and short run causality, the co-movement between exchange rates and stock prices became stronger. Spillover effect is mostly from stock price shocks to exchange rates. Analysis of industry causality showed that the co-movement is generally driven by capital account balance than that of trade. Volatilities of changes in foreign reserves and interest rates are more during the crisis and market liberalization period. Aslam and Ramzan (2013) studied the effects of the real effective exchange rate index, CPI, per capita income and discount rate on the stock prices using annual data from 1991 to 2012. By applying NLS and ARMA techniques, they found that while discount rates and inflation negatively affected Karachi stock price index, per capita income and real effective exchange rate index affected positively. Discount rate impacted stock index the most.

A new variable, commodity prices were introduced by Groenewold and Paterson (2013) who considered monthly data for the period 1979-2010 from Australia. Their results showed that when commodity prices are not considered, there is no cointegration between exchange rates and stock prices. With the inclusion of commodity prices, all the three variables are cointegrated in the long 
run. When only exchange rates and stock prices are considered, there is no causality between them in either direction as well. In the short run, exchange rates affect commodity prices and commodity prices in turn affect stock prices. Macroeconomic variables such as market returns, CPI, risk-free rate of return, industrial production and M2 were considered by Khan et al. (2013). Using monthly data from 1998 to 2008, they found that both stock prices and exchange rates affect each other in the short run but there is no long run association between the variables. In the long run, market return and risk-free return are not related to stock prices but there is some association of industrial production and stock prices. There exists both short run and long-run relationship between stock prices and inflation and money supply. Unlu (2013) studied the relationship among oil prices, exchange rates and stock prices using monthly data from 2006 to 2012 for countries such as Indonesia, Malaysia, the Philippines, Singapore and Thailand. Methods of panel cointegration and Granger causality tests were employed. The study found evidence of long-run relationship among stock prices, exchange rates and oil prices. In the long run, exchange rates and oil prices Granger cause stock prices but oil prices and stock prices do not affect exchange rates. In the short run, there is bi-directional causality between oil prices and stock prices.

Boonyanam (2014) explored the relationship between different monetary variables with stock prices for Thailand. The monetary variables included were nominal bilateral exchange rate in terms of Baht per U.S. dollar, CPI, narrow money and 14 days repurchase rate and the methodologies adopted were multivariate cointegration, VECM and variance decomposition analysis. Monthly data from 1999 to 2012 were used and the results show evidence of long-run relationship between stock prices and monetary variables. In the short run, narrow money and interest rate affect stock prices. There is also one way causality from exchange rates to stock prices and from interest rates to stock prices. And a positive relationship exists between CPI and stock price. 
To explore the relationship between stock return differentials and real exchange rates, Moore and Wang (2014) examines monthly data for Australia, Canada, Indonesia, Japan, the Philippines, Malaysia, Singapore, South Korea, Thailand and the U.K. At the first stage, the dynamic conditional correlation (DCC) is derived between the two variables and then the derived DCC is used to regress on the interest rate differentials and the trade balance. With the help of bivariate GARCH model with DCC they found that there is a negative relationship between the relative stock prices and real exchange rates. There exists time-varying correlation between stock return differentials and the real exchange rate changes. The U.S. stock market influences the foreign exchange market and local stock market. Trade balance is the major determinant of the dynamic correlation for the Asian market and the interest rate differential is the key factor for developed countries. For the countries where capital mobility is low, economic integration acts as the cause of the linkage and thus it supports the flow-orientated model. But where capital mobility is more, financial integration acts as the cause of the linkage which in turn favors the stock-oriented model. Tuncer and Turaboglu (2014) used quarterly data from 1990 to 2008 for Turkey to examine the short run and long run relationships between stock prices and GDP, treasury bills rates and exchange rates. They employed the method of Johansen test for cointegration to study the long run relationship and found evidence of long run relationship between stock prices and the other variables. In the short run, stock prices and real effective exchange rate affect GDP but there is no causality relationship from treasury bills to GDP. There is causality from real effective exchange rates to stock prices. All the variables do not affect exchange rates in the short run hence exchange rate is comparatively an exogenous variable.

To summarize, it can be said that the relationship between stock prices and exchange rates is dependent on the frequency of the data, the period chosen and the countries studied. But in general 
most of the papers concluded that in the short run, there exists some relationship between stock prices and exchange rates but there is no relationship between them in the long run. Other macroeconomic variables such as CPI (measure of inflation rate), interest rates, discount rates, oil prices, money supply, industrial production, GDP and foreign capital also are found to affect stock prices. 


\section{Chapter Three: Model and Methodology}

For each of the cases, two different models are presented; a linear model (following literature) where the determinants of stock prices are nominal effective exchange rates, Industrial Production Index, Consumer Price Index and nominal money supply and a non-linear model (modelled to capture the asymmetric effect of exchange rate changes) which includes a variable representing appreciation of home currency, a variable representing depreciation of home currency, Industrial Production Index, Consumer Price Index and nominal money supply as the determinants of stock prices.

\subsection{The Multivariate Model}

For the multivariate model, the explanatory variables considered are exchange rates, Industrial Production Index, Consumer Price Index and nominal money supply. Using monthly data from 1973:M1 to 2014:M3, the multivariate model is estimated for ten countries such as Brazil, Canada, Chile, Indonesia, Japan, Korea, Malaysia, Mexico, U.K. and U.S.A. (monthly data on all the variables were available only for these countries).

\subsubsection{The Linear Model: $E X, I P I, C P I$ and $M 2$ as independent variables}

The linear model is used as a benchmark to compare the results with that of the non-linear model. Let $S P$ denote the stock price index for a country; $E X$, the Nominal Effective Exchange Rate for the country; IPI, the Industrial Production Index (a measure of economic activity); $C P I$, the Consumer Price Index (price level) and $M 2$, the nominal supply of money. In log-linear form the long-run specification of the model can be represented as:

$\ln S P_{t}=\mathrm{c}_{1}+\mathrm{c}_{2} \ln E X_{t}+\mathrm{c}_{3} \ln I P I_{t}+\mathrm{c}_{4} \ln C P I_{t}+\mathrm{c}_{5} \ln M 2_{t}+\varepsilon_{\mathrm{t}} \quad\left(\varepsilon_{\mathrm{t}} \sim\right.$ n.i.i.d $\left.\left(0, \sigma^{2}\right)\right)$ 
Stock prices are affected by each of the right hand side variables of equation (1) in different ways. The relationship between exchange rates and stock prices can be either positive or negative depending on whether the firm is an export oriented or an import oriented. An export-orientated firm will benefit from depreciation of the home currency as depreciation makes exports cheaper. This will lead to an increase in competitiveness and increase in earnings of the firm, hence, stock prices will increase (a positive relationship). Whereas an import-oriented firm is hurt by depreciation of the home currency as the cost of imported inputs is increased as a result of depreciation of home currency. This will lead to a decline in profitability thus stock prices will decrease (a negative relationship). The relationship between stock prices and CPI (a measure of inflation or price level) is expected to be negative (Fama (1981), Chen et al. (1986)). With increase in inflation, for a firm the input prices to produce goods increase which leads to a reduction in future profits of the firm and thus stock prices are expected to decline. Mukherjee and Naka (1995) also found a negative relationship between stock returns and inflation. Anari and Kolari (2001) reported that in the short run there is negative correlation between stock prices and inflation but in the long run the correlation is positive. When stocks are held over a longer time horizons, stocks are considered or expected to be a good inflation hedge and thus, a positive relationship between inflation and stock prices can be established. Newer studies, such as, Eita (2012) found a negative relationship between stock prices and inflation for Namibia however Boonyanam (2014) found a positive relationship between stock prices and CPI for Thailand. The relationship between stock prices and money supply (M1, M2) can be positive or negative. Increase in money supply leads to a decrease in interest rates which leads to increase in the level of investment in the economy and hence there is an increase in economic activity. Thus earnings and profitability of the firms increase leading to an increase in stock prices. This establishes a positive relationship between stock prices 
and money supply (Mukherjee and Naka (1995), Tian and Ma (2010), Eita (2012), Boonyanam (2014)). But according to Fama (1981), with an increase in money supply there is an increase in inflation which in turn might decrease stock prices, so establishing a negative relationship between stock prices and money supply. There is a general consensus about a positive relationship between economic activity and stock prices. With an increase in economic activity, the expected corporate earnings will increase which in turn increases stock prices. In this paper, Industrial Production Index (IPI) is used as a proxy for measuring economic activity. The study by Chen, Roll and Ross (1986) found positive relationship between stock returns and economic activity for the U.S. A similar relationship was found by Mukherjee and Naka (1995) for Japan and by Eita (2012) for Namibia.

Estimation of equation (1) will yield only the estimates of long-run coefficients. But all the variables in the right hand side of equation (1), have both short run and long run effects. So to incorporate the short-run dynamics, an error-correction model can be specified using Engle Granger (1987) cointegration methodology:

$$
\begin{aligned}
\Delta \ln S P_{t}=\alpha_{0} & +\sum_{k=1}^{n 1} \alpha_{1, k} \Delta \ln S P_{t-k}+\sum_{k=0}^{n 2} \alpha_{2, k} \Delta \ln E X_{t-k}+\sum_{k=0}^{n 3} \alpha_{3, k} \Delta \ln I P I_{t-k} \\
& +\sum_{k=0}^{n 4} \alpha_{4, k} \Delta \ln C P I_{t-k}+\sum_{k=0}^{n 5} \alpha_{5, k} \Delta \ln M 2_{t-k}+\lambda \varepsilon_{t-1}+U_{t}
\end{aligned}
$$

In the above equation (2), $\lambda$ measures the speed of adjustment and a negative and significant value of $\lambda$ implies cointegration among stock prices and its determinants (Banerjee et al. (1998)). But in the above model, if one of the variables is integrated of order one, I(1), and the other is integrated of order zero, I(0), the Engle-Granger cointegration methodology cannot be applied. To overcome 
this problem, Pesaran et al. (2001) proposed the ARDL (Autoregressive Distributive Lag) model approach which can test for cointegration among the variables in levels irrespective of whether the variables are purely I(1) or purely I(0) or combination of both. According to Pesaran et al. (2001), the error correction model in equation (2) can be modified by replacing the lagged value of error term $\left(\varepsilon_{t-1}\right)$ with the linear combination of lagged level variables in the model ${ }^{2}$, which results in the following equation (the error-correction model):

$$
\begin{aligned}
\Delta \ln S P_{t}=\alpha_{0} & +\sum_{k=1}^{n 1} \alpha_{1, k} \Delta \ln S P_{t-k}+\sum_{k=0}^{n 2} \alpha_{2, k} \Delta \ln E X_{t-k}+\sum_{k=0}^{n 3} \alpha_{3, k} \Delta \ln I P I_{t-k} \\
& +\sum_{k=0}^{n 4} \alpha_{4, k} \Delta \ln C P I_{t-k}+\sum_{k=0}^{n 5} \alpha_{5, k} \Delta \ln M 2_{t-k}+\beta_{1} \ln S P_{t-1}+\beta_{2} \ln E X_{t-1} \\
& +\beta_{3} \ln I P I_{t-1}+\beta_{4} \ln C P I_{t-1}+\beta_{5} \ln M 2_{t-1}+U_{t}
\end{aligned}
$$

Equation (3) provides a one-step approach to estimate both the short-run and the long-run effects. The short run effects are captured by the estimates of the coefficients of the first differenced variables (for example, the short run effect of money supply (M2) on stock prices are determined by $\alpha_{5, k}$ 's) and the long run effects are captured by the estimates of $\beta_{2}-\beta_{5}$, normalized on $\beta_{1}$. Tests for cointegration are provided by the joint significance of $\beta_{1}-\beta_{5}$ through $\mathrm{F}$ test. Pesaran et al. (2001) provided two sets of critical values. The upper bound critical value is obtained by assuming that all variables are I(1) and the lower bound critical value is obtained by assuming all variables to be $\mathrm{I}(0)$. If the computed F statistic is greater than the upper bound critical value, then there is existence of cointegration among the variables and no cointegration otherwise. Since most of the

\footnotetext{
${ }^{2}$ The detailed steps of obtaining the equations are provided in Appendix D.
} 
macroeconomic variables are either $\mathrm{I}(1)$ or $\mathrm{I}(0)$, there is no need to carry out pre unit root testing ${ }^{3}$ before applying this method.

\subsubsection{The Non-Linear Model: POS, NEG, IPI, CPI and $M 2$ as independent variables}

The previous studies that estimated similar models, have assumed that the effect of exchange rates on stock prices is symmetric. But this might not be true always, as appreciation and depreciation might not have similar effects in terms of magnitude and sign on stock prices. Because, the amount of increase in stock prices due to depreciation of currency might not match with the amount of decrease in stock prices due to appreciation of the currency. Hence, the effect of changes in exchange rates on stock prices can be asymmetric. So to test this hypothesis $\operatorname{Ln} \mathrm{EX}_{\mathrm{t}}$ (natural logarithm of Nominal Effective Exchange Rate) is decomposed into partial sum of positive and negative changes as ${ }^{4}: \Delta \operatorname{Ln} \mathrm{EX}_{t}=\operatorname{Ln} \mathrm{EX}_{0}+\operatorname{Ln} \mathrm{EX}_{t}^{+}+\operatorname{Ln} \mathrm{EX}_{t}^{-}$; where, $\operatorname{Ln} \mathrm{EX}_{0}$ means no change in

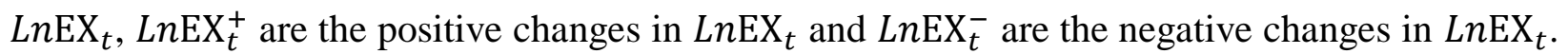
From these equations, $P O S$ (positive changes reflecting appreciation of the home currency) and $N E G$ (negative changes reflecting depreciation of the home currency) are constructed as follows:

$$
\begin{aligned}
& P O S=\operatorname{LnEX_{t}^{+}}=\sum_{j=1}^{t} \Delta \operatorname{LnEX_{j}^{+}}=\sum_{j=1}^{t} \max \left(\Delta \operatorname{LnEX} X_{j}, 0\right) \\
& N E G=\operatorname{LnEX}_{t}^{-}=\sum_{j=1}^{t} \Delta \operatorname{LnEX_{j}^{-}}=\sum_{j=1}^{t} \min \left(\Delta \operatorname{LnEX} X_{j}, 0\right)
\end{aligned}
$$

\footnotetext{
${ }^{3}$ Akinlo (2006), Pesaran et al. (2001) suggested that there is no need for unit root testing to apply the ARDL method.

${ }^{4}$ For more on the applications of this concept see Apergis and Miller (2006), Delatte and Lopez-Villavicencio (2012), Verheyen (2013), Bahmani-Oskooee and Fariditavana (2014), Bahmani-Oskooee and Bahmani (2015), BahmaniOskooee and Ghodsi (2016) and Shin et al. (2014).
} 
The new model can be referred to as the non-linear model (non-linearity comes from the construction of the two new variables $P O S$ and $N E G$ ). In accordance with the same intuition and explanation for equations (1) and (3), the following equations for the non-linear model are obtained. The logarithmic form of the long-run specification of the model can be represented as:

$\ln S P_{t}=\mathrm{c}_{1}+\mathrm{c}_{21} P O S_{t}+\mathrm{c}_{22} N E G_{t}+\mathrm{c}_{3} \ln I P I_{t}+\mathrm{c}_{4} \ln C P I_{t}+\mathrm{c}_{5} \ln M 2_{t}+\varepsilon_{\mathrm{t}}$

and the error-correction model is:

$$
\begin{aligned}
\Delta \ln S P_{t}=\alpha_{0} & +\sum_{k=1}^{n 1} \alpha_{1, k} \Delta \ln S P_{t-k}+\sum_{k=0}^{n 2} \alpha_{21, k} \Delta P O S_{t-k}+\sum_{k=0}^{n 3} \alpha_{22, k} \Delta N E G_{t-k} \\
& +\sum_{k=0}^{n 4} \alpha_{3, k} \Delta \ln I P I_{t-k}+\sum_{k=0}^{n 5} \alpha_{4, k} \Delta \ln C P I_{t-k}+\sum_{k=0}^{n 6} \alpha_{5, k} \Delta \ln M 2_{t-k} \\
& +\beta_{1} \ln S P_{t-1}+\beta_{2} P O S_{t-1}+\beta_{3} N E G_{t-1}+\beta_{4} \ln I P I_{t-1}+\beta_{5} \ln C P I_{t-1} \\
& +\beta_{6} \ln M 2_{t-1}+U_{t}
\end{aligned}
$$

Shin et al. (2014) proposed that the ARDL method of cointegration by Pesaran et al. (2001) can be applied to the non-linear model in equation (6) hence the usual F test criteria of Pesaran et al. (2001) can be applied too. From equation (6), the short run effects are captured by the estimates of the coefficients of the first differenced variables. $\sum_{k=1}^{n 2} \alpha_{21, k}$ measures the short run cumulative effects of appreciation of the home currency on changes in stock prices while $\sum_{k=1}^{n 3} \alpha_{22, k}$ measures the short run cumulative effects of depreciation of the home currency on changes in stock prices. If the estimated values of $\alpha_{21, k}$ (the coefficient of $\triangle P O S_{t-k}$ ) and $\alpha_{22, k}$ (the coefficient of $\Delta N E G_{t-k}$ ) have the same numerical value and the same sign (either both positive or both negative) then it can be concluded that exchange rate changes have symmetric short run effects on stock prices. The long run effects are interpreted from the estimates of the coefficients of the lagged 
level variables. The symmetric or the asymmetric long run effects of changes in exchange rates on stock prices are given by $\beta_{2}$ (the sign and the coefficient of $P O S_{t-1}$ ) and $\beta_{3}$ (the sign and the coefficient of $\left.N E G_{t-1}\right)$ normalized on $\beta_{1}$.

\subsection{The Bivariate Model}

Due to data unavailability, only ten countries are considered in the multivariate model. To extend the range of this study, I consider a model with exchange rate as the only determinant of stock prices so that more countries can be added to the study. Since exchange rate is exogenously determined and not correlated with the other macroeconomic variables (IPI, CPI, M2) so it can assumed that the other determinants are contained in the error term. This helps to establish the fact of dropping the other variables because of data unavailability. The countries considered now are Argentina, Australia, Austria, Belgium, Brazil, Canada, Chile, China, France, Germany, Greece, Hong Kong, India, Indonesia, Japan, Korea, Malaysia, Mexico, Netherlands, New Zealand, Singapore, Switzerland, United Kingdom and United States of America ${ }^{5}$. Following the same line of thought from the previous section, for the bivariate model (where exchange rate is the only determinant of stock price), the model takes the following forms:

\subsubsection{Linear Model:}

Long run specification:

$\ln S P_{t}=\mathrm{c}_{1}+\mathrm{c}_{2} \ln E X_{t}+\varepsilon_{\mathrm{t}} \quad\left(\varepsilon_{\mathrm{t}} \sim\right.$ n.i.i.d $\left.\left(0, \sigma^{2}\right)\right)$

Error-correction model (Pesaran et al. (2001)):

\footnotetext{
${ }^{5}$ A detailed description on the data period and data source is provided in Appendices B and C.2.
} 
$\Delta \ln S P_{t}=\alpha_{0}+\sum_{k=1}^{n 1} \alpha_{1, k} \Delta \ln S P_{t-k}+\sum_{k=0}^{n 2} \alpha_{2, k} \Delta \ln E X_{t-k}+\beta_{1} \ln S P_{t-1}+\beta_{2} \ln E X_{t-1}+U_{t}$

\subsubsection{Non Linear Model:}

Long run specification:

$\ln S P_{t}=\beta_{1}+\mathrm{c}_{21} P O S_{t}+\mathrm{c}_{22} N E G_{t}+\varepsilon_{\mathrm{t}} \quad\left(\varepsilon_{\mathrm{t}} \sim\right.$ n.i.i.d $\left.\left(0, \sigma^{2}\right)\right)$

Error-correction model:

$$
\begin{aligned}
\Delta \ln S P_{t}=\alpha_{0} & +\sum_{k=1}^{n 1} \alpha_{1, k} \Delta \ln S P_{t-k}+\sum_{k=0}^{n 2} \alpha_{21, k} \Delta P O S_{t-k}+\sum_{k=0}^{n 3} \alpha_{22, k} \Delta N E G_{t-k} \\
& +\beta_{1} \ln S P_{t-1}+\beta_{2} P_{O S S_{t-1}}+\beta_{3} N E G_{t-1}+U_{t}
\end{aligned}
$$




\section{Chapter Four: Empirical Results}

Both the linear and the non-linear models are estimated for the multivariate and bivariate models. Initially a maximum of eight lags is imposed and using the Akaike's Information Criterion (AIC), the optimum number of lags is chosen. A table is provided for each of the estimated models and each of the tables consist of three panels, the short run estimates are reported in Panel A, the long run estimates are reported in Panel B and Panel C reports the diagnostic statistics.

\subsection{Multivariate Model}

One of the requirements of Pesaran et al.'s (2001) method is that the variables could be I(0) or I(1) but not I(2), hence the ADF test is applied to the level as well as the first-differenced variables. The results are reported in Tables 1 and 2 and they reveal that there are no I(2) variables. The top sections (section I) of each of the Tables 3-12, report the results of the linear model; the linear model is used as a benchmark to compare the results with the non-linear model and it is revealed that the results corroborate the results in the literature with the linear model (the linear model captures the symmetric effect of exchange rate changes on stock prices). Panel A reports the short run estimates of the linear multivariate model. The stock price index of countries such as; Canada, Japan, Korea, Malaysia, UK and USA have a positive relationship with the industrial production index as hypothesized. Stock price index for all the countries except for Japan and U.K., are negatively affected by Consumer Price Index (CPI). Japan, Malaysia and Mexico are positively affected by nominal money supply (M2). However, Chile and Korea are negatively affected by an increase in nominal money supply which implies that, the positive effect of increase in money supply which leads to increase in investment level is being offset by the negative effect of increase in money supply leading to increase in inflation. Focusing on the effects of exchange rate changes 
on stock prices, it is found that the stock prices of all the countries except for Brazil and U.K. are affected by changes in exchange rates. The stock prices of Indonesia, Japan, Korea and U.S.A. are negatively affected by appreciation of their respective domestic currencies. Nominal effective exchange rates for countries such as Canada, Chile Malaysia and Mexico carry a positive and significant coefficient which implies that these countries gain from domestic currency appreciation unlike other countries. Appreciation of home currency can be beneficial for an import orientated sector within each of the countries or for any import oriented country. Also for a country which has both export and import components can gain from appreciation of home currency if the negative effects of currency appreciation on exports is offset by the positive effect of increase in imports due to currency appreciation.

From the estimation of the long-run coefficients (Panel B), Industrial Production Index (IPI) carries a significant and expectedly positive coefficient only for Canada. CPI carries a significant and expectedly negative coefficient only for Mexico. However CPI carries a significant and positive coefficient for U.K., which could be due to the fact that when stocks are held over longer time horizons, they are considered or expected to be a good inflation hedge and thus, a positive relationship between inflation and stock prices can exist. Money supply (M2) carries significant and expectedly positive coefficients in Korea and Mexico. In the long run, nominal effective exchange rates (EX) affect stock prices in Korea only, which supports the existing literature that stock prices are affected by exchange rates in the short run and there is no or very little relationship between them in the long run. None of the variables affect stock prices in all the countries. So for most of the cases, the short run relationship between the variables is not sustained in the long run. The above long run relationship in different countries will be relevant only if cointegration can be established among the variables. The F test results are reported under Panel $\mathrm{C}$ of the tables for the 
linear model. According to Pesaran et al. (2001), with four exogenous variables at 5\% significance level, the lower and the upper bound critical values are 2.86 and $4.01^{6}$. For three of the countries (Korea, Malaysia and Mexico), the F statistic is significant which establishes cointegration among the variables. But according to Bahmani-Oskooee and Ardalani (2006) a significant and negative coefficient of the lagged ECM term $\left(\mathrm{ECM}_{\mathrm{t}-1}\right)$ supports adjustment towards the long-run equilibrium which is another indication of cointegration. Following Bahmani-Oskooee and Tanku (2008), from the normalized long run coefficients from Panel B, the lagged error term $\left(\mathrm{ECM}_{\mathrm{t}-1}\right)$ is generated. The linear combination of lagged level variables is then replaced by the $\mathrm{ECM}_{\mathrm{t}-1}$ term and the new equation is estimated at the optimum levels. All the countries have a significant and negative coefficient of the $\mathrm{ECM}_{\mathrm{t}-1}$ term, which supports cointegration among the variables and it also implies that stock prices adjust to any long run disequilibrium.

Under Panel C, a few other diagnostic statistics are also reported. In time series data, it is important to make sure that the error terms are not auto correlated. If error terms are auto correlated then the estimators will not be efficient and will lead to incorrect conclusions. In order to check for autocorrelation among the residuals, the Lagrange Multiplier (LM) test is conducted. The LM statistic follows a chi-square $\left(\chi^{2}\right)$ distribution and the order of lag equals to the frequency of the data. For example, for monthly data, the degree of freedom is 12 . At the $5 \%$ significance level with 12 degrees of freedom, the critical value is 21.03 and for all the countries the LM statistic is insignificant implying autocorrelation free residuals.

\footnotetext{
${ }^{6}$ The upper bound critical value of the F statistic when there are four exogenous variables is 4.01 at the $5 \%$ significance level and the lower bound is 2.86. These figures come from Pesaran et al. (2001, Table CI(iii) Case III on page 300). Appendix E reports the critical values.
} 
Ramsey's Regression Specification Error Test (RESET) is a test to check whether or not the functional form used in the regression model is misspecified. The RESET statistic follows a chisquare $\left(\chi^{2}\right)$ distribution with one degree of freedom and the critical value is 3.84 at the $5 \%$ significance level. The RESET statistic is insignificant in most of the models, which implies that the models are correctly specified in most of the cases. To test for the structural stability in the estimated short run and long run coefficients, the methods of the cumulative sum of recursive residuals (CUSUM- in the tables it is denoted by CS) and the cumulative sum of recursive residuals of square (CUSUMQ- in the tables it is denoted by $\mathrm{CS}^{2}$ ) tests proposed by Brown et al. (1975) are adopted. From Panel C of the Tables 3-12 (top section: I), it can be concluded that most of the models are stable, where, "S" stands for stability and "U" stands for instability". The adjusted $\mathrm{R}^{2}$ is also reported and for all the models. The adjusted $\mathrm{R}^{2}$ is low, which could be due to the fact that stock prices are volatile. So the variation in stock prices cannot be sufficiently explained by any variables and thus, it is difficult to predict.

To check whether or not changes in exchange rates have asymmetric effects on stock prices, I analyze the results of the non-linear models for all the countries. How does the result change if I rely upon non-linear adjustment process? Tables 3-12 (the bottom part: section II) report the results of the non-linear model. From the short run results (Panel A), it can be inferred that the coefficient associated with 'POS' (appreciation of home currency) is negative ${ }^{8}$ and significant in six of the countries (Chile, Indonesia, Japan, Korea, Mexico, U.S.A.) which implies that with more appreciation of the respective home currencies, the stock prices of the countries have declined. Appreciation of home currency makes imports cheaper and exports expensive, which means any

\footnotetext{
${ }^{7}$ The CUSUM and CUSUM Square plots are provided in Figure 1.

${ }^{8}$ At least one of the coefficients associated with the lags is negative.
} 
export orientated firm will be hurt by appreciation of the home currency. However, Brazil gains from appreciation of Brazilian Real as stock prices are seen to have increased. One of the reasons for this could be that Brazil, being an import oriented country, with appreciation of the home currency, the imported goods are now cheaper and hence it gains. The short run estimated coefficients of 'NEG' are significant for seven countries (Canada, Chile, Indonesia, Korea, Malaysia and Mexico). The countries which have significant export exponents; they gain from currency depreciation. From the above results, it can be inferred that exchange rate changes have asymmetric effects on stock price indices, as exchange rate changes have different effect in terms of sign and magnitude on stock prices, i.e. countries are affected by currency appreciation and currency depreciation differently. For the U.S., it is affected negatively by currency appreciation which means that when the value of dollar appreciates, the balance sheet of the U.S. companies deteriorate.

Concentrating on the long run coefficient estimates of POS and NEG (Panel B), for most of the countries; they are insignificant which implies that the short run relationship does not transform into long run relationship. For further validity of the short run and the long run asymmetric effects, the test for equality of short-run and long-run coefficient estimates are carried out. Since there are different lag orders in the short run, Shin et al. (2014) recommend applying the Wald test to establish whether $\sum_{k=0}^{n 2} \alpha_{21, k}=\sum_{k=0}^{n 3} \alpha_{22, k}$. As for the long-run asymmetry it is tested whether $\beta_{2} / \beta_{1}=\beta_{3} / \beta_{1}$. Both the Wald tests have $\chi^{2}$ distributions with different degrees of freedom, depending on the lag orders. The Wald statistic is reported in Panel C of the tables with its p-value inside the bracket and a significant Wald statistic is indicated by by a *. From the results it can be inferred that short run asymmetry is not supported by the Wald test except for the results of Canada. Asymmetric significant long-run effects are found for Brazil, Canada, Chile, Malaysia, and 
Mexico by the Wald test. The implication of this is that in the linear model when the exchange rate does not carry long-run significant coefficient, it should not be concluded that exchange rate has no long-run effects. Clearly, in the cases of Malaysia and Mexico, once depreciations are separated from appreciations, due to asymmetric effects currency appreciations have significant long-run effects but depreciations do not.

For the other variables (IPI, CPI, M2) where the variables are significant, in most of the countries the coefficients are of the expected signs both in the short run and in the long run. From Panel C, cointegration is supported by the coefficient of the $\mathrm{ECM}_{\mathrm{t}-1}$ term for all the countries. For the nonlinear model, for all the countries, the LM statistic is insignificant and the RESET statistic is insignificant in most of the models. Also in most of the cases, most of the models are stable according to the CUSUM and CUSUMQ tests.

\subsection{The Bivariate Model:}

The multivariate model is estimated for ten countries: Brazil, Canada, Chile, Indonesia, Japan, Korea, Malaysia, Mexico, U.K. and U.S.A. These are the only countries for which monthly data on all the related variables are available. In this section, I analyze the results of a bivariate specification, which encompasses more countries as a robustness check to see whether the asymmetric effects of exchange rate changes on stock prices is dependent on the countries considered. To do so, I have considered only exchange rates (as monthly data on all the other variables are available for only the ten countries which have been considered in the multivariate model) as the determinant of stock prices so that the hypothesis can be tested on more number of countries (since exchange rate is exogenously determined and it is not correlated with the other macroeconomic variables (IPI, CPI, M2) so it can assumed that the other determinants are 
contained in the error term. This helps to establish the fact of dropping the other variables because of data unavailability). A total of twenty four countries are now considered, the countries are Argentina, Australia, Austria, Belgium, Brazil, Canada, Chile, China, France, Germany, Greece, Hong Kong, India, Indonesia, Japan, Korea, Malaysia, Mexico, Netherlands, New Zealand, Singapore, Switzerland, United Kingdom and United States of America.

In this case as well, both the linear and the nonlinear models are estimated. Tables 13.1-13.4 report the results of the linear model and the Tables 14.1-14.4 report the estimates of the non-linear models. In the multivariate model, the stock prices of the countries that were affected by exchange rates are still affected by exchange rates even after dropping few variables and in addition to those, more countries are added to the list that are affected by exchange rates. From Tables 13.1-13.4, for the linear model, for eighteen out of twenty four countries, the short run coefficients associated with exchange rates are significant at $10 \%$ or higher significance level. Most of the countries are affected negatively by home currency appreciation. From Panel B, only in seven countries, the short run relationship is translated into long run relationship between stock price indices and exchange rates. From Panel C, cointegration among the variables is suggested by negative and significant coefficients of the $\mathrm{ECM}_{\mathrm{t}-1}$ term. The $\mathrm{LM}$ statistic is insignificant for all the countries suggesting an autocorrelation free residuals and the RESET statistic suggests that the model is correctly specified in most of the countries. The CUSUM and CUSUM square tests show that the estimated parameters are stable for almost all the countries.

For the non-linear ARDL model, the results are reported in Tables 14.1-14.4. From the short-run estimates it is first observed that there is 'adjustment asymmetry' in Argentina, Austria, Canada, Chile, Indonesia, Japan, Korea, Malaysia, New Zealand, Singapore and the U.K., since $\triangle P O S$ and $\triangle N E G$ variables carry different lag orders. Shin et al. (2014) recommend testing for short-run 
'impact asymmetry' by applying the Wald test to determine if sum of the short-run coefficients attached to $\triangle P O S$ are different than the sum of the short-run coefficients attached to $\triangle N E G$. Denoting this test by Wald-S in Panel C of Tables 14.1-14.4, it can be concluded that there exists significant short-run cumulative or impact asymmetry in the cases for Argentina, Canada, Chile, Greece, India, and Malaysia since the Wald-S statistic is significant in these cases. Does these short-run effects last into the long run? From the long-run results reported in Panel B it is clear that in Argentina, Canada, and Malaysia, either POS or NEG carry a significant coefficient that is supported by one of the significant tests for cointegration. Thus, with the introduction of nonlinear adjustment of the exchange rate there is increase in the number of countries in which either appreciation or depreciation or both have significant long-run impact on stock prices. According the Wald test (Wald-L in Panel C of Tables 14.1-14.4), it is significant for Canada and Malaysia but not for Argentina. 


\section{Chapter Five: Sectoral Analysis}

In the previous cases, composite stock price indices at the country level were considered which aggregates information of the overall stock market. But composite data might suffer from aggregation bias as composite data do not reflect how each of the different sectors in a particular country is affected by changes in different macroeconomic variables. In a particular country, there are different industrial sectors which will react differently to changes in macroeconomic variables.

So it is important to disaggregate data by considering the sectoral stock price indices for a specific country, U.S.A. Monthly data over the period of 1973:M1 to 2015:M5 are considered. Following the same line of thought from the multivariate model, for the sectoral analysis, the models take the following form:

\subsection{Linear Model:}

Long run specification:

$\ln S P^{i}{ }_{t}=\mathrm{c}_{1}+\mathrm{c}_{2} \ln E X_{t}+\mathrm{c}_{3} \ln I P I_{t}+\mathrm{c}_{4} \ln C P I_{t}+\mathrm{c}_{5} \ln M 2_{t}+\varepsilon_{\mathrm{t}} \quad\left(\varepsilon_{\mathrm{t}} \sim\right.$ n.i.i.d $\left.\left(0, \sigma^{2}\right)\right)$

Error-correction model (Pesaran et al. (2001)):

$$
\begin{aligned}
\Delta \ln S P_{t}^{i}=\alpha_{0} & +\sum_{k=1}^{n 1} \alpha_{1, k} \Delta \ln S P_{t-k}^{i}+\sum_{k=0}^{n 2} \alpha_{2, k} \Delta \ln E X_{t-k}+\sum_{k=0}^{n 3} \alpha_{3, k} \Delta \ln I P I_{t-k} \\
& +\sum_{k=0}^{n 4} \alpha_{4, k} \Delta \ln C P I_{t-k}+\sum_{k=0}^{n 5} \alpha_{5, k} \Delta \ln M 2_{t-k}+\beta_{1} \ln S P_{t-1}^{i}+\beta_{2} \ln E X_{t-1} \\
& +\beta_{3} \ln I P I_{t-1}+\beta_{4} \ln C P I_{t-1}+\beta_{5} \ln M 2_{t-1}+U_{t}
\end{aligned}
$$

\footnotetext{
${ }^{9}$ A detailed description on the data period and data source is provided in Appendices B and C.3.
} 
$\left(S P^{i}\right.$ denotes the stock price index for a particular sector of the U.S., interpretation of rest of the variables remain the same ${ }^{10}$ )

\subsection{Non-Linear Model:}

Long run specification:

$\ln S P_{t}^{i}=\mathrm{c}_{1}+\mathrm{c}_{21} P O S_{t}+\mathrm{c}_{22} N E G_{t}+\mathrm{c}_{3} \ln I P I_{t}+\mathrm{c}_{4} \ln C P I_{t}+\mathrm{c}_{5} \ln M 2_{t}+\varepsilon_{\mathrm{t}}$

Error-correction model:

$$
\begin{aligned}
\Delta \ln S P_{t}^{i}=\alpha_{0} & +\sum_{k=1}^{n 1} \alpha_{1, k} \Delta \ln S P_{t-k}^{i}+\sum_{k=0}^{n 2} \alpha_{21, k} \Delta P O S_{t-k}+\sum_{k=0}^{n 3} \alpha_{22, k} \Delta N E G_{t-k} \\
& +\sum_{k=0}^{n 4} \alpha_{3, k} \Delta \ln I P I_{t-k}+\sum_{k=0}^{n 5} \alpha_{4, k} \Delta \ln C P I_{t-k}+\sum_{k=0}^{n 6} \alpha_{5, k} \Delta \ln M 2_{t-k} \\
& +\beta_{1} \ln S P_{t-1}^{i}+\beta_{2} P O S_{t-1}+\beta_{3} N E G_{t-1}+\beta_{4} \ln I P I_{t-1}+\beta_{5} \ln C P I_{t-1} \\
& +\beta_{6} \ln M 2_{t-1}+U_{t}
\end{aligned}
$$

To explore whether exchange rate changes have symmetric or asymmetric effects on stock prices of each of the sectors and to examine the relationship among the variables at the sectoral level both the linear and the non-linear models are estimated. Tables 16.1-16.4 report the results of all the eleven ${ }^{11}$ sectors.

\footnotetext{
${ }^{10}$ A detailed description of the variables is provided in Appendix A.

${ }^{11}$ The sectoral stock price indices are: Dow Jones Industrial Average Index, Dow Jones Transportation Average Index, Dow Jones Utility Average Index, NASDAQ Bank Index, NASDAQ Biotechnology Index, NASDAQ Computer Index, NASDAQ Industrial Index, NASDAQ Insurance Index, NASDAQ Telecommunications Index, NASDAQ Transportation Index and PHLX Semiconductor Sector.
} 


\subsection{Results}

As a preliminary exercise, the ADF and Elliot-Rothenberg-Stock DF-GLS unit root tests are conducted to the level and the first-differenced variables to make sure that the variables are either $\mathrm{I}(0)$ or I(1).The results reported in Table 15 clearly reveal that none of the variables are I(2) (the requirement of application of ARDL method is that the variables could be combination if $\mathrm{I}(0)$ and I(1) but not I(2)). Panel A of Tables 16.1-16.4 reports the estimates of the short-run coefficients. Out of the eleven sectors, seven sectors have expectedly positive significant coefficients for industrial production index. For CPI, most of the sectors have negative significant coefficients and nominal money supply (M2) affects nearly half of the studied sectors significantly in the short run. Focusing on the effects of exchange rate changes on stock prices of different sectors, it is revealed that for nine out of the eleven sectors in the U.S., stock prices are affected by changes in exchange rates. For most of these nine sectors ${ }^{12}$, stock prices declined with appreciation of the U.S. dollar. Few of the lags of nominal effective exchange rate carry a positive significant coefficient for sectors such as Dow Jones Utility Average Index, NASDAQ Biotechnology Index and NASDAQ Telecommunication Index. This result implies that these three sectors gain from U.S. dollar appreciation unlike other sectors. Any import orientated sector will benefit from home currency appreciation or may be these sectors offset the negative effect of appreciation of U.S. dollar on exports by the positive effect of increase in imports due to appreciation of U.S. currency.

From the estimation of the long-run coefficients (Panel B), Industrial Production Index (IPI) carries a significant and expectedly positive coefficient in seven sectors. CPI carries a significant and an expectedly negative coefficient in two sectors. However, CPI carries a significant and

\footnotetext{
${ }^{12}$ At least one of the coefficients associated with the lags is negative.
} 
positive coefficient in another two sectors, which could be due to the fact that when stocks are held over longer time horizons, stocks are considered or expected to be a good inflation hedge and thus, a positive relationship between inflation and stock prices can exist. Money supply (M2) carries significant and expectedly positive coefficients in three sectors. In the long run, nominal effective exchange rates (EX) affect stock prices only in the two sectors (Dow Jones Transportation and NASDAQ Industrial), which supports the existing literature that stock prices are affected by exchange rates in the short run and there is no or very little relationship between them in the long run. None of the variables affect all the sectors in the short run with only the NASDAQ Industrial Index being affected by all the variables in the long run. The above long run relationship in different sectors will be relevant only if cointegration can be established among the variables. The F test results are reported under Panel C. According to Pesaran et al. (2001), with four exogenous variables, at 5\% significance level the lower and the upper bound critical values are 2.86 and $4.01^{13}$. For four of the sectors, the F statistic is significant, which establishes cointegration among the variables for these four sectors and all the eleven sectors have a significant and negative coefficient of the $E C M_{t-1}$ term which supports cointegration. Under Panel C, the LM statistic is insignificant and the RESET statistic is insignificant in most of the models. From the tables, it can also be concluded that most of the models are stable, where, "S" stands for stability and "U" stands for instability.

Considering the results of the non-linear models for the sectoral analysis, earlier for the multivariate model for the U.S., when the country as a whole was considered, I found that, the aggregate stock price of the U.S., is negatively affected by currency appreciation only. It would be

\footnotetext{
${ }^{13}$ The values are from Pesaran et al. (2001), Table CI(iii), case III, page 300 (k=4). A table is provided in Appendix E.
} 
interesting to see how the results change when the sectoral level stock price indices are considered. From the short run results (Panel A), it can be inferred that the coefficient associated with 'POS' (appreciation of U.S. dollar) is negative ${ }^{14}$ and significant in six of the sectors (Dow Jones Transportation, Dow Jones Utility, NASDAQ Computer, NASDAQ Industrial, NASDAQ Telecommunications, NASDAQ Transportation), which implies that with more appreciation of U.S. dollar, stock prices of these sectors decline. Appreciation of home currency makes imports cheaper and exports expensive, which mean any export orientated firm or sector will be hurt by appreciation of home currency. For example, in the U.S., transportation sector (travel sector) is mostly export-oriented ${ }^{15}$ as services or products are sold to the visitors (foreigners) more than the residents, so appreciation will affect this sector negatively which will lead to a decline in stock prices in this sector. This fact is supported by this study as both Dow Jones Transportation Average Index and NASDAQ Transportation Index are affected negatively by appreciation of U.S. dollar. However, the short run estimated coefficients of ' $N E G$ ' are significant for only four sectors, which means that more sectors are affected as a result of appreciation of home currency than the depreciation of home currency. Indices such as NASDAQ Telecommunications and NASDAQ Biotechnology are affected positively as a result of currency depreciation. These sectors have significant export exponents so they gain from currency depreciation. From the above results, it can be inferred that exchange rate changes have asymmetric effects on changes in sectoral stock price indices of ten sectors as exchange rate changes have different effects in terms of sign and magnitude on stock prices. Concentrating on the long run coefficient estimates of $P O S$ and $N E G$ (Panel B), for most of the sectors they are insignificant which implies that the short run relationship

\footnotetext{
${ }^{14}$ At least one of the coefficients associated with the lags is negative.

${ }^{15}$ For example, the Dow Jones Transportation average Index comprises mostly of airlines, marine transportation, delivery services, etc. which are associated with overseas services. So this sector can be considered as an export orientated sector.
} 
does not persist into long run. The long run effects of exchange rate changes are asymmetric in six sectors, i.e., DJ Industrial Average, NASDAQ Biotech, NASDAQ Computer, NASDAQ Industrial, NASDAQ Insurance, and NASDAQ Telecom. For all the five sectors except for the DJ Industrial Average sector, the NEG variable carries a negative and significant coefficient, whereas the POS variable does not. These findings were absent in the results from the linear model except for NADAQ Industrial sector since only this sector was affected by exchange rate changes in the long run. And other diagnostic statistics for the non-linear models, such as the LM, the RESET, CUSUM and CUSUMSQ indicate that most of the models enjoy autocorrelation free residuals, they are correctly specified, and coefficient estimates are stable respectively. 


\section{Chapter Six: Conclusion}

In this dissertation, I analyze whether movements of exchange rates have symmetric or asymmetric effects on stock prices and the dynamic relationship between stock prices and different macroeconomic variables, focusing on the effect of exchange rate changes on stock prices. An export-orientated firm will benefit from depreciation of the home currency as depreciation makes exports cheaper. This will lead to an increase in competitiveness and increase in earnings of the firm hence, stock prices will increase (a positive relationship). Whereas an import-oriented firm is hurt by depreciation of home currency as the cost of imported inputs is increased as a result of depreciation of home currency. This will lead to decline in profitability thus stock prices will decrease (a negative relationship). Several studies have been done to examine how stock prices are affected by exchange rates and other variables. The previous studies have assumed a linear relationship among the variables, which implies that exchange rate changes will have symmetric effects on stock prices. Furthermore, the previous studies considered data on composite (aggregate) stock price index to carry out the analysis and so they might suffer from aggregation bias.

Here, I consider data on developed and developing countries (Brazil, Canada, Chile, Indonesia, Japan, Korea, Malaysia, Mexico, U.K. and the U.S.) for the period of 1973-2015 and by employing the non-linear ARDL approach it is found that exchange rate changes have asymmetric effects on stock prices. For the multivariate model, when the linear model is considered, where all the variables are assumed to have symmetric effects it is found that almost all variables do have shortrun effects. The long-run effects are found only in few cases. Exchange rate had significant longrun effects on stock prices in Brazil and Korea. The long run effect of industrial production index

on stock prices is witnessed only for Canada and CPI (inflation rate) has significant long-run 
effects in Brazil, Mexico, and the U.K. Money supply has significant long-run effects on stock prices in Korea, Malaysia, and Mexico. But, when the nonlinear ARDL approach of Shin et al. (2014) is considered and currency depreciations are separated from appreciations, I found that exchange rate changes have asymmetric effects on stock prices both in the short run and in the long run.

For the bivariate case (where only exchange rate is the determinant of stock prices), monthly data from 24 countries are used to test for the asymmetric effects of exchange rates on stock prices. The findings could be summarized by saying that short-run 'adjustment asymmetry' and short-run asymmetric effects are observed in many of the countries in the sample. The long-run asymmetric effects were, however, country specific. Significant non-spurious asymmetric effects of exchange rate changes on stock prices is established only in Canada and Malaysia.

Furthermore, at the sectoral level analysis of the U.S., it is also revealed that different macroeconomic variables, differently affect different sectoral stock price indices and appreciation of U.S. dollar and depreciation of U.S. dollar have asymmetric effect on stock price indices. In the short run, most of the sectors are either affected by appreciation of the U.S. dollar or by depreciation of the U.S. dollar. The nonlinear model supported asymmetric cointegration in 10 out of the 11 sectors, implying that the macroeconomic variables do have long-run effects on the 10 sectoral stock price indices. In 6 out of the 11 sectors, exchange rate changes have asymmetric effects in the long run. Furthermore, for NASDAQ Biotech, NASDAQ Computer, NASDAQ Industrial, NASDAQ Insurance, and NASDAQ Telecom, dollar depreciation have positive impact on stock prices whereas dollar appreciation does not. Such discovery is due to nonlinear adjustment process which was absent in the linear model. The level of economic activity was found to be the main long run determinant in almost all the sectors. 
So it can be concluded that exchange rate changes have asymmetric effects on stock prices of different countries and different sectors. The results also have policy implications, based on the sensitivity to either depreciation or appreciation of currency, the sectors can adopt policies to safeguard or hedge them from exchange rate fluctuation risk. Investors should also be aware of asymmetric effects of exchange rate changes on stock prices in specific sectors and form their expectations accordingly. Moreover, there can be different policy implications for tradable and non-tradable sectors, as tradable sectors will be affected by exchange rate fluctuations more than a non-tradable sector. If a sector has both tradable and non-tradable components then during exchange rate fluctuations, it can switch investment plans from tradable products to non-tradable products in order to safe guard itself from exchange rate risk. It will be a key factor for policy makers to understand whether the tradable sector is affected more by increase or decrease in exchange rates. Both appreciation of currency and depreciation of currency will have different policy implications. Depreciation of home currency is beneficial for an economy if the economy is stuck in a recession or is uncompetitive. In such a scenario, depreciation of home currency will lead to increase in exportable and increase in jobs. During boom, depreciation can lead to inflation but during recession, inflation is unlikely to happen. However, appreciation of currency can target import oriented sectors where cost of input prices decrease leading to decline in inflation. This study on asymmetric effects helps to capture both the form of asymmetries: one arising from depreciation or appreciation of currency (sign of the coefficient) and the other arising from the amount of the change in exchange rates (magnitude of the coefficient) so that countries or different sectors within a country can adopt policies accordingly. 
Table 1: The ADF Test Results for variables in level

\begin{tabular}{|c|ccccc|}
\hline & Ln SP & Ln EX & Ln IPI & Ln CPI & Ln M2 \\
\hline Brazil & $-1.77(0)$ & $-2.02(3)$ & $-1.54(0)$ & $-0.18(12)$ & $0.81(12)$ \\
\hline Canada & $-0.85(1)$ & $-1.60(3)$ & $-0.30(12)$ & $-2.21(12)$ & $-0.53(9)$ \\
\hline Chile & $-2.01(4)$ & $-3.39(1)^{*}$ & $-2.13(2)$ & $-0.32(12)$ & $-1.25(0)$ \\
\hline Indonesia & $-0.60(1)$ & $-0.86(2)$ & $-0.39(12)$ & $-0.58(1)$ & $1.51(12)$ \\
\hline Japan & $-1.57(0)$ & $-2.96(11)^{*}$ & $-3.47(2)^{*}$ & $-2.14(12)$ & $-2.40(6)$ \\
\hline Korea & $-2.55(1)$ & $-2.16(4)$ & $-2.34(0)$ & $-0.31(12)$ & $-0.12(12)$ \\
\hline Malaysia & $-1.09(11)$ & $-2.84(10)$ & $-1.96(12)$ & $0.21(5)$ & $-0.14(12)$ \\
\hline Mexico & $-1.76(0)$ & $-1.98(8)$ & $-4.47(4)^{*}$ & $-1.16(12)$ & $-3.93(12)^{*}$ \\
\hline U.K & $-1.79(0)$ & $-1.75(1)$ & $-1.03(1)$ & $-1.00(12)$ & $-2.46(1)$ \\
\hline U.S.A & $-0.37(0)$ & $-1.89(1)$ & $-0.69(3)$ & $-6.81(2)^{*}$ & $-2.08(5)$ \\
\hline
\end{tabular}

Notes:

- Numbers inside the parentheses are the optimum lag order in the ADF test selected by the AIC.

- $95 \%$ critical value for the $\mathrm{ADF}$ test statistic is -2.8842 .

- * indicates the null of unit root is rejected and the variable is stationary. 
Table 2: The ADF Test Results for first differenced variables

\begin{tabular}{|c|ccccc|}
\hline & Ln SP & Ln EX & Ln IPI & Ln CPI & Ln M2 \\
\hline Brazil & $-15.76(0)^{*}$ & $-9.68(1)^{*}$ & $-16.11(0)^{*}$ & $-3.96(12)^{*}$ & $-4.23(12)^{*}$ \\
\hline Canada & $-17.13(0)^{*}$ & $-15.53(0)^{*}$ & $-5.66(12)^{*}$ & $-3.55(11)^{*}$ & $-3.62(7)^{*}$ \\
\hline Chile & $-4.74(3)^{*}$ & $-8.46(0)^{*}$ & $-11.31(1)^{*}$ & $-5.00(3)^{*}$ & $-3.46(7)^{*}$ \\
\hline Indonesia & $-10.61(0)^{*}$ & $-11.05(1)^{*}$ & $-6.30(11)^{*}$ & $-10.20(0)^{*}$ & $-4.30(11)^{*}$ \\
\hline Japan & $-17.14(0)^{*}$ & $-4.55(10)^{*}$ & $-11.00(1)^{*}$ & $-4.77(10)^{*}$ & $-2.97(4)^{*}$ \\
\hline Korea & $-12.29(0)^{*}$ & $-5.67(3)^{*}$ & $-13.31(0)^{*}$ & $-3.57(11)^{*}$ & $-3.80(11)^{*}$ \\
\hline Malaysia & $-4.74(10)^{*}$ & $-4.67(9)^{*}$ & $-3.60(11)^{*}$ & $-7.20(4)^{*}$ & $-3.60(10)^{*}$ \\
\hline Mexico & $-15.83(0)^{*}$ & $-6.05(7)^{*}$ & $-5.87(3)^{*}$ & $-4.90(12)^{*}$ & $-3.06(7)^{*}$ \\
\hline U.K & $-16.57(0)^{*}$ & $-13.65(0)^{*}$ & $-4.47(7)^{*}$ & $-3.98(10)^{*}$ & $-11.62(1)^{*}$ \\
\hline U.S.A & $-20.92(0)^{*}$ & $-15.84(0)^{*}$ & $-7.82(2)^{*}$ & $-2.45(11)$ & $-6.15(4)^{*}$ \\
\hline
\end{tabular}

Notes:

- Numbers inside the parentheses are the optimum lag order in the ADF test selected by the AIC.

- $\quad 95 \%$ critical value for the ADF test statistic is -2.8842 .

- * indicates the null of unit root is rejected and the variable is stationary.

- $\quad$ LnCPI is stationary at the first difference level according to ERS DF-GLS Test (-6.01 [4]*) 
Table 3: Estimates of Linear and Non-linear Models for Brazil (multivariate model)

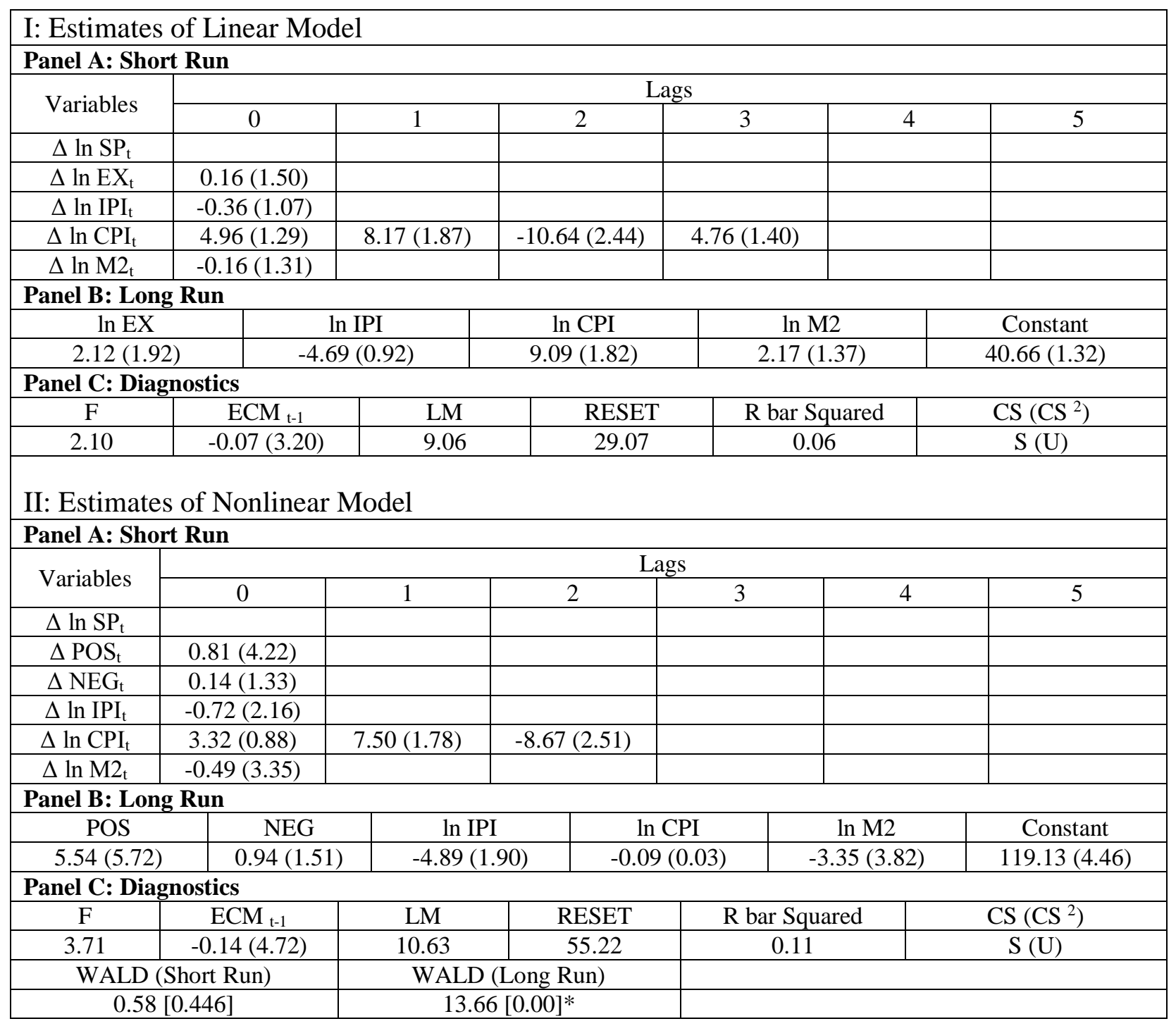

Note: a. Numbers inside parentheses are absolute value of the t-ratios.

b. Numbers inside the brackets are the p-values. * indicates a significant Wald statistic. 
Table 4: Estimates of Linear and Non-linear Models for Canada (multivariate model)

\begin{tabular}{|c|c|c|c|c|c|c|c|c|c|}
\hline \multicolumn{10}{|c|}{ I: Estimates of Linear Model } \\
\hline \multicolumn{10}{|c|}{ Panel A: Short Run } \\
\hline \multirow{2}{*}{ Variables } & \multicolumn{9}{|c|}{ Lags } \\
\hline & 0 & 1 & & 2 & 3 & & 4 & & 5 \\
\hline \multicolumn{10}{|l|}{$\Delta \ln \mathrm{SP}_{\mathrm{t}}$} \\
\hline$\Delta \ln \mathrm{EX}_{\mathrm{t}}$ & $0.84(5.11)$ & \multirow[t]{2}{*}{$0.28(1.69)$} & & & & & & & \\
\hline$\Delta \ln \mathrm{IPI}_{\mathrm{t}}$ & $0.67(2.89)$ & & & & & & & & \\
\hline$\Delta \ln \mathrm{CPI}_{\mathrm{t}}$ & \multirow{2}{*}{$\begin{array}{l}0.24(0.38) \\
0.01(0.26)\end{array}$} & $0.43(0.68)$ & \multicolumn{2}{|c|}{$-0.53(0.83)$} & \multicolumn{2}{|c|}{$-1.25(1.97)$} & \multicolumn{2}{|c|}{$-1.78(2.83)$} & \\
\hline$\Delta \ln M 2_{\mathrm{t}}$ & & & & & & & & & \\
\hline \multicolumn{10}{|c|}{ Panel B: Long Run } \\
\hline \multicolumn{2}{|c|}{$\ln \mathrm{EX}$} & ln IPI & \multicolumn{2}{|r|}{$\ln \mathrm{CPI}$} & \multicolumn{3}{|c|}{$\ln \mathrm{M} 2$} & \multicolumn{2}{|r|}{ Constant } \\
\hline $0.16(0.27)$ & \multicolumn{2}{|c|}{$1.54(2.31)$} & \multicolumn{2}{|c|}{$-0.04(0.03)$} & \multicolumn{3}{|c|}{$0.18(0.25)$} & \multicolumn{2}{|r|}{$-3.10(0.29)$} \\
\hline \multicolumn{10}{|c|}{ Panel C: Diagnostics } \\
\hline $\mathrm{F}$ & \multirow{2}{*}{$\begin{array}{c}\mathrm{ECM}_{\mathrm{t}-1} \\
-0.05(3.67)\end{array}$} & \multicolumn{2}{|l|}{ LM } & \multicolumn{2}{|l|}{ RESET } & $\mathrm{R}$ bar $\mathrm{S}$ & uared & & $\mathrm{CS}\left(\mathrm{CS}^{2}\right)$ \\
\hline 2.75 & & 6.70 & & 7.46 & & 0. & & & $\mathrm{~S}(\mathrm{~S})$ \\
\hline II: Estimates & of Nonlinea & Model & & & & & & & \\
\hline Panel A: Short & Run & & & & & & & & \\
\hline & & & & $\mathrm{La}$ & & & & & \\
\hline Variables & 0 & 1 & & 2 & 3 & & 4 & & 5 \\
\hline$\Delta \ln \mathrm{SP}_{\mathrm{t}}$ & & & & & & & & & \\
\hline$\Delta \mathrm{POS}_{\mathrm{t}}$ & $0.56(1.87)$ & & & & & & & & \\
\hline$\Delta \mathrm{NEG}_{\mathrm{t}}$ & $1.10(3.86)$ & $0.61(2.33)$ & & & & & & & \\
\hline$\Delta \ln \mathrm{IPI}_{\mathrm{t}}$ & $0.60(2.60)$ & & & & & & & & \\
\hline$\Delta \ln \mathrm{CPI}_{\mathrm{t}}$ & $0.25(0.40)$ & $0.37(0.59)$ & & $5(0.87)$ & $-1.22(1$ & 1.93) & $-1.66(2$ & $2.67)$ & \\
\hline$\Delta \ln M 2_{t}$ & $-0.07(1.42)$ & & & & & & & & \\
\hline Panel B: Long & Run & & & & & & & & \\
\hline POS & NEG & $\ln$ IPI & & & SPI & & $\ln \mathrm{M} 2$ & & Constant \\
\hline $0.49(0.94)$ & $-0.65(0.8$ & $0.45(0$. & & 1.67 & 1.19) & & $.21(1.42)$ & & $21.30(1.59)$ \\
\hline Panel C: DiagI & ostics & & & & & & & & \\
\hline $\mathrm{F}$ & $\mathrm{ECM}_{\mathrm{t}-1}$ & LM & & RESET & & $\operatorname{ar} \mathrm{Squ}$ & red & & $\mathrm{CS}\left(\mathrm{CS}^{2}\right)$ \\
\hline 2.75 & $-0.05(4.07)$ & 5.66 & & 6.50 & & 0.14 & & & $\mathrm{~S}(\mathrm{~S})$ \\
\hline WALD (S & hort Run) & WALD & Long & Run) & & & & & \\
\hline $3.86[0$ & $.049]^{*}$ & 3.31 & 0.06 & & & & & & \\
\hline
\end{tabular}

Note: a. Numbers inside parentheses are absolute value of the t-ratios.

b. Numbers inside the brackets are the p-values. * indicates a significant Wald statistic. 
Table 5: Estimates of Linear and Non-linear Models for Chile (multivariate model)

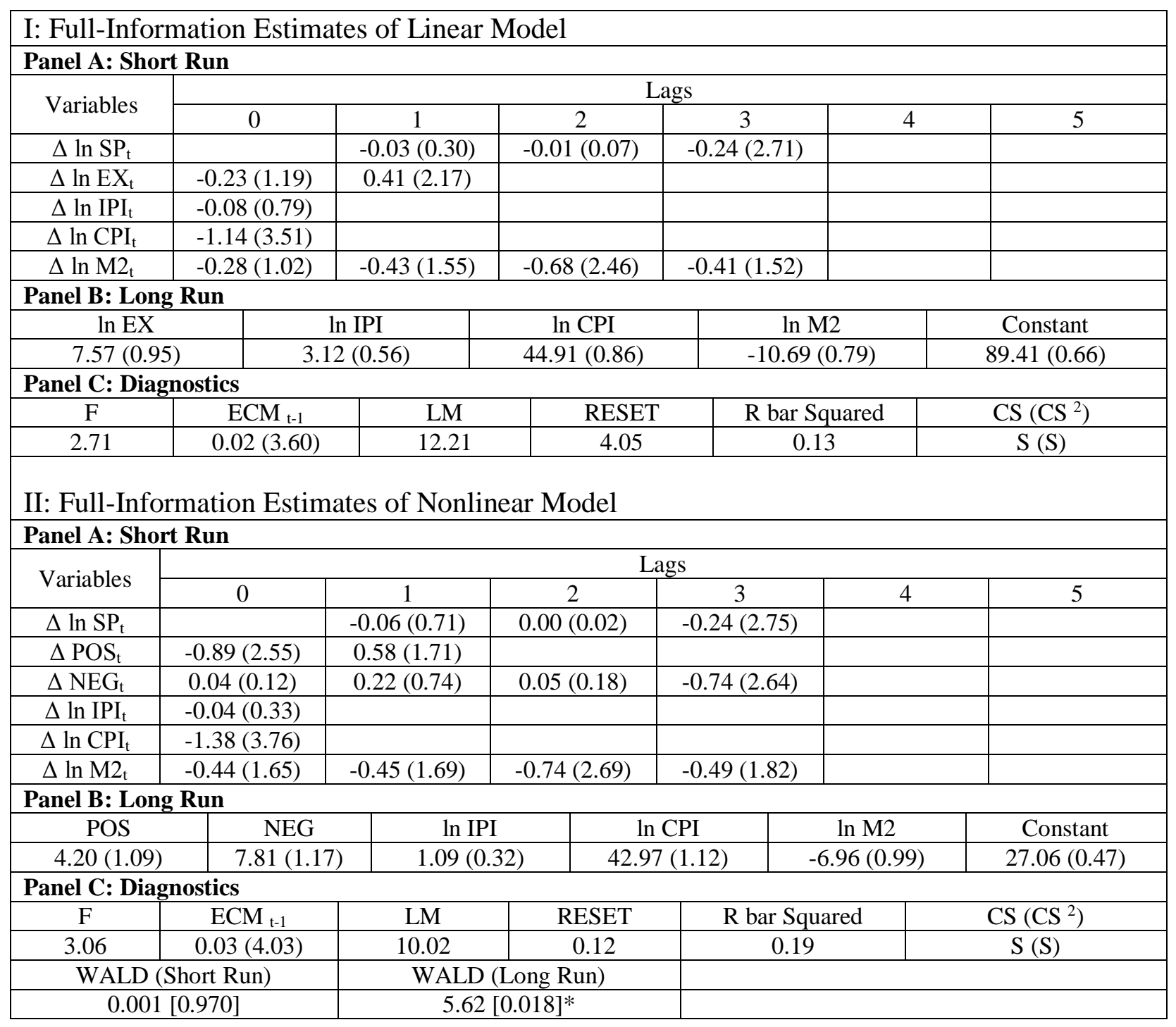

Note: a. Numbers inside parentheses are absolute value of the t-ratios.

b. Numbers inside the brackets are the p-values. * indicates a significant Wald statistic. 
Table 6: Estimates of Linear and Non-linear Models for Indonesia (multivariate model)

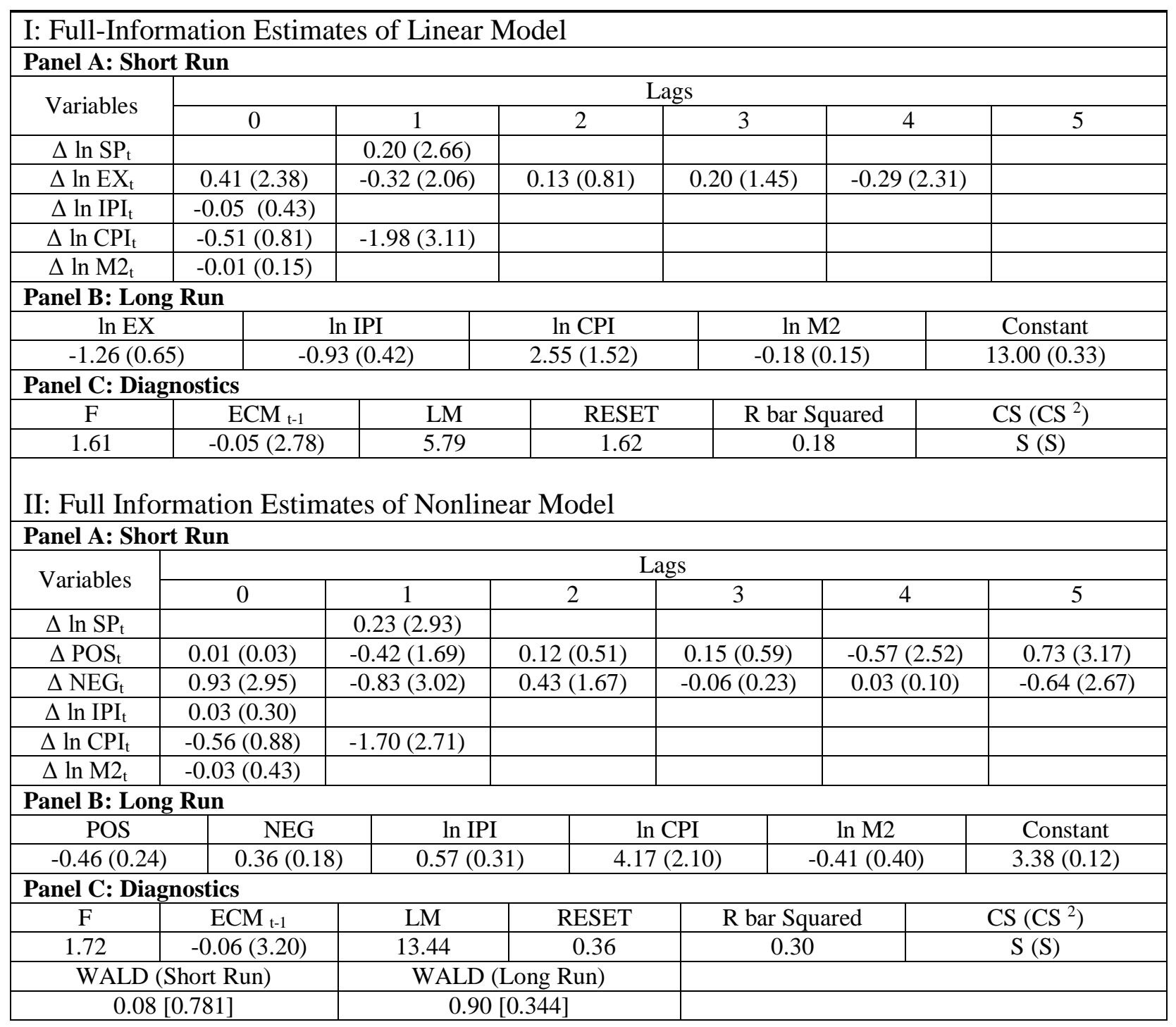

Note: a. Numbers inside parentheses are absolute value of the t-ratios.

b. Numbers inside the brackets are the p-values. * indicates a significant Wald statistic. 
Table 7: Estimates of Linear and Non-linear Models for Japan (multivariate model)

\begin{tabular}{|c|c|c|c|c|c|c|c|c|c|}
\hline \multicolumn{10}{|c|}{$\begin{array}{l}\text { I: Full-Information E } \\
\text { Panel A: Short Run }\end{array}$} \\
\hline \multirow{2}{*}{ Variables } & \multicolumn{9}{|c|}{ Lags } \\
\hline & 0 & 1 & & 2 & \multirow{2}{*}{\multicolumn{2}{|c|}{3}} & \multicolumn{2}{|c|}{4} & 5 \\
\hline \multicolumn{8}{|l|}{$\Delta \ln \mathrm{SP}_{\mathrm{t}}$} & & \\
\hline$\Delta \ln \mathrm{EX}_{\mathrm{t}}$ & $-0.43(3.02)$ & $0.24(1.10)$ & \multicolumn{2}{|c|}{$-0.33(2.25)$} & \multicolumn{2}{|c|}{$0.10(0.68)$} & \multicolumn{2}{|c|}{$-0.13(0.86)$} & $0.35(2.47)$ \\
\hline$\Delta \ln \mathrm{IPI}_{\mathrm{t}}$ & $0.26(1.51)$ & $0.08(0.49)$ & & & & & & \\
\hline$\Delta \ln \mathrm{CPI}_{\mathrm{t}}$ & $1.36(1.51)$ & \multirow{2}{*}{$-2.68(1.86)$} & \multicolumn{2}{|c|}{$0.38(2.25)$} & & & & & \\
\hline$\Delta \ln M 2_{t}$ & $3.06(2.14)$ & & & & & & & & \\
\hline \multicolumn{10}{|c|}{ Panel B: Long Run } \\
\hline $\ln \mathrm{EX}$ & \multicolumn{2}{|c|}{$\ln$ IPI } & \multicolumn{2}{|c|}{$\ln \mathrm{CPI}$} & \multicolumn{3}{|c|}{$\ln \mathrm{M} 2$} & \multicolumn{2}{|r|}{ Constant } \\
\hline $0.37(0.37)$ & \multicolumn{2}{|c|}{$-1.41(0.54)$} & \multicolumn{2}{|c|}{$-3.07(0.67)$} & \multicolumn{3}{|c|}{$-0.78(0.99)$} & & $5.22(2.29)$ \\
\hline Panel C: Diagn & 10stics & & & & & & & & \\
\hline $\mathrm{F}$ & $\mathrm{ECM}_{\mathrm{t}-1}$ & LM & & RESE & & bars & uared & & $\mathrm{CS}\left(\mathrm{CS}^{2}\right)$ \\
\hline 3.15 & $-0.03(3.99)$ & 8.82 & & 0.97 & & 0 . & & & $\mathrm{S}(\mathrm{S})$ \\
\hline II: Full-Infor & mation Estim & ites of Nonlir & ear $N$ & Iodel & & & & & \\
\hline Panel A: Short & Run & & & & & & & & \\
\hline & & & & & & & & & \\
\hline Variables & 0 & 1 & & 2 & 3 & & 4 & & 5 \\
\hline$\Delta \ln \mathrm{SP}_{\mathrm{t}}$ & & & & & & & & & \\
\hline$\Delta \mathrm{POS}_{\mathrm{t}}$ & $-0.63(3.06)$ & $0.43(2.03)$ & -0.4 & $4(2.06)$ & $0.12(0$ & $.56)$ & -0.06( & .26) & $0.58(2.82)$ \\
\hline$\Delta \mathrm{NEG}_{\mathrm{t}}$ & $0.02(0.44)$ & & & & & & & & \\
\hline$\Delta \ln \mathrm{IPI}_{\mathrm{t}}$ & $0.27(1.58)$ & $0.09(0.51)$ & 0.4 & $(2.36)$ & & & & & \\
\hline$\Delta \ln \mathrm{CPI}_{\mathrm{t}}$ & $1.36(1.49)$ & & & & & & & & \\
\hline$\Delta \ln M 2_{t}$ & $3.30(2.29)$ & $-2.44(1.69)$ & & & & & & & \\
\hline Panel B: Long & Run & & & & & & & & \\
\hline POS & NEG & $\ln$ IP & & & & & $\ln \mathrm{M} 2$ & & Constant \\
\hline$-0.06(0.07)$ & $0.39(0.45$ & $-1.42(0$ & & -4.1 & (0.96) & & $.13(0.50$ & & $-2.51(0.04)$ \\
\hline Panel C: Diagn & lostics & & & & & & & & \\
\hline $\mathrm{F}$ & $\mathrm{ECM}_{\mathrm{t}-1}$ & LM & & RESET & & bar $\mathrm{Sq}$ & ared & & $\mathrm{CS}\left(\mathrm{CS}^{2}\right)$ \\
\hline 2.65 & $-0.04(4.01)$ & 7.49 & & 0.14 & & 0.12 & & & S (S) \\
\hline WALD (S & hort Run) & WALD & Long & Run) & & & & & \\
\hline $0.37[0$ & $0.544]$ & 0.68 & $0.40 s$ & & & & & & \\
\hline
\end{tabular}

Note: a. Numbers inside parentheses are absolute value of the t-ratios.

b. Numbers inside the brackets are the p-values. * indicates a significant Wald statistic. 
Table 8: Estimates of Linear and Non-linear Models for Korea (multivariate model)

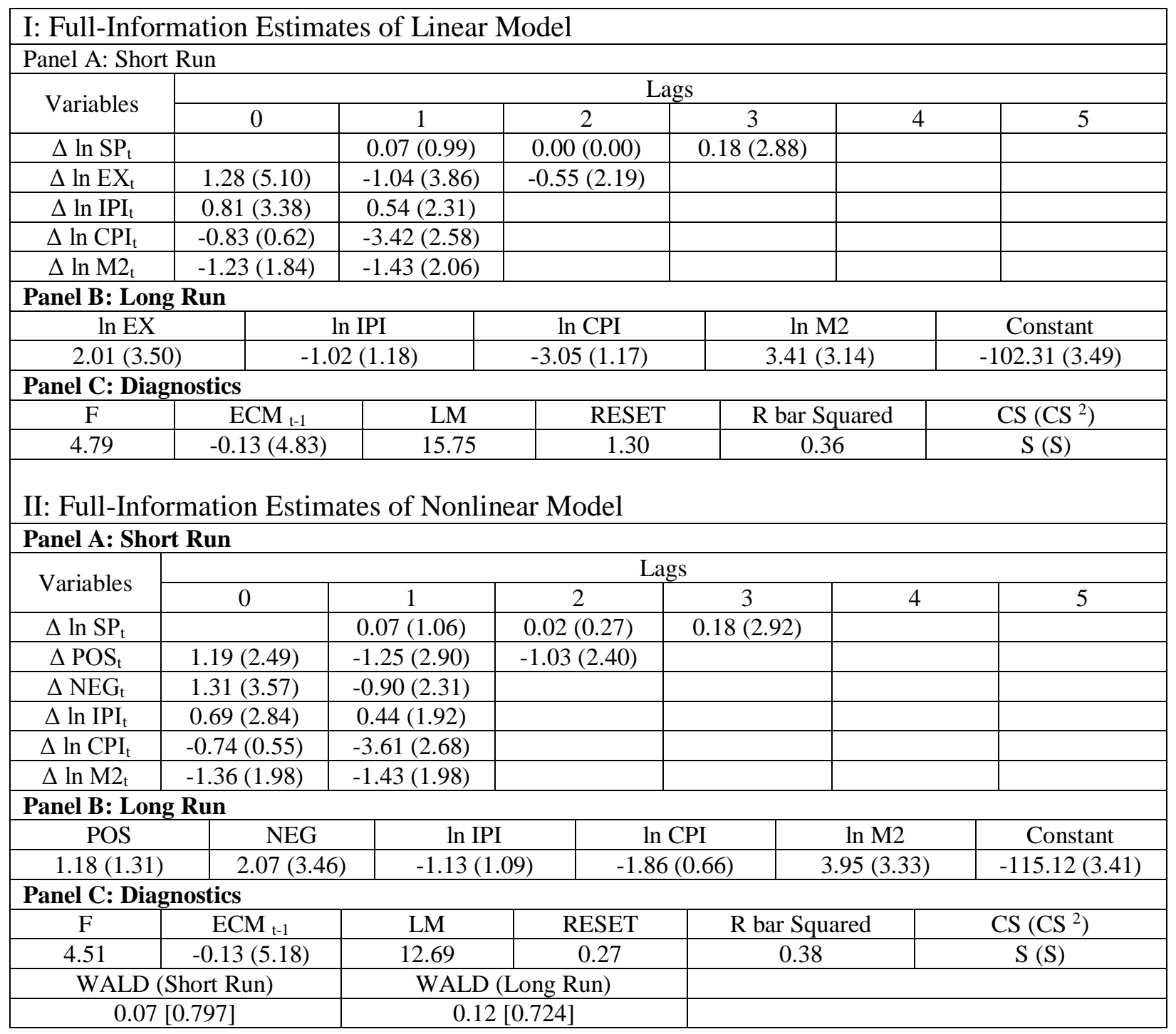

Note: a. Numbers inside parentheses are absolute value of the t-ratios.

b. Numbers inside the brackets are the p-values. * indicates a significant Wald statistic. 
Table 9: Estimates of Linear and Non-linear Models for Malaysia (multivariate model)

\begin{tabular}{|c|c|c|c|c|c|c|c|c|c|}
\hline \multicolumn{10}{|c|}{ I: Estimates of Linear Model } \\
\hline \multicolumn{10}{|c|}{ Panel A: Short Run } \\
\hline \multirow{2}{*}{ Variables } & \multicolumn{9}{|c|}{ Lags } \\
\hline & \multirow[t]{2}{*}{0} & 1 & \multicolumn{2}{|r|}{2} & \multicolumn{2}{|c|}{3} & \multicolumn{2}{|c|}{4} & \multirow[t]{2}{*}{5} \\
\hline$\Delta \ln \mathrm{SP}_{\mathrm{t}}$ & & \multirow[t]{2}{*}{$0.22(3.24)$} & \multicolumn{2}{|c|}{ 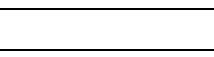 } & \multirow{2}{*}{\multicolumn{2}{|c|}{ 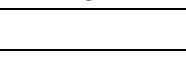 }} & & \\
\hline$\Delta \ln \mathrm{EX}_{\mathrm{t}}$ & $1.34(5.04)$ & & & & & & & & \\
\hline$\Delta \ln \mathrm{IPI}_{\mathrm{t}}$ & $0.10(0.84)$ & $0.25(1.70)$ & \multicolumn{2}{|c|}{$0.45(3.13)$} & \multicolumn{2}{|c|}{$0.47(3.26)$} & \multicolumn{2}{|c|}{$0.28(2.41)$} & \\
\hline$\Delta \ln \mathrm{CPI}_{\mathrm{t}}$ & $0.34(0.28)$ & $1.49(1.25)$ & \multicolumn{2}{|c|}{$-2.77(2.28)$} & \multicolumn{2}{|c|}{$0.49(0.40)$} & \multicolumn{2}{|c|}{$-3.35(2.85)$} & \\
\hline$\Delta \ln M 2_{t}$ & $0.58(1.50)$ & $0.63(1.59)$ & \multicolumn{2}{|c|}{$0.17(0.41)$} & \multicolumn{2}{|c|}{$0.30(0.76)$} & 1.09 & $(2.70)$ & \\
\hline Panel B: Long & Run & & & & & & & & \\
\hline $\ln \mathrm{EX}$ & & १ IPI & & n CPI & & $\ln 1$ & & & Constant \\
\hline $0.67(0.93$ & -0.3 & $7(1.24)$ & & $21(0.09)$ & & 0.82( & .79) & & $-16.03(3.58)$ \\
\hline Panel C: Diag & ostics & & & & & & & & \\
\hline $\mathrm{F}$ & $\mathrm{ECM}_{\mathrm{t}-1}$ & LM & & RESET & & $\mathrm{R}$ bar $\mathrm{S}$ & uared & & $\mathrm{CS}\left(\mathrm{CS}^{2}\right)$ \\
\hline 6.11 & $-0.18(5.49)$ & 16.78 & & 3.69 & & 0.2 & & & $\mathrm{~S}(\mathrm{U})$ \\
\hline II: Estimates & of Nonlinea & Model & & & & & & & \\
\hline Panel A: Shor & Run & & & & & & & & \\
\hline & & & & $\mathrm{La}$ & & & & & \\
\hline Variables & 0 & 1 & & 2 & 3 & & & 4 & 5 \\
\hline$\Delta \ln \mathrm{SP}_{\mathrm{t}}$ & $0.26(3.65)$ & & & & & & & & \\
\hline$\Delta \mathrm{POS}_{\mathrm{t}}$ & $2.72(6.22)$ & $-1.24(2.83)$ & & $(0.98)$ & -0.22( & $0.57)$ & -0.60 & $(1.54)$ & $-1.35(3.52)$ \\
\hline$\Delta \mathrm{NEG}_{\mathrm{t}}$ & $-0.61(1.33)$ & $1.49(3.58)$ & & & & & & & \\
\hline$\Delta \ln \mathrm{IPI}_{\mathrm{t}}$ & $0.01(0.13)$ & $0.18(1.40)$ & & $(2.40)$ & $0.33(2$ & $2.45)$ & 0.36 & (3.21) & \\
\hline$\Delta \ln \mathrm{CPI}_{\mathrm{t}}$ & $-0.01(0.01)$ & $3.01(2.59)$ & & $3(1.48)$ & $0.54(C$ & $0.46)$ & -2.46 & $(2.15)$ & $1.67(1.47)$ \\
\hline$\Delta \ln \mathrm{M} 2_{\mathrm{t}}$ & $0.31(2.95)$ & & & & & & & & \\
\hline Panel B: Long & Run & & & & & & & & \\
\hline POS & NEG & $\ln$ IP & & & & & $\ln \mathrm{M} 2$ & & Constant \\
\hline $1.87(1.87)$ & $-0.48(0.48$ & $-1.07(2$ & & -9.15 & 2.44) & & $89(3.2$ & & $-0.06(0.01)$ \\
\hline Panel C: Diag & lostics & & & & & & & & \\
\hline $\mathrm{F}$ & $\mathrm{ECM}_{\mathrm{t}-1}$ & LM & & RESET & & bar Squ & ared & & $\mathrm{CS}\left(\mathrm{CS}^{2}\right)$ \\
\hline 5.74 & $-0.16(5.95)$ & 12.41 & & 0.54 & & 0.40 & & & S (U) \\
\hline WALD & hort Run) & WALD & Long & Run) & & & & & \\
\hline 0.53 & 0.467] & 6.11 & 0.01 & & & & & & \\
\hline
\end{tabular}

Note: a. Numbers inside parentheses are absolute value of the t-ratios.

b. Numbers inside the brackets are the p-values. * indicates a significant Wald statistic. 
Table 10: Estimates of Linear and Non-linear Models for Mexico (multivariate model)

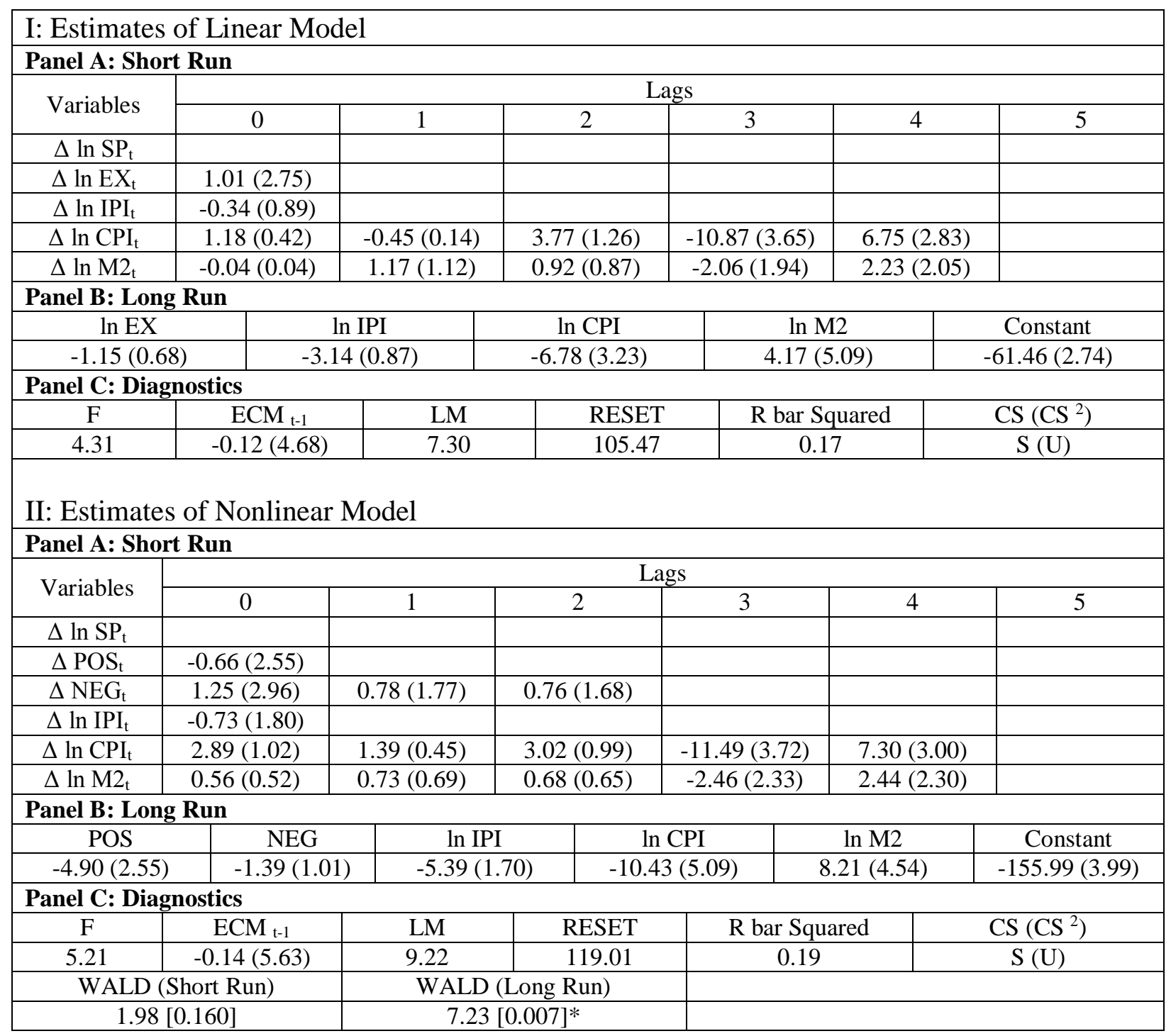

Note: a. Numbers inside parentheses are absolute value of the t-ratios.

b. Numbers inside the brackets are the p-values. * indicates a significant Wald statistic. 
Table 11: Estimates of Linear and Non-linear Models for U.K. (multivariate model)

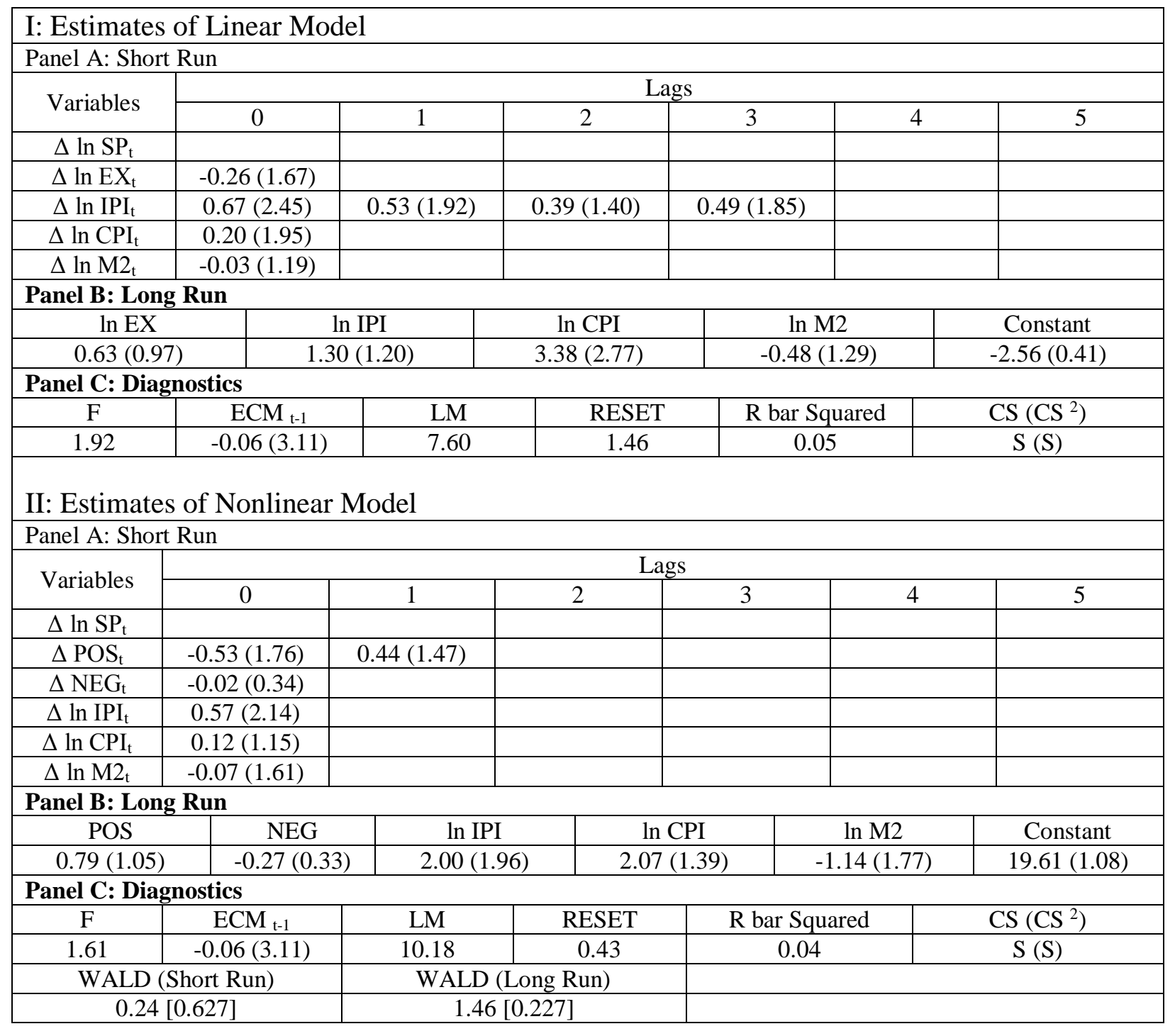

Note: a. Numbers inside parentheses are absolute value of the t-ratios.

b. Numbers inside the brackets are the p-values. * indicates a significant Wald statistic. 
Table 12: Estimates of Linear and Non-linear Models for U.S. (multivariate model)

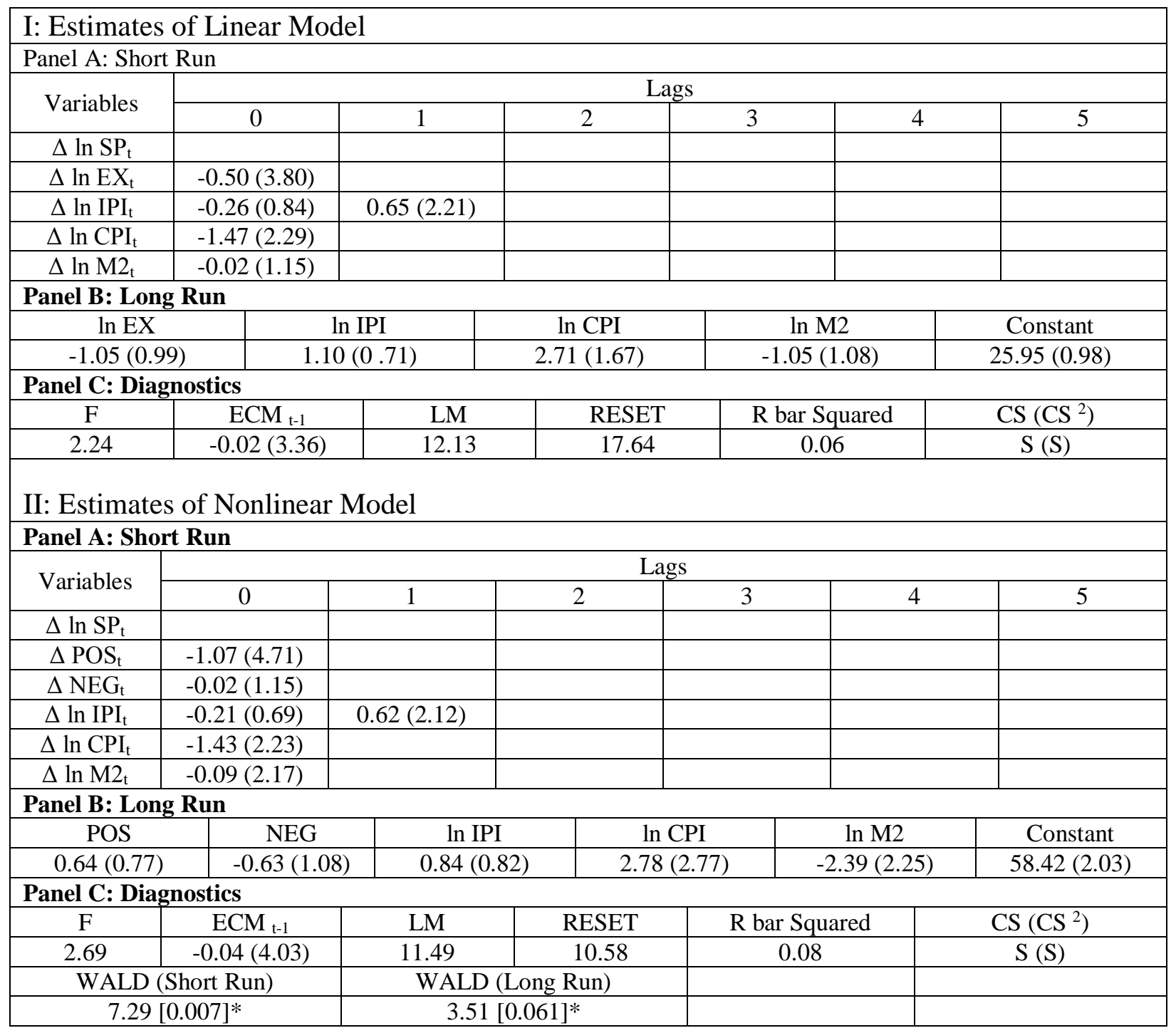

Note: a. Numbers inside parentheses are absolute value of the t-ratios.

b. Numbers inside the brackets are the p-values. * indicates a significant Wald statistic. 
Table 13.1: Estimates of the Linear Model for the bivariate model

\begin{tabular}{|c|c|c|c|c|c|c|}
\hline \multicolumn{7}{|c|}{ Panel A: Short Run Results } \\
\hline Variable & Argentina & Australia & Austria & Belgium & Brazil & Canada \\
\hline$\Delta \ln \mathrm{SP}_{\mathrm{t}-1}$ & & & $0.21(3.18)^{* *}$ & $0.20(3.24) * *$ & & \\
\hline$\Delta \ln \mathrm{SP}_{\mathrm{t}-2}$ & & & $0.11(1.66)^{*}$ & $-0.02(0.35)$ & & \\
\hline$\Delta \ln \mathrm{SP}_{\mathrm{t}-3}$ & & & $-0.03(0.40)$ & $0.00(0.04)$ & & \\
\hline$\Delta \ln \mathrm{SP}_{\mathrm{t}-4}$ & & & $0.12(1.88)^{*}$ & $0.22(3.54)^{* *}$ & & \\
\hline$\Delta \ln \mathrm{SP}_{\mathrm{t}-5}$ & & & $-0.13(1.96)^{* *}$ & & & \\
\hline$\Delta \ln \mathrm{SP}_{\mathrm{t}-6}$ & & & $-0.09(1.40)$ & & & \\
\hline \multicolumn{7}{|l|}{$\Delta \ln \mathrm{SP}_{\mathrm{t}-7}$} \\
\hline$\Delta \ln \mathrm{EX}_{\mathrm{t}}$ & $-1.07(5.42) * *$ & $0.55(4.84)^{* *}$ & $-0.03(0.19)$ & $0.00(0.00)$ & $0.47(1.53)$ & $0.87(5.53)^{* *}$ \\
\hline$\Delta \ln \mathrm{EX}_{\mathrm{t}-1}$ & $0.66(2.85)^{* *}$ & & & & & \\
\hline$\Delta \ln \mathrm{EX}_{\mathrm{t}-2}$ & $-0.15(0.64)$ & & & & & \\
\hline$\Delta \ln \mathrm{EX}_{\mathrm{t}-3}$ & $0.64(3.09)^{* * *}$ & & & & & \\
\hline \multicolumn{7}{|l|}{$\Delta \ln \mathrm{EX}_{\mathrm{t}-4}$} \\
\hline \multicolumn{7}{|l|}{$\Delta \ln \mathrm{EX}_{\mathrm{t}-5}$} \\
\hline \multicolumn{7}{|l|}{$\Delta \ln \mathrm{EX}_{\mathrm{t}-6}$} \\
\hline \multicolumn{7}{|l|}{$\Delta \ln \mathrm{EX}_{\mathrm{t}-7}$} \\
\hline \multicolumn{7}{|l|}{$\Delta \ln \mathrm{EX}_{\mathrm{t}-8}$} \\
\hline \multicolumn{7}{|l|}{$\Delta \ln \mathrm{EX}_{\mathrm{t}-9}$} \\
\hline \multicolumn{7}{|c|}{ Panel B: Long Run Results } \\
\hline $\ln \mathrm{EX}$ & $-1.50(8.63)^{* *}$ & $-0.21(0.10)$ & $-3.59(0.18)$ & $0.02(0.00)$ & $-2.18(1.06)$ & $-3.15(0.47)$ \\
\hline Constant & $14.91(16.4)^{* *}$ & $9.35(0.99)$ & $24.29(0.27)$ & $7.82(0.33)$ & $20.24(2.17)^{* *}$ & $24.03(0.78)$ \\
\hline \multicolumn{7}{|c|}{ Panel C: Other Diagnostics } \\
\hline $\mathrm{F}$ & $9.33 * *$ & 3.55 & 0.85 & 2.55 & 3.47 & 1.03 \\
\hline ECM t-1 & $-0.07(4.33)^{* *}$ & $-0.01(2.63)$ & $-0.01(1.31)$ & $-0.02(2.26)$ & $-0.03(2.64)$ & $-0.00(1.41)$ \\
\hline LM & 10.92 & 4.31 & 9.82 & 8.73 & 7.79 & 5.86 \\
\hline RESET & 3.30 & 3.18 & $3.94 * *$ & $9.42 * *$ & 1.23 & 2.06 \\
\hline $\mathrm{CS}$ & $\mathrm{S}$ & $\mathrm{S}$ & $\mathrm{S}$ & $\mathrm{S}$ & $\mathrm{S}$ & $\mathrm{S}$ \\
\hline $\mathrm{CS} 2$ & $\mathrm{~S}$ & $\mathrm{U}$ & $\mathrm{S}$ & $\mathrm{S}$ & $\mathrm{U}$ & $\mathrm{S}$ \\
\hline
\end{tabular}

Notes:

a. Numbers inside the parentheses next to coefficient estimates are absolute value of t-ratios. *,** indicate significance at the $10 \%$ and $5 \%$ levels respectively.

b. The upper bound critical value of the F-test for cointegration when there is one exogenous variable $(\mathrm{k}=1)$ is 4.78 (5.73) at the $10 \%$ (5\%) level of significance. These come from Pesaran et al. (2001, Table CI, Case III, p. 300).

c. The upper bound critical value of the t-test for significance of $\mathrm{ECM}_{\mathrm{t}-1}$ is $-2.91(-3.22)$ at the $10 \%(5 \%)$ level when $\mathrm{k}=1$. The comparable figures when $\mathrm{k}=2$ are -3.21 and -3.53 respectively. These come from Pesaran et al. (2001, Table CII, Case III, p. 303).

d. LM is the Lagrange Multiplier statistic to test for autocorrelation. It is distributed as $\chi^{2}$ with 12 degrees of freedom. The critical value is 18.54 and 21.03 at the $10 \%$ and $5 \%$ levels respectively.

e. RESET is Ramsey's test for misspecification. It is distributed as $\chi^{2}$ with one degree of freedom. The critical value is 2.70 at the $10 \%$ level and 3.84 at the $5 \%$ level. 
Table 13.2: Estimates of the Linear Model for the bivariate model

\begin{tabular}{|c|c|c|c|c|c|c|}
\hline \multicolumn{7}{|c|}{ Panel A: Short Run Results } \\
\hline Variable & Chile & China & France & Germany & Greece & Hong Kong \\
\hline$\Delta \ln \mathrm{SP}_{\mathrm{t}-1}$ & $0.13(1.59)$ & $0.05(0.75)$ & & & $0.13(2.15)^{* *}$ & \\
\hline$\Delta \ln \mathrm{SP}_{\mathrm{t}-2}$ & $0.07(0.83)$ & $0.17(2.57)^{* *}$ & & & $0.01(0.23)$ & \\
\hline$\Delta \ln \mathrm{SP}_{\mathrm{t}-3}$ & $-0.18(2.07)^{* *}$ & $-0.03(0.40)$ & & & $0.14(2.28)^{* *}$ & \\
\hline$\Delta \ln \mathrm{SP}_{\mathrm{t}-4}$ & $0.12(1.45)$ & $0.18(2.65)^{* *}$ & & & & \\
\hline$\Delta \ln \mathrm{SP}_{\mathrm{t}-5}$ & & $0.05(0.74)$ & & & & \\
\hline$\Delta \ln \mathrm{SP}_{\mathrm{t}-6}$ & & $-0.13(1.95)^{*}$ & & & & \\
\hline$\Delta \ln \mathrm{SP}_{\mathrm{t}-7}$ & & $0.12(1.80)^{*}$ & & & & \\
\hline$\Delta \ln \mathrm{EX}_{\mathrm{t}}$ & $-0.06(0.31)$ & $-0.81(1.83)^{*}$ & $-0.70(1.29)$ & $0.11(1.07)$ & $-2.19(2.84) * *$ & $-1.24(4.03) * *$ \\
\hline$\Delta \ln \mathrm{EX}_{\mathrm{t}-1}$ & $0.48(2.64)^{* *}$ & & & & & \\
\hline \multicolumn{7}{|l|}{$\Delta \ln \mathrm{EX}_{\mathrm{t}-2}$} \\
\hline \multicolumn{7}{|l|}{$\Delta \ln \mathrm{EX}_{\mathrm{t}-3}$} \\
\hline \multicolumn{7}{|l|}{$\Delta \ln \mathrm{EX}_{\mathrm{t}-4}$} \\
\hline \multicolumn{7}{|l|}{$\Delta \ln \mathrm{EX}_{\mathrm{t}-5}$} \\
\hline \multicolumn{7}{|l|}{$\Delta \ln \mathrm{EX}_{\mathrm{t}-6}$} \\
\hline \multicolumn{7}{|l|}{$\Delta \ln \mathrm{EX}_{\mathrm{t}-7}$} \\
\hline \multicolumn{7}{|l|}{$\Delta \ln \mathrm{EX}_{\mathrm{t}-8}$} \\
\hline \multicolumn{7}{|l|}{$\Delta \ln \mathrm{EX}_{\mathrm{t}-9}$} \\
\hline \multicolumn{7}{|c|}{ Panel B: Long Run Results } \\
\hline $\ln \mathrm{EX}$ & $-6.65(0.57)$ & $1.55(0.97)$ & $3.87(0.59)$ & $10.35(0.78)$ & $-5.26(1.92)^{*}$ & $-3.49(1.17)$ \\
\hline Constant & $39.06(0.72)$ & $0.53(0.07)$ & $-9.38(0.31)$ & $-38.44(0.64)$ & $31.77(2.51)^{* *}$ & $26.08(1.87)^{*}$ \\
\hline \multicolumn{7}{|c|}{ Panel C: Other Diagnostics } \\
\hline $\mathrm{F}$ & 4.51 & $5.16^{*}$ & 1.63 & 2.02 & 2.51 & 1.53 \\
\hline ECM t-1 & $-0.01(3.01)^{*}$ & $-0.05(3.21)^{*}$ & $-0.01(1.72)$ & $-0.01(2.01)$ & $-0.02(2.24)$ & $-0.01(1.72)$ \\
\hline LM & 3.95 & 13.09 & 17.55 & 10.41 & 10.54 & 12.64 \\
\hline RESET & 0.67 & $10.92 * *$ & 0.03 & 0.59 & $13.11 * *$ & 1.02 \\
\hline $\mathrm{CS}$ & $\mathrm{S}$ & $\mathrm{S}$ & $\mathrm{S}$ & $\mathrm{S}$ & $\mathrm{S}$ & $\mathrm{S}$ \\
\hline $\mathrm{CS} 2$ & $\mathrm{~S}$ & $\mathrm{~S}$ & $\mathrm{~S}$ & $\mathrm{~S}$ & $\mathrm{~S}$ & $\mathrm{~S}$ \\
\hline
\end{tabular}

Notes:

a. Numbers inside the parentheses next to coefficient estimates are absolute value of t-ratios. *,** indicate significance at the $10 \%$ and $5 \%$ levels respectively.

b. The upper bound critical value of the F-test for cointegration when there is one exogenous variable $(\mathrm{k}=1)$ is 4.78 (5.73) at the $10 \%$ (5\%) level of significance. These come from Pesaran et al. (2001, Table CI, Case III, p. 300).

c. The upper bound critical value of the t-test for significance of $\mathrm{ECM}_{\mathrm{t}-1}$ is $-2.91(-3.22)$ at the $10 \%(5 \%)$ level when $\mathrm{k}=1$. The comparable figures when $\mathrm{k}=2$ are -3.21 and -3.53 respectively. These come from Pesaran et al. (2001, Table CII, Case III, p. 303).

d. LM is the Lagrange Multiplier statistic to test for autocorrelation. It is distributed as $\chi^{2}$ with 12 degrees of freedom. The critical value is 18.54 and 21.03 at the $10 \%$ and $5 \%$ levels respectively.

e. RESET is Ramsey's test for misspecification. It is distributed as $\chi^{2}$ with one degree of freedom. The critical value is 2.70 at the $10 \%$ level and 3.84 at the $5 \%$ level. 
Table 13.3: Estimates of the Linear Model for the bivariate model

\begin{tabular}{|c|c|c|c|c|c|c|}
\hline \multicolumn{7}{|c|}{ Panel A: Short Run Results } \\
\hline Variable & India & Indonesia & Japan & Korea & Malaysia & Mexico \\
\hline$\Delta \ln \mathrm{SP}_{\mathrm{t}-1}$ & & $0.17(2.21)^{* *}$ & & & $0.21(2.89)^{* *}$ & \\
\hline \multicolumn{7}{|l|}{$\Delta \ln \mathrm{SP}_{\mathrm{t}-2}$} \\
\hline \multicolumn{7}{|l|}{$\Delta \ln \mathrm{SP}_{\mathrm{t}-3}$} \\
\hline \multicolumn{7}{|l|}{$\Delta \ln \mathrm{SP}_{\mathrm{t}-4}$} \\
\hline \multicolumn{7}{|l|}{$\Delta \ln \mathrm{SP}_{\mathrm{t}-5}$} \\
\hline \multicolumn{7}{|l|}{$\Delta \ln \mathrm{SP}_{\mathrm{t}-6}$} \\
\hline \multicolumn{7}{|l|}{$\Delta \ln \mathrm{SP}_{\mathrm{t}-7}$} \\
\hline$\Delta \ln \mathrm{EX}_{\mathrm{t}}$ & $1.02(2.96)^{* *}$ & $0.44(2.40)^{* *}$ & $-0.45(3.12)^{* *}$ & $1.23(4.67)^{* *}$ & $0.60(1.63)$ & $1.18(2.56)^{* *}$ \\
\hline$\Delta \ln \mathrm{EX}_{\mathrm{t}-1}$ & & $-0.27(1.55)$ & $0.24(1.66)^{*}$ & $-0.74(2.82)^{* *}$ & $0.01(0.03)$ & \\
\hline$\Delta \ln \mathrm{EX}_{\mathrm{t}-2}$ & & $0.19(1.13)$ & $-0.29(1.97)^{* *}$ & & $0.19(0.61)$ & \\
\hline$\Delta \ln \mathrm{EX}_{\mathrm{t}-3}$ & & $0.12(0.74)$ & $0.05(0.33)$ & & $0.44(1.72)^{*}$ & \\
\hline$\Delta \ln \mathrm{EX}_{\mathrm{t}-4}$ & & $-0.11(0.65)$ & $-0.11(0.75)$ & & $-0.25(1.02)$ & \\
\hline$\Delta \ln \mathrm{EX}_{\mathrm{t}-5}$ & & $0.20(1.32)$ & $0.38(2.73) * *$ & & $0.13(0.54)$ & \\
\hline$\Delta \ln \mathrm{EX}_{\mathrm{t}-6}$ & & $0.00(0.00)$ & & & $-0.53(2.32)^{* *}$ & \\
\hline$\Delta \ln \mathrm{EX}_{\mathrm{t}-7}$ & & $0.04(0.26)$ & & & $1.52(6.76)^{* *}$ & \\
\hline$\Delta \ln \mathrm{EX}_{\mathrm{t}-8}$ & & $0.22(1.74)^{*}$ & & & $0.34(1.41)$ & \\
\hline$\Delta \ln \mathrm{EX}_{\mathrm{t}-9}$ & & $0.06(0.45)$ & & & $0.54(2.34)^{* *}$ & \\
\hline$\Delta \operatorname{lnEX} \mathrm{X}_{\mathrm{t}-10}$ & & $-0.27(3.02)^{* *}$ & & & & \\
\hline \multicolumn{7}{|c|}{ Panel B: Long Run Results } \\
\hline $\ln \mathrm{EX}$ & $-4.92(1.89)^{*}$ & $-6.42(3.38) * *$ & $-1.47(1.91)^{*}$ & $-1.40(0.83)$ & $-8.71(1.12)$ & $-2.79(2.46) * *$ \\
\hline Constant & $32.78(2.67) * *$ & $37.80(4.21)^{* *}$ & $16.10(4.78)^{* *}$ & $13.98(1.75)^{*}$ & $47.16(1.32)$ & $23.88(4.34)^{* *}$ \\
\hline \multicolumn{7}{|c|}{ Panel C: Other Diagnostics } \\
\hline $\mathrm{F}$ & 1.04 & 1.93 & 3.11 & 1.04 & 3.06 & 1.68 \\
\hline ECM t-1 & $-0.01(1.40)$ & $-0.02(1.98)$ & $-0.02(2.50)$ & $-0.01(1.01)$ & $-0.02(2.47)$ & $-0.01(1.04)$ \\
\hline LM & 5.20 & 9.89 & 9.84 & 16.26 & 10.27 & 6.71 \\
\hline RESET & 3.82 & 1.35 & 0.52 & 0.33 & 1.94 & 3.26 \\
\hline $\mathrm{CS}$ & $\mathrm{S}$ & $\mathrm{S}$ & $\mathrm{S}$ & $\mathrm{S}$ & $\mathrm{S}$ & $\mathrm{S}$ \\
\hline CS2 & $\mathrm{S}$ & $\mathrm{S}$ & $\mathrm{S}$ & $\mathrm{U}$ & $\mathrm{S}$ & $\mathrm{U}$ \\
\hline
\end{tabular}

Notes:

a. Numbers inside the parentheses next to coefficient estimates are absolute value of t-ratios. $*, * *$ indicate significance at the $10 \%$ and $5 \%$ levels respectively.

b. The upper bound critical value of the F-test for cointegration when there is one exogenous variable $(\mathrm{k}=1)$ is 4.78 (5.73) at the 10\% (5\%) level of significance. These come from Pesaran et al. (2001, Table CI, Case III, p. 300).

c. The upper bound critical value of the $t$-test for significance of $\mathrm{ECM}_{\mathrm{t}-1}$ is $-2.91(-3.22)$ at the $10 \%(5 \%)$ level when $\mathrm{k}=1$. The comparable figures when $\mathrm{k}=2$ are -3.21 and -3.53 respectively. These come from Pesaran et al. (2001, Table CII, Case III, p. 303).

d. LM is the Lagrange Multiplier statistic to test for autocorrelation. It is distributed as $\chi^{2}$ with 12 degrees of freedom. The critical value is 18.54 and 21.03 at the $10 \%$ and $5 \%$ levels respectively.

e. RESET is Ramsey's test for misspecification. It is distributed as $\chi^{2}$ with one degree of freedom. The critical value is 2.70 at the $10 \%$ level and 3.84 at the $5 \%$ level. 
Table 13.4: Estimates of the Linear Model for the bivariate model

\begin{tabular}{|c|c|c|c|c|c|c|}
\hline \multicolumn{7}{|c|}{ Panel A: Short Run Results } \\
\hline Variable & Netherlands & New Zealand & Singapore & Switzerland & UK & USA \\
\hline$\Delta \ln \mathrm{SP}_{\mathrm{t}-1}$ & & & $0.10(1.60)$ & $0.13(2.10)^{* *}$ & & \\
\hline$\Delta \ln \mathrm{SP}_{\mathrm{t}-2}$ & & & & $-0.05(0.83)$ & & \\
\hline$\Delta \ln \mathrm{SP}_{\mathrm{t}-3}$ & & & & $0.11(1.81)^{*}$ & & \\
\hline$\Delta \ln \mathrm{SP}_{\mathrm{t}-4}$ & & & & $-0.06(1.06)$ & & \\
\hline$\Delta \ln \mathrm{SP}_{\mathrm{t}-5}$ & & & & $0.15(2.60)^{* *}$ & & \\
\hline \multicolumn{7}{|l|}{$\Delta \ln \mathrm{SP}_{\mathrm{t}-6}$} \\
\hline \multicolumn{7}{|l|}{$\Delta \ln \mathrm{SP}_{\mathrm{t}-7}$} \\
\hline$\Delta \ln \mathrm{EX}_{\mathrm{t}}$ & $0.03(0.25)$ & $0.41(2.78)^{* *}$ & $2.12(5.11)^{* *}$ & $-0.81(3.90)^{* *}$ & $-0.31(2.03) * *$ & $-0.46(3.62) * *$ \\
\hline$\Delta \ln \mathrm{EX}_{\mathrm{t}-1}$ & & & $-1.43(3.35)^{* *}$ & & & \\
\hline$\Delta \ln \mathrm{EX}_{\mathrm{t}-2}$ & & & $0.34(0.82)$ & & & \\
\hline$\Delta \ln \mathrm{EX}_{\mathrm{t}-3}$ & & & $-0.77(1.86)^{*}$ & & & \\
\hline$\Delta \ln \mathrm{EX}_{\mathrm{t}-4}$ & & & $-0.68(1.63)$ & & & \\
\hline$\Delta \ln \mathrm{EX}_{\mathrm{t}-5}$ & & & $0.12(0.29)$ & & & \\
\hline$\Delta \ln \mathrm{EX}_{\mathrm{t}-6}$ & & & $-0.78(1.93)^{*}$ & & & \\
\hline$\Delta \ln \mathrm{EX}_{\mathrm{t}-7}$ & & & $0.76(1.90)^{*}$ & & & \\
\hline \multicolumn{7}{|l|}{$\Delta \ln \mathrm{EX}_{\mathrm{t}-8}$} \\
\hline \multicolumn{7}{|l|}{$\Delta \ln \mathrm{EX}_{\mathrm{t}-9}$} \\
\hline \multicolumn{7}{|c|}{ Panel B: Long Run Results } \\
\hline $\ln \mathrm{EX}$ & $1.47(0.23)$ & $2.23(2.44)^{* *}$ & $-1.18(0.30)$ & $1.46(1.13)$ & $-2.11(1.02)$ & $-7.47(0.56)$ \\
\hline Constant & $-0.65(0.02)$ & $-2.12(0.50)$ & $13.15(0.72)$ & $2.31(0.40)$ & $18.70(1.89)^{*}$ & $46.23(0.68)$ \\
\hline \multicolumn{7}{|c|}{ Panel C: Other Diagnostics } \\
\hline $\mathrm{F}$ & 2.03 & 3.49 & 2.24 & 3.25 & 3.25 & 0.19 \\
\hline $\mathrm{ECM}_{\mathrm{t}-1}$ & $-0.03(2.02)$ & $-0.05(2.65)$ & $-0.02(2.12)$ & $-0.02(2.54)$ & $-0.01(2.55)$ & $-0.00(0.60)$ \\
\hline LM & 14.61 & 13.49 & 6.29 & 8.81 & 6.86 & 11.56 \\
\hline RESET & 2.07 & $6.13 * *$ & 0.49 & $5.06 * *$ & 1.54 & $6.24 * *$ \\
\hline CS & $\mathrm{S}$ & $\mathrm{S}$ & $\mathrm{S}$ & $\mathrm{S}$ & $\mathrm{S}$ & $\mathrm{S}$ \\
\hline $\mathrm{CS}^{2}$ & $\mathrm{U}$ & $\mathrm{S}$ & $\mathrm{S}$ & $\mathrm{S}$ & $\mathrm{S}$ & $\mathrm{S}$ \\
\hline
\end{tabular}

Notes:

a. Numbers inside the parentheses next to coefficient estimates are absolute value of t-ratios. $*, * *$ indicate significance at the $10 \%$ and $5 \%$ levels respectively.

b. The upper bound critical value of the F-test for cointegration when there is one exogenous variable $(\mathrm{k}=1)$ is 4.78 (5.73) at the 10\% (5\%) level of significance. These come from Pesaran et al. (2001, Table CI, Case III, p. 300).

c. The upper bound critical value of the t-test for significance of $\mathrm{ECM}_{\mathrm{t}-1}$ is $-2.91(-3.22)$ at the $10 \%(5 \%)$ level when $\mathrm{k}=1$. The comparable figures when $\mathrm{k}=2$ are -3.21 and -3.53 respectively. These come from Pesaran et al. (2001, Table CII, Case III, p. 303).

d. LM is the Lagrange Multiplier statistic to test for autocorrelation. It is distributed as $\chi^{2}$ with 12 degrees of freedom. The critical value is 18.54 and 21.03 at the $10 \%$ and $5 \%$ levels respectively.

e. RESET is Ramsey's test for misspecification. It is distributed as $\chi^{2}$ with one degree of freedom. The critical value is 2.70 at the $10 \%$ level and 3.84 at the $5 \%$ level. 
Table 14.1: Estimates of the Non Linear Model for the bivariate model

\begin{tabular}{|c|c|c|c|c|c|c|}
\hline \multicolumn{7}{|c|}{ Panel A: Short Run Results } \\
\hline Variables & Argentina & Australia & Austria & Belgium & Brazil & Canada \\
\hline$\Delta \ln \mathrm{SP}_{\mathrm{t}-1}$ & & & $0.21(3.29)^{* *}$ & $0.20(3.31)^{* *}$ & & \\
\hline$\Delta \ln \mathrm{SP}_{\mathrm{t}-2}$ & & & $0.08(1.24)$ & $-0.02(0.24)$ & & \\
\hline$\Delta \ln \mathrm{SP}_{\mathrm{t}-3}$ & & & $-0.01(0.23)$ & $0.01(0.14)$ & & \\
\hline$\Delta \ln \mathrm{SP}_{\mathrm{t}-4}$ & & & $0.14(2.09)^{* *}$ & $0.22(3.64)^{* *}$ & & \\
\hline$\Delta \ln \mathrm{SP}_{\mathrm{t}-5}$ & & & $-0.14(2.16)^{* *}$ & & & \\
\hline \multicolumn{7}{|l|}{$\Delta \ln \mathrm{SP}_{\mathrm{t}-6}$} \\
\hline$\Delta \operatorname{POS}_{\mathrm{t}}$ & $-3.28(4.85)^{* *}$ & $-0.01(0.23)$ & $0.14(0.68)$ & $-0.02(0.20)$ & $1.11(1.60)$ & $0.50(1.70)^{*}$ \\
\hline \multicolumn{7}{|l|}{$\Delta \mathrm{POS}_{\mathrm{t}-1}$} \\
\hline \multicolumn{7}{|l|}{$\Delta \mathrm{POS}_{\mathrm{t}-2}$} \\
\hline \multicolumn{7}{|l|}{$\Delta \mathrm{POS}_{\mathrm{t}-3}$} \\
\hline$\Delta \mathrm{NEG}_{\mathrm{t}}$ & $-0.89(4.16) * *$ & $0.84(5.20)^{* *}$ & $0.95(0.52)$ & $-0.04(0.43)$ & $0.02(0.42)$ & $1.10(3.87)^{* *}$ \\
\hline$\Delta \mathrm{NEG}_{\mathrm{t}-1}$ & $0.78(3.26)^{* *}$ & & $1.56(0.82)$ & & & $0.53(2.02)^{* *}$ \\
\hline$\Delta \mathrm{NEG}_{\mathrm{t}-2}$ & $-0.16(0.67)$ & & $1.36(0.71)$ & & & \\
\hline$\Delta \mathrm{NEG}_{\mathrm{t}-3}$ & $0.77(3.47)^{* *}$ & & $0.77(0.40)$ & & & \\
\hline$\Delta \mathrm{NEG}_{\mathrm{t}-4}$ & & & $3.60(1.90)^{*}$ & & & \\
\hline$\Delta \mathrm{NEG}_{\mathrm{t}-5}$ & & & $-4.78(2.55)^{* *}$ & & & \\
\hline$\Delta \mathrm{NEG}_{\mathrm{t}-6}$ & & & $0.76(0.40)$ & & & \\
\hline$\Delta \mathrm{NEG}_{\mathrm{t}-7}$ & & & $-4.08(2.28)^{* *}$ & & & \\
\hline \multicolumn{7}{|c|}{ Panel B: Long Run Results } \\
\hline POS & $-2.13(2.35)^{* *}$ & $-0.10(0.23)$ & $5.70(0.79)$ & $-0.73(0.20)$ & $1.09(1.29)$ & $-0.64(1.37)$ \\
\hline NEG & $-1.56(4.87)^{* *}$ & $-0.57(1.36)$ & $2.46(0.35)$ & $-1.68(0.46)$ & $0.35(0.46)$ & $-1.68(3.41)^{* *}$ \\
\hline Constant & $6.81(21.74)^{* *}$ & $7.17(29.41)^{* *}$ & $6.79(13.77)^{* *}$ & $7.57(26.12)^{* *}$ & $10.05(5.55)^{* *}$ & $7.82(60.30)^{* *}$ \\
\hline \multicolumn{7}{|c|}{ Panel C: Other Diagnostics } \\
\hline $\mathrm{F}$ & $9.93^{* *}$ & $5.54^{*}$ & 1.22 & 2.12 & 3.04 & 3.70 \\
\hline $\mathrm{ECM}_{\mathrm{t}-1}$ & $-0.11(5.49)^{* *}$ & $-0.06(4.07)^{* *}$ & $-0.03(1.91)$ & $-0.03(2.53)$ & $-0.07(3.02)$ & $-0.04(3.30)^{*}$ \\
\hline LM & 12.80 & 7.16 & 11.84 & 10.07 & 6.73 & 7.52 \\
\hline RESET & 0.04 & 3.36 & $4.07 * *$ & $9.01 * *$ & $5.93 * *$ & 2.16 \\
\hline $\mathrm{CS}$ & $\mathrm{S}$ & $\mathrm{S}$ & $\mathrm{S}$ & $\mathrm{S}$ & $\mathrm{S}$ & $\mathrm{S}$ \\
\hline $\mathrm{CS}^{2}$ & $\mathrm{~S}$ & $\mathrm{U}$ & $\mathrm{S}$ & $\mathrm{S}$ & $\mathrm{U}$ & $\mathrm{S}$ \\
\hline WALD-S & $24.11^{* * *}$ & 2.09 & 0.08 & 0.08 & 0.30 & $3.75^{*}$ \\
\hline WALD-L & 1.47 & $73.23 * *$ & $4.38^{* * *}$ & 1.82 & $10.33^{* *}$ & $147.07 * *$ \\
\hline
\end{tabular}

Notes:

a. Numbers inside the parentheses next to coefficient estimates are absolute value of t-ratios. $*, * *$ indicate significance at the $10 \%$ and $5 \%$ levels respectively.

b. The upper bound critical value of the F-test for cointegration when there is one exogenous variable $(\mathrm{k}=1)$ is 4.78 (5.73) at the 10\% (5\%) level of significance. These come from Pesaran et al. (2001, Table CI, Case III, p. 300).

c. The upper bound critical value of the $t$-test for significance of $\mathrm{ECM}_{\mathrm{t}-1}$ is $-2.91(-3.22)$ at the $10 \%(5 \%)$ level when $\mathrm{k}=1$. The comparable figures when $\mathrm{k}=2$ are -3.21 and -3.53 respectively. These come from Pesaran et al. (2001, Table CII, Case III, p. 303).

d. LM is the Lagrange Multiplier statistic to test for autocorrelation. It is distributed as $\chi^{2}$ with 12 degrees of freedom. The critical value is 18.54 and 21.03 at the $10 \%$ and $5 \%$ levels respectively.

e. RESET is Ramsey's test for misspecification. It is distributed as $\chi^{2}$ with one degree of freedom. The critical value is 2.70 at the $10 \%$ level and 3.84 at the $5 \%$ level. 
Table 14.2: Estimates of the Non Linear Model for the bivariate model

\begin{tabular}{|c|c|c|c|c|c|c|}
\hline \multicolumn{7}{|c|}{ Panel A: Short Run Results } \\
\hline Variables & Chile & China & France & Germany & Greece & Hong Kong \\
\hline$\Delta \ln \mathrm{SP}_{\mathrm{t}-1}$ & & $0.05(0.70)$ & $0.09(1.41)$ & & $0.11(1.94) *$ & \\
\hline$\Delta \ln \mathrm{SP}_{\mathrm{t}-2}$ & & $0.16(2.48)^{* *}$ & & & $0.02(0.39)$ & \\
\hline$\Delta \ln \mathrm{SP}_{\mathrm{t}-3}$ & & $-0.02(0.33)$ & & & $0.12(2.09)^{* *}$ & \\
\hline$\Delta \ln \mathrm{SP}_{\mathrm{t}-4}$ & & $0.18(2.65)^{* *}$ & & & & \\
\hline$\Delta \ln \mathrm{SP}_{\mathrm{t}-5}$ & & $0.05(0.82)$ & & & & \\
\hline$\Delta \ln \mathrm{SP}_{\mathrm{t}-6}$ & & $-0.14(2.02)^{* *}$ & & & & \\
\hline$\Delta \ln \mathrm{SP}_{\mathrm{t}-7}$ & & $0.12(1.70)^{*}$ & & & & \\
\hline \multicolumn{7}{|l|}{$\Delta \ln \mathrm{SP}_{\mathrm{t}-8}$} \\
\hline \multicolumn{7}{|l|}{$\Delta \ln \mathrm{SP}_{\mathrm{t}-9}$} \\
\hline$\Delta \mathrm{POS}_{\mathrm{t}}$ & $-0.64(1.91)^{*}$ & $-1.38(1.96)^{* *}$ & $0.03(0.24)$ & $-1.18(1.48)$ & $2.64(1.49)$ & $-1.52(2.55)^{* *}$ \\
\hline \multicolumn{7}{|l|}{$\Delta \mathrm{POS}_{\mathrm{t}-1}$} \\
\hline$\Delta \mathrm{NEG}_{\mathrm{t}}$ & $0.51(1.82)^{*}$ & $-0.01(0.12)$ & $0.02(0.12)$ & $0.05(0.41)$ & $-4.24(4.08)^{* *}$ & $-0.88(1.53)$ \\
\hline$\Delta \mathrm{NEG}_{\mathrm{t}-1}$ & $0.80(2.91)^{* *}$ & & & & & \\
\hline \multirow{2}{*}{\multicolumn{7}{|c|}{$\begin{array}{l}\Delta \mathrm{NEG}_{\mathrm{t}-2} \\
\text { Panel B: Long Run Results }\end{array}$}} \\
\hline & & & & & & \\
\hline POS & $-2.73(0.68)$ & $0.42(0.26)$ & $1.45(0.23)$ & $3.31(0.64)$ & $-5.20(1.00)$ & $-0.73(0.38)$ \\
\hline NEG & $-3.45(0.87)$ & $-0.28(0.12)$ & $0.83(0.12)$ & $1.94(0.36)$ & $-5.11(1.46)$ & $-1.53(0.88)$ \\
\hline Constant & $8.43(8.29)^{* * *}$ & $7.29(19.63)^{* *}$ & $7.96(17.29)^{* *}$ & $8.07(16.13) * *$ & $3.43(1.67) *$ & $8.67(20.91)^{* *}$ \\
\hline \multicolumn{7}{|c|}{ Panel C: Other Diagnostics } \\
\hline $\mathrm{F}$ & 3.43 & 3.85 & 1.27 & 1.78 & 1.97 & 1.73 \\
\hline $\mathrm{ECM}_{\mathrm{t}-1}$ & $-0.03(3.20)$ & $-0.06(3.41)^{*}$ & $-0.02(1.90)$ & $-0.03(2.31)$ & $-0.02(2.42)$ & $-0.03(2.19)$ \\
\hline LM & 7.58 & 10.76 & 18.15 & 11.84 & 8.80 & 12.25 \\
\hline RESET & 2.36 & $8.75 * *$ & 0.51 & 0.32 & $5.04 * *$ & 1.09 \\
\hline $\mathrm{CS}$ & $\mathrm{S}$ & $\mathrm{S}$ & $\mathrm{S}$ & $\mathrm{S}$ & $\mathrm{S}$ & $\mathrm{S}$ \\
\hline $\mathrm{CS}^{2}$ & $\mathrm{~S}$ & $\mathrm{~S}$ & $\mathrm{~S}$ & $\mathrm{~S}$ & $\mathrm{~S}$ & $\mathrm{~S}$ \\
\hline WALD-S & $11.20^{* *}$ & 0.55 & 0.03 & 0.60 & $7.32 * *$ & 0.04 \\
\hline WALD-L & 2.00 & 2.06 & 0.57 & $3.21 *$ & 0.09 & $8.10^{* * *}$ \\
\hline
\end{tabular}

Notes:

a. Numbers inside the parentheses next to coefficient estimates are absolute value of t-ratios. $*, * *$ indicate significance at the $10 \%$ and $5 \%$ levels respectively.

b. The upper bound critical value of the F-test for cointegration when there is one exogenous variable $(\mathrm{k}=1)$ is 4.78 (5.73) at the 10\% (5\%) level of significance. These come from Pesaran et al. (2001, Table CI, Case III, p. 300).

c. The upper bound critical value of the t-test for significance of $\mathrm{ECM}_{\mathrm{t}-1}$ is $-2.91(-3.22)$ at the $10 \%(5 \%)$ level when $\mathrm{k}=1$. The comparable figures when $\mathrm{k}=2$ are -3.21 and -3.53 respectively. These come from Pesaran et al. (2001, Table CII, Case III, p. 303).

d. LM is the Lagrange Multiplier statistic to test for autocorrelation. It is distributed as $\chi^{2}$ with 12 degrees of freedom. The critical value is 18.54 and 21.03 at the $10 \%$ and $5 \%$ levels respectively.

e. RESET is Ramsey's test for misspecification. It is distributed as $\chi^{2}$ with one degree of freedom. The critical value is 2.70 at the $10 \%$ level and 3.84 at the $5 \%$ level. 
Table 14.3: Estimates of the Non Linear Model for the bivariate model

\begin{tabular}{|c|c|c|c|c|c|c|}
\hline \multicolumn{7}{|c|}{ Panel A: Short Run Results } \\
\hline Variables & India & Indonesia & Japan & Korea & Malaysia & Mexico \\
\hline$\Delta \ln \mathrm{SP}_{\mathrm{t}-1}$ & & $0.18(2.17)^{* *}$ & & $0.13(1.72)^{*}$ & $0.23(3.29)^{* *}$ & \\
\hline$\Delta \ln \mathrm{SP}_{\mathrm{t}-2}$ & & $0.02(0.22)$ & & & $0.11(1.66)^{*}$ & \\
\hline$\Delta \ln \mathrm{SP}_{\mathrm{t}-3}$ & & $0.15(1.97)^{* *}$ & & & $0.02(0.27)$ & \\
\hline$\Delta \ln \mathrm{SP}_{\mathrm{t}-4}$ & & $0.04(0.56)$ & & & $0.08(1.17)$ & \\
\hline$\Delta \ln \mathrm{SP}_{\mathrm{t}-5}$ & & $0.01(0.15)$ & & & $0.08(1.18)$ & \\
\hline$\Delta \ln \mathrm{SP}_{\mathrm{t}-6}$ & & $0.94(1.25)$ & & & $0.03(0.43)$ & \\
\hline$\Delta \ln \mathrm{SP}_{\mathrm{t}-7}$ & & $0.03(0.36)$ & & & $0.15(2.32)^{* *}$ & \\
\hline$\Delta \ln \mathrm{SP}_{\mathrm{t}-8}$ & & $0.01(0.15)$ & & & & \\
\hline$\Delta \ln \mathrm{SP}_{\mathrm{t}-9}$ & & $-0.23(3.21)^{* *}$ & & & & \\
\hline$\Delta \mathrm{POS}_{\mathrm{t}}$ & $0.10(0.57)$ & $-0.15(0.51)$ & $-0.65(3.23)^{* *}$ & $0.93(1.60)$ & $1.19(2.00)^{* *}$ & $-0.23(0.98)$ \\
\hline$\Delta \mathrm{POS}_{\mathrm{t}-1}$ & & $-0.41(1.46)$ & $0.37(1.73)^{*}$ & $-0.96(1.75)^{* *}$ & $-0.73(1.20)$ & \\
\hline$\Delta \mathrm{POS}_{\mathrm{t}-2}$ & & $0.04(0.16)$ & $-0.46(2.15)^{* *}$ & $-0.45(0.93)$ & $0.62(1.26)$ & \\
\hline$\Delta \mathrm{POS}_{\mathrm{t}-3}$ & & $0.30(1.06)$ & $-0.04(0.20)$ & $0.56(1.18)$ & $1.15(2.35)^{* *}$ & \\
\hline$\Delta \mathrm{POS}_{\mathrm{t}-4}$ & & $-0.12(0.45)$ & $-0.09(0.44)$ & $-0.20(0.43)$ & $-0.46(1.00)$ & \\
\hline$\Delta \mathrm{POS}_{\mathrm{t}-5}$ & & $0.63(2.42)^{* *}$ & $0.54(2.63)^{* *}$ & $0.28(0.63)$ & $-0.16(0.35)$ & \\
\hline$\Delta \mathrm{POS}_{\mathrm{t}-6}$ & & & & $0.88(2.05)^{* *}$ & $-0.66(1.44)$ & \\
\hline$\Delta \mathrm{POS}_{\mathrm{t}-7}$ & & & & $-0.18(0.41)$ & $1.00(2.26)^{* *}$ & \\
\hline$\Delta \mathrm{POS}_{\mathrm{t}-8}$ & & & & $0.45(1.02)$ & $0.56(1.34)$ & \\
\hline$\Delta \mathrm{POS}_{\mathrm{t}-9}$ & & & & $0.79(1.76)^{*}$ & $1.14(2.88)^{* *}$ & \\
\hline$\Delta \mathrm{POS}_{\mathrm{t}-10}$ & & & & $-1.04(2.36)^{* *}$ & & \\
\hline$\Delta \mathrm{POS}_{\mathrm{t}-11}$ & & & & $1.15(2.81)^{* *}$ & & \\
\hline$\Delta \mathrm{NEG}_{\mathrm{t}}$ & $1.71(3.48)^{* *}$ & $0.85(2.67)^{* *}$ & $0.01(0.23)$ & $1.05(2.81)^{* *}$ & $-0.43(0.69)$ & $1.39(2.28)^{* *}$ \\
\hline$\Delta \mathrm{NEG}_{\mathrm{t}-1}$ & & $-0.78(2.23)^{* *}$ & & $-0.69(1.74)^{*}$ & $1.05(1.69)^{*}$ & \\
\hline$\Delta \mathrm{NEG}_{\mathrm{t}-2}$ & & $0.40(1.15)$ & & & $0.38(0.63)$ & \\
\hline$\Delta \mathrm{NEG}_{\mathrm{t}-3}$ & & $-0.50(1.51)$ & & & $-0.02(0.04)$ & \\
\hline$\Delta \mathrm{NEG}_{\mathrm{t}-4}$ & & $0.12(0.38)$ & & & $0.78(1.63)$ & \\
\hline$\Delta \mathrm{NEG}_{\mathrm{t}-5}$ & & $-0.52(1.76)^{*}$ & & & $0.21(0.46)$ & \\
\hline$\Delta \mathrm{NEG}_{\mathrm{t}-6}$ & & $-0.16(0.58)$ & & & $-0.05(0.11)$ & \\
\hline$\Delta \mathrm{NEG}_{\mathrm{t}-7}$ & & $-0.03(0.09)$ & & & $1.06(2.46)^{* *}$ & \\
\hline$\Delta \mathrm{NEG}_{\mathrm{t}-8}$ & & $0.63(2.50)^{* *}$ & & & & \\
\hline$\Delta \mathrm{NEG}_{\mathrm{t}-9}$ & & $0.26(1.06)$ & & & & \\
\hline$\Delta \mathrm{NEG}_{\mathrm{t}-10}$ & & $-0.28(1.87)^{*}$ & & & & \\
\hline \multicolumn{7}{|c|}{ Panel B: Long Run Results } \\
\hline POS & $2.74(0.71)$ & $-3.27(0.64)$ & $-0.16(0.24)$ & $1.60(1.97)^{* *}$ & $-0.18(0.22)$ & $-4.77(0.86)$ \\
\hline NEG & $-0.04(0.02)$ & $-4.16(1.13)$ & $0.18(0.23)$ & $0.42(0.61)$ & $-1.82(2.16)^{* *}$ & $-4.13(1.07)$ \\
\hline Constant & $8.38(19.9)^{* *}$ & $0.30(0.13)$ & $10.34(35.1)^{* *}$ & $5.77(21.8)^{* *}$ & $5.43(21.33) * *$ & $6.35(2.10)^{* *}$ \\
\hline \multicolumn{7}{|c|}{ Panel C: Other Diagnostics } \\
\hline $\mathrm{F}$ & 1.78 & 1.48 & 3.43 & 2.86 & $7.05 * *$ & 2.12 \\
\hline $\mathrm{ECM}_{\mathrm{t}-1}$ & $-0.04(2.28)$ & $-0.03(2.08)$ & $-0.04(3.22)^{*}$ & $-0.08(2.95)$ & $-0.13(4.61)^{* *}$ & $-0.01(0.86)$ \\
\hline LM & 5.92 & 12.55 & 9.46 & 16.22 & 17.59 & 6.37 \\
\hline RESET & 0.41 & $7.08 * *$ & 0.78 & 1.44 & 0.04 & 1.52 \\
\hline $\mathrm{CS}$ & $S$ & $\mathrm{~S}$ & $\mathrm{~S}$ & $S$ & $\mathrm{~S}$ & $S$ \\
\hline $\mathrm{CS}^{2}$ & $S$ & $S$ & $S$ & $S$ & $S$ & $\mathrm{U}$ \\
\hline WALD-S & $4.44 * *$ & 0.65 & 0.00 & 1.94 & $3.49 *$ & 2.09 \\
\hline WALD-L & $9.52 * *$ & 1.00 & $5.76 * *$ & $3.85^{*}$ & $126.66^{* *}$ & $3.73^{*}$ \\
\hline
\end{tabular}


Table 14.4: Estimates of the Non Linear Model for the bivariate model

\begin{tabular}{|c|c|c|c|c|c|c|}
\hline \multicolumn{7}{|c|}{ Panel A: Short Run Results } \\
\hline Variables & Netherlands & New Zealand & Singapore & Switzerland & UK & USA \\
\hline$\Delta \ln \mathrm{SP}_{\mathrm{t}-1}$ & & $0.09(0.93)$ & $0.09(1.57)$ & $0.13(2.09) * *$ & & \\
\hline$\Delta \ln \mathrm{SP}_{\mathrm{t}-2}$ & & $-0.17(1.90)^{*}$ & $0.08(1.40)$ & $-0.06(0.94)$ & & \\
\hline$\Delta \ln \mathrm{SP}_{\mathrm{t}-3}$ & & & & $0.10(1.63)$ & & \\
\hline$\Delta \ln \mathrm{SP}_{\mathrm{t}-4}$ & & & & $-0.06(1.08)$ & & \\
\hline$\Delta \ln \mathrm{SP}_{\mathrm{t}-5}$ & & & & $0.16(2.67)^{* *}$ & & \\
\hline \multicolumn{7}{|l|}{$\Delta \ln \mathrm{SP}_{\mathrm{t}-6}$} \\
\hline \multicolumn{7}{|l|}{$\Delta \ln \mathrm{SP}_{\mathrm{t}-7}$} \\
\hline \multicolumn{7}{|l|}{$\Delta \ln \mathrm{SP}_{\mathrm{t}-8}$} \\
\hline$\Delta \mathrm{POS}_{\mathrm{t}}$ & $-0.02(0.13)$ & $0.04(0.38)$ & $2.23(3.11)^{* *}$ & $-1.25(3.94) * *$ & $-0.57(1.94)^{*}$ & $-0.99(4.44) * *$ \\
\hline$\Delta \mathrm{POS}_{\mathrm{t}-1}$ & & & $-2.12(3.04) * *$ & & $0.41(1.46)$ & \\
\hline$\Delta \mathrm{POS}_{\mathrm{t}-2}$ & & & $0.66(0.93)$ & & & \\
\hline$\Delta \mathrm{POS}_{\mathrm{t}-3}$ & & & $-1.61(2.39) * *$ & & & \\
\hline \multicolumn{7}{|l|}{$\Delta \mathrm{POS}_{\mathrm{t}-4}$} \\
\hline$\Delta \mathrm{NEG}_{\mathrm{t}}$ & $0.04(0.29)$ & $0.64(2.66)^{* *}$ & $2.50(3.41)^{* *}$ & $-0.00(0.03)$ & $-0.02(0.66)$ & $0.00(0.27)$ \\
\hline$\Delta \mathrm{NEG}_{\mathrm{t}-1}$ & & $-0.14(0.51)$ & & & & \\
\hline$\Delta \mathrm{NEG}_{\mathrm{t}-2}$ & & $0.33(1.22)$ & & & & \\
\hline$\Delta \mathrm{NEG}_{\mathrm{t}-3}$ & & $0.31(1.14)$ & & & & \\
\hline$\Delta \mathrm{NEG}_{\mathrm{t}-4}$ & & $0.02(0.06)$ & & & & \\
\hline$\Delta \mathrm{NEG}_{\mathrm{t}-5}$ & & $0.43(1.64)$ & & & & \\
\hline$\Delta \mathrm{NEG}_{\mathrm{t}-6}$ & & $0.10(0.40)$ & & & & \\
\hline$\Delta \mathrm{NEG}_{\mathrm{t}-7}$ & & $0.14(0.54)$ & & & & \\
\hline$\Delta \mathrm{NEG}_{\mathrm{t}-8}$ & & $-0.68(2.74)^{* *}$ & & & & \\
\hline \multicolumn{7}{|c|}{ Panel B: Long Run Results } \\
\hline POS & $-0.45(0.14)$ & $0.86(0.45)$ & $0.37(0.37)$ & $0.46(0.23)$ & $-0.30(0.19)$ & $1.57(1.20)$ \\
\hline NEG & $0.95(0.28)$ & $0.75(0.40)$ & $-0.21(0.18)$ & $-0.10(0.04)$ & $-0.77(0.57)$ & $0.32(0.27)$ \\
\hline Constant & $\begin{array}{c}6.65 \\
(21.46)^{* *}\end{array}$ & $\begin{array}{c}8.37 \\
(15.37)^{* *}\end{array}$ & $\begin{array}{c}7.48 \\
(27.75)^{* *}\end{array}$ & $\begin{array}{c}8.60 \\
(15.66)^{* *}\end{array}$ & $\begin{array}{c}7.84 \\
(24.45)^{* *}\end{array}$ & $\begin{array}{c}5.04 \\
(12.82)^{* *}\end{array}$ \\
\hline \multicolumn{7}{|c|}{ Panel C: Other Diagnostics } \\
\hline $\mathrm{F}$ & 2.60 & 0.91 & 4.28 & 2.46 & 2.50 & 1.81 \\
\hline $\mathrm{ECM}_{\mathrm{t}-1}$ & $-0.04(2.80)$ & $-0.04(1.66)$ & $-0.06(3.59) * *$ & $-0.02(2.71)$ & $-0.02(2.74)$ & $-0.02(2.33)$ \\
\hline LM & 15.09 & 9.27 & 4.70 & 8.61 & 7.35 & 12.75 \\
\hline RESET & 0.12 & $13.12 * *$ & 1.72 & 2.60 & 2.73 & 0.69 \\
\hline $\mathrm{CS}$ & $\mathrm{S}$ & $\mathrm{S}$ & $\mathrm{S}$ & $\mathrm{S}$ & $\mathrm{S}$ & $\mathrm{S}$ \\
\hline $\mathrm{CS}^{2}$ & $\mathrm{U}$ & $\mathrm{S}$ & $\mathrm{S}$ & $\mathrm{S}$ & $\mathrm{S}$ & $\mathrm{S}$ \\
\hline WALD-S & 1.13 & 1.26 & $5.05 * *$ & 0.73 & 0.16 & $7.03 * *$ \\
\hline WALD-L & $4.34 * *$ & 0.32 & $5.82 * *$ & 0.33 & $3.61 *$ & $47.29 * *$ \\
\hline
\end{tabular}

Notes:

a. Numbers inside the parentheses next to coefficient estimates are absolute value of t-ratios. *, ** indicate significance at the $10 \%$ and $5 \%$ levels respectively.

b. The upper bound critical value of the F-test for cointegration when there is one exogenous variable $(\mathrm{k}=1)$ is 4.78 (5.73) at the 10\% (5\%) level of significance. These come from Pesaran et al. (2001, Table CI, Case III, p. 300).

c. The upper bound critical value of the $t$-test for significance of $\mathrm{ECM}_{\mathrm{t}-1}$ is $-2.91(-3.22)$ at the $10 \%(5 \%)$ level when $\mathrm{k}=1$. The comparable figures when $\mathrm{k}=2$ are -3.21 and -3.53 respectively. These come from Pesaran et al. (2001, Table CII, Case III, p. 303).

d. LM is the Lagrange Multiplier statistic to test for autocorrelation. It is distributed as $\chi^{2}$ with 12 degrees of freedom. The critical value is 18.54 and 21.03 at the $10 \%$ and $5 \%$ levels respectively.

e. RESET is Ramsey's test for misspecification. It is distributed as $\chi^{2}$ with one degree of freedom. The critical value is 2.70 at the $10 \%$ level and 3.84 at the $5 \%$ level. 
Table 15: The ADF Test Results for the sectoral analysis

\begin{tabular}{|l|c|c|c|c|}
\hline \multirow{2}{*}{\multicolumn{1}{|c|}{ Variables }} & \multicolumn{2}{c|}{ ADF Test } & \multicolumn{2}{c|}{ ERS DF-GLS Test } \\
\cline { 2 - 5 } & Level & First Difference & Level & First Difference \\
\hline DJ Industrial Index & $-1.83[0]$ & $-18.35[0]^{* * *}$ & $1.89[0]$ & $-17.74[0]^{* * *}$ \\
\hline DJ Transport Index & $-0.51[0]$ & $-20.59[0]^{* * *}$ & $1.89[0]$ & $-2.85[6]^{* * *}$ \\
\hline DJ Utility Index & $-0.33[0]$ & $-21.95[0]^{* * *}$ & $0.94[0]$ & $-5.01[4]^{* * *}$ \\
\hline NASDAQ Bank Index & $-3.81[0]^{* * *}$ & $-15.14[0]^{* * *}$ & $1.26[0]$ & $-13.82[0]^{* * *}$ \\
\hline NASDAQ Biotech Index & $-0.30[0]$ & $-15.33[0]^{* * *}$ & $1.64[0]$ & $-15.35[0]^{* * *}$ \\
\hline NASDAQ Computer Index & $-1.77[0]$ & $-14.65[0]^{* * *}$ & $0.45[0]$ & $-14.49[0]^{* * *}$ \\
\hline NASDAQ Industrial Index & $-1.77[0]$ & $-15.12[0]^{* * *}$ & $1.11[0]$ & $-13.15[0]^{* * *}$ \\
\hline NASDAQ Insurance Index & $-2.13[0]$ & $-15.82[0]^{* * *}$ & $2.50[0]$ & $-3.56[3]^{* * *}$ \\
\hline NASDAQ Telecom Index & $-1.39[0]$ & $-12.94[0]^{* * *}$ & $-1.36[0]$ & $-2.63[3]^{* * *}$ \\
\hline NASDAQ Transport Index & $-1.38[0]$ & $-15.95[0]^{* * *}$ & $1.47[0]$ & $-2.13[6]^{* *}$ \\
\hline PHLX Semi-Conductor Index & $-2.37[0]$ & $-15.56[0]^{* * *}$ & $-1.22[0]$ & $-15.14[0]^{* * *}$ \\
\hline Nominal Effective Exchange Rate & $-1.89[1]$ & $-15.84[0]^{* * *}$ & $-1.33[1]$ & $-2.01[3]^{* *}$ \\
\hline Industrial Production Index & $-0.69[3]$ & $-7.82[2]^{* * *}$ & $1.43[3]$ & $-2.83[3]^{* * *}$ \\
\hline Consumer Price Index & $-6.81[2]^{* * *}$ & $-2.45[11]$ & $2.54[4]$ & $-2.17[8]^{* *}$ \\
\hline Nominal Money Supply & $-2.08[5]$ & $-6.15[4]^{* * *}$ & $1.46[9]$ & $-6.01[4]^{* * *}$ \\
\hline
\end{tabular}

\section{Notes:}

a. All variables are in logarithmic scale.

b. Maximum number of lags imposed is 12 .

c. Numbers inside the parentheses are the optimum lag order in the tests selected by the SBC.

d. The critical values for the ADF test statistic at $1 \%, 5 \%$ and $10 \%$ significance levels are -3.443123 , -2.867171 and -2.569831 respectively.

e. The critical values for the ERS DF-GLS test statistic at $1 \%, 5 \%$ and $10 \%$ significance levels are $-3.443123,-2.867171$ and -2.569831 respectively.

f. $\quad * * *, * *$ and $*$ indicate the relevant statistic is significant at $1 \%, 5 \%$ and $10 \%$ significance levels respectively. 
Table 16.1: Estimates of Both Linear and Nonlinear ARDL Models (sectoral analysis)

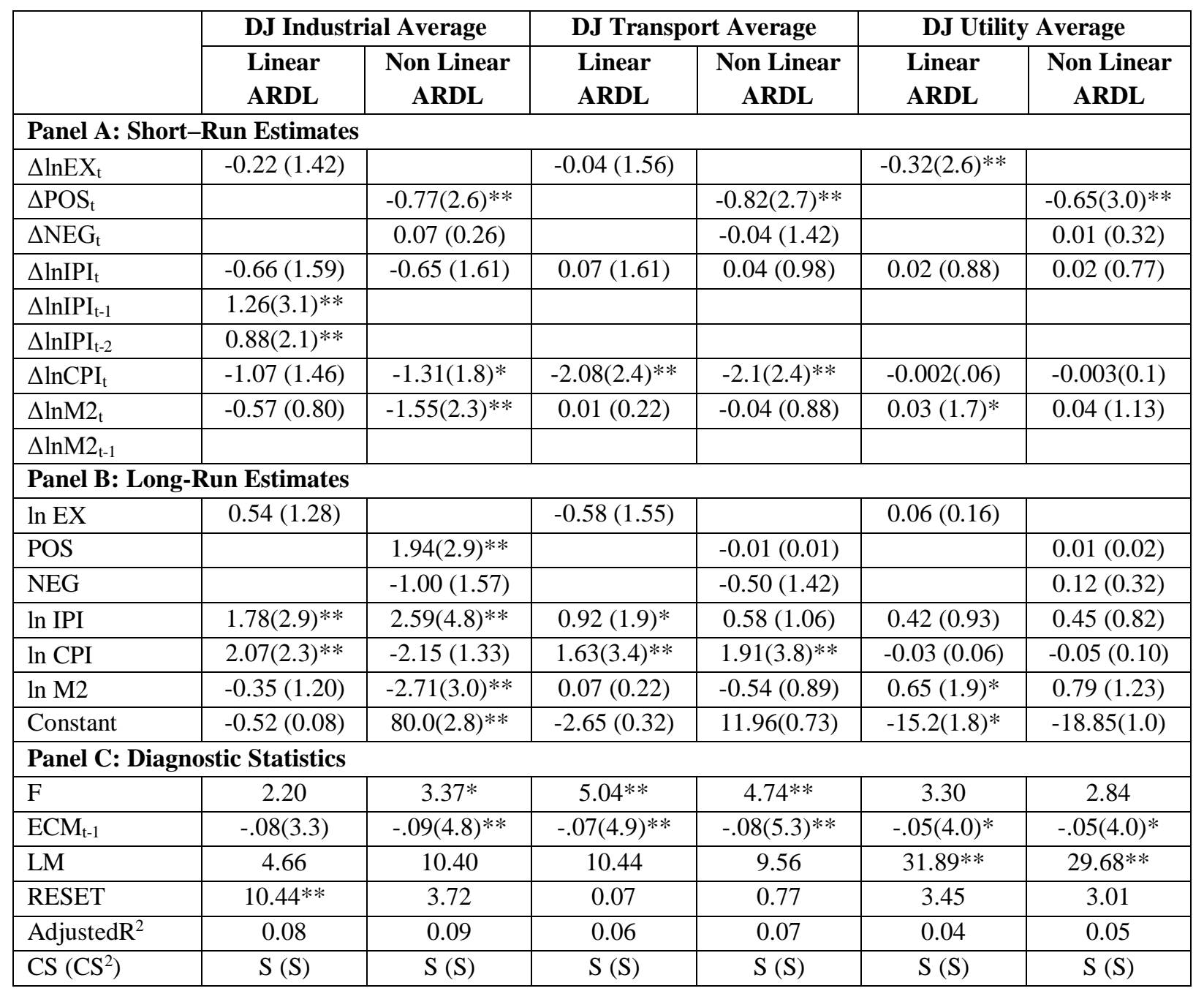

Notes:

a. Numbers inside the parentheses next to coefficient estimates are absolute value of t-ratios. *, ** indicate significance at the $10 \%$ and $5 \%$ levels respectively.

b. The upper bound critical value of the F-test for cointegration in the linear model where there are four exogenous variables is $3.52(4.01)$ at the $10 \%(5 \%)$ level of significance. Comparable figure for the nonlinear model where there are five exogenous variables are 3.35 and 3.79 respectively. These come from Pesaran et al. (2001, Table CI, Case III, p. 300).

c. The critical value for significance of $\mathrm{ECM}_{\mathrm{t}-1}$ is $-3.67(-4.03)$ at the $10 \%(5 \%)$ level when $\mathrm{k}=4$. The comparable figures when $\mathrm{k}=5$ are -3.85 and -4.30 respectively. These come from Banerjee et al. (1998, Table 1).

d. LM is the Lagrange Multiplier statistic to test for autocorrelation. It is distributed as $\chi^{2}$ with 12 degrees of freedom. The critical value is 21.03 .

e. RESET is Ramsey's test for misspecification. It is distributed as $\chi^{2}$ with one degree of freedom. The critical value is 3.84 .

f. In this sector, in order to make sure the models are not misspecified, some additional lags of the dependent variable were included. 
Table 16.2: Estimates of Both Linear and Nonlinear ARDL Models (sectoral analysis)

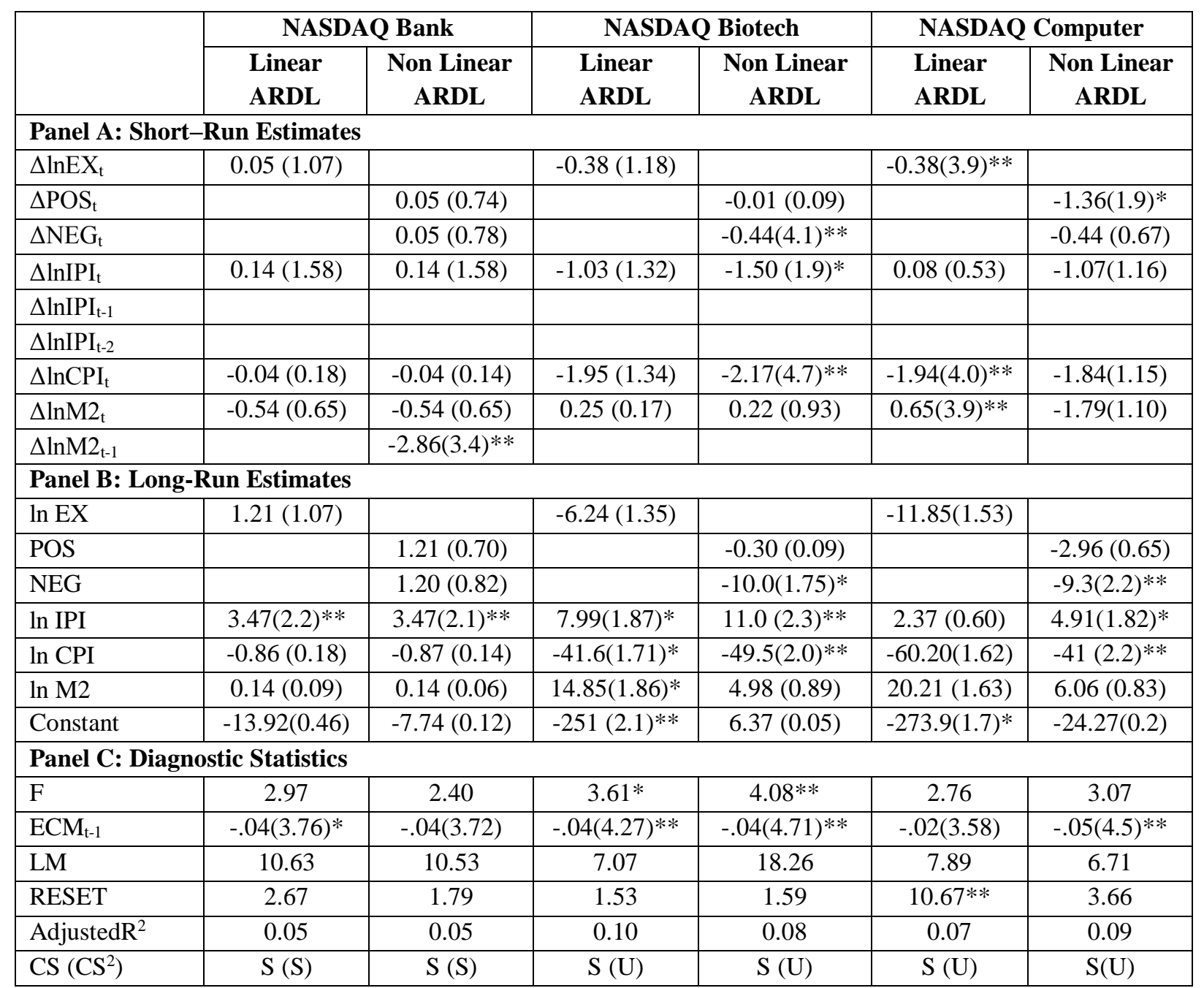

Notes:

a. Numbers inside the parentheses next to coefficient estimates are absolute value of t-ratios. *, ** indicate significance at the $10 \%$ and $5 \%$ levels respectively.

b. The upper bound critical value of the F-test for cointegration in the linear model where there are four exogenous variables is 3.52 (4.01) at the 10\% (5\%) level of significance. Comparable figure for the nonlinear model where there are five exogenous variables are 3.35 and 3.79 respectively. These come from Pesaran et al. (2001, Table CI, Case III, p. 300).

c. The critical value for significance of $\mathrm{ECM}_{\mathrm{t}-1}$ is $-3.67(-4.03)$ at the $10 \%(5 \%)$ level when $\mathrm{k}=4$. The comparable figures when $\mathrm{k}=5$ are -3.85 and -4.30 respectively. These come from Banerjee et al. (1998, Table 1).

d. LM is the Lagrange Multiplier statistic to test for autocorrelation. It is distributed as $\chi^{2}$ with 12 degrees of freedom. The critical value is 21.03 .

e. RESET is Ramsey's test for misspecification. It is distributed as $\chi^{2}$ with one degree of freedom. The critical value is 3.84 .

f. In this sector, in order to make sure the models are not misspecified, some additional lags of the dependent variable were included. 
Table 16.3: Estimates of Both Linear and Nonlinear ARDL Models (sectoral analysis)

\begin{tabular}{|c|c|c|c|c|c|c|}
\hline & \multicolumn{2}{|c|}{ NASDAQ Industrial } & \multicolumn{2}{|c|}{ NASDAQ Insurance } & \multicolumn{2}{|c|}{ NASDAQ Telecom } \\
\hline & $\begin{array}{l}\text { Linear } \\
\text { ARDL }\end{array}$ & $\begin{array}{l}\text { Non Linear } \\
\text { ARDL }\end{array}$ & $\begin{array}{l}\text { Linear } \\
\text { ARDL }\end{array}$ & $\begin{array}{c}\text { Non Linear } \\
\text { ARDL }\end{array}$ & $\begin{array}{l}\text { Linear } \\
\text { ARDL }\end{array}$ & $\begin{array}{c}\text { Non Linear } \\
\text { ARDL }\end{array}$ \\
\hline \multicolumn{7}{|c|}{ Panel A: Short-Run Estimates } \\
\hline$\Delta \operatorname{lnEX_{t}}$ & $-.77(3.1)^{* *}$ & & $-0.04(0.96)$ & & $-1.34(3.9)^{* *}$ & \\
\hline$\triangle \mathrm{POS}_{\mathrm{t}}$ & & $-1.3(3.1)^{* *}$ & & $0.03(0.58)$ & & $-2.32(3.3)^{* *}$ \\
\hline$\Delta \mathrm{NEG}_{\mathrm{t}}$ & & $-0.4(4.3)^{* *}$ & & $-0.09(1.81)^{*}$ & & $-0.45(0.70)$ \\
\hline$\Delta \ln I P I_{t}$ & $0.28(2.3)^{* *}$ & $0.49(3.9)^{* *}$ & $0.19(2.4)^{* *}$ & $0.23(2.8)^{* *}$ & $-1.13(1.33)$ & $-1.93(2.2)^{* *}$ \\
\hline \multicolumn{7}{|l|}{$\Delta \operatorname{lnIPI} I_{t-1}$} \\
\hline \multicolumn{7}{|l|}{$\Delta \operatorname{lnIPI} I_{t-2}$} \\
\hline$\Delta \operatorname{lnCPI} I_{t}$ & $-0.7(2.6)^{* *}$ & $-1.54(4.5)^{*}$ & $-0.09(0.53)$ & $-0.28(1.34)$ & $-2.26(1.47)$ & $-3.14(2.0)^{* *}$ \\
\hline$\Delta \ln M 2_{\mathrm{t}}$ & $0.25(2.7)^{* *}$ & $-0.05(0.45)$ & $0.10(1.8)^{*}$ & $0.01(0.11)$ & $-0.19(0.12)$ & $-0.82(0.52)$ \\
\hline \multirow{2}{*}{\multicolumn{7}{|c|}{$\begin{array}{l}\Delta \ln M 2_{\mathrm{t}-1} \\
\text { Panel B: I }\end{array}$}} \\
\hline & & & & & & \\
\hline \multicolumn{7}{|c|}{\begin{tabular}{l|l}
$\ln \mathrm{EX}$ & $-2.7(2.1)^{* *}$
\end{tabular}} \\
\hline POS & & $0.83(0.87)$ & & $0.36(0.57)$ & & $-12.79(0.97)$ \\
\hline NEG & & $-4.1(4.1)^{* *}$ & & $-1.01(1.67)^{*}$ & & $-22.2(1.73)^{*}$ \\
\hline $\ln$ IPI & $4.72(2.9)^{* *}$ & $5.03(5.1)^{* *}$ & $2.17(3.4)^{* *}$ & $2.5(3.89)^{* *}$ & $4.13(0.67)$ & $7.14(1.29)$ \\
\hline $\ln \mathrm{CPI}$ & $-12(2.1)^{* *}$ & $-16(3.9)^{* *}$ & $-1.04(0.50)$ & $-2.96(1.19)$ & $-115.5(1.49)$ & $-86.50(1.59)$ \\
\hline $\ln \mathrm{M} 2$ & $4.27(2.2)^{* *}$ & $-0.56(0.45)$ & $1.14(1.64)^{*}$ & $0.10(0.11)$ & $34.96(1.43)$ & $14.38(0.78)$ \\
\hline Constant & $-72(2.1)^{* *}$ & $59.82(1.63)$ & $-29.0(2.4)^{* *}$ & $3.81(0.16)$ & $-393.3(1.32)$ & $-90.45(0.27)$ \\
\hline \multicolumn{7}{|c|}{ Panel C: Diagnostic Statistics } \\
\hline $\mathrm{F}$ & 3.15 & $5.81 * *$ & 2.94 & 3.27 & $5.28 * *$ & $4.68 * *$ \\
\hline $\mathrm{ECM}_{\mathrm{t}-1}$ & $-.06(4.0)^{*}$ & $-.11(6.0)^{* *}$ & $-.07(3.76)^{*}$ & $-.08(4.33)^{* *}$ & $-.02(5.00)^{* *}$ & $-.03(5.29)^{* *}$ \\
\hline LM & 10.57 & 8.70 & 21.59 & 21.30 & 15.50 & 16.70 \\
\hline RESET & $9.70 * *$ & $5.97 * *$ & 0.04 & 0.51 & $11.97 * *$ & $6.57 * *$ \\
\hline AdjustedR $^{2}$ & 0.07 & 0.14 & 0.05 & 0.07 & 0.15 & 0.17 \\
\hline $\mathrm{CS}\left(\mathrm{CS}^{2}\right)$ & S (S) & S (S) & S (S) & S (S) & $\mathrm{S}(\mathrm{U})$ & $\mathrm{S}(\mathrm{U})$ \\
\hline
\end{tabular}

Notes:

a. Numbers inside the parentheses next to coefficient estimates are absolute value of t-ratios. *, ** indicate significance at the $10 \%$ and $5 \%$ levels respectively.

b. The upper bound critical value of the F-test for cointegration in the linear model where there are four exogenous variables is $3.52(4.01)$ at the $10 \%$ (5\%) level of significance. Comparable figure for the nonlinear model where there are five exogenous variables are 3.35 and 3.79 respectively. These come from Pesaran et al. (2001, Table CI, Case III, p. 300).

c. The critical value for significance of $\mathrm{ECM}_{\mathrm{t}-1}$ is $-3.67(-4.03)$ at the $10 \%(5 \%)$ level when $\mathrm{k}=4$. The comparable figures when $\mathrm{k}=5$ are -3.85 and -4.30 respectively. These come from Banerjee et al. (1998, Table 1).

d. LM is the Lagrange Multiplier statistic to test for autocorrelation. It is distributed as $\chi^{2}$ with 12 degrees of freedom. The critical value is 21.03 .

e. RESET is Ramsey's test for misspecification. It is distributed as $\chi^{2}$ with one degree of freedom. The critical value is 3.84 .

f. In this sector, in order to make sure the models are not misspecified, some additional lags of the dependent variable were included. 
Table 16.4: Estimates of Both Linear and Nonlinear ARDL Models (sectoral analysis)

\begin{tabular}{|c|c|c|c|c|}
\hline & \multicolumn{2}{|c|}{ NASDAQ Transport } & \multicolumn{2}{|c|}{ PHLX Semi-Conductor } \\
\hline & Linear ARDL & $\begin{array}{c}\text { Non Linear } \\
\text { ARDL }\end{array}$ & Linear ARDL & $\begin{array}{c}\text { Non Linear } \\
\text { ARDL }\end{array}$ \\
\hline \multicolumn{5}{|c|}{ Panel A: Short-Run Estimates } \\
\hline$\Delta \operatorname{lnEX_{t}}$ & $-0.08(1.43)$ & & $-0.11(0.91)$ & \\
\hline$\Delta \mathrm{POS}_{\mathrm{t}}$ & & $-0.90(2.50)^{* *}$ & & $0.15(0.76)$ \\
\hline$\Delta \mathrm{NEG}_{\mathrm{t}}$ & & $-0.08(1.16)$ & & $-0.24(1.66)^{*}$ \\
\hline$\Delta \operatorname{lnIPI} I_{t}$ & $0.20(2.21)^{* *}$ & $0.19(2.02)^{* *}$ & $0.54(2.80)^{* *}$ & $0.68(3.21)^{* *}$ \\
\hline \multicolumn{5}{|l|}{$\Delta \operatorname{lnIPI} I_{t-1}$} \\
\hline \multicolumn{5}{|l|}{$\Delta \operatorname{lnIPI} I_{t-2}$} \\
\hline$\Delta \operatorname{lnCPI} I_{t}$ & $-0.40(1.78)^{*}$ & $-0.44(1.58)$ & $-1.61(2.67)^{* *}$ & $-1.86(2.99)^{* *}$ \\
\hline$\Delta \ln M 2_{\mathrm{t}}$ & $0.18(2.37)^{* *}$ & $0.13(1.15)$ & $0.53(2.53)^{* *}$ & $0.12(0.35)$ \\
\hline \multicolumn{5}{|l|}{$\Delta \ln M 2_{\mathrm{t}-1}$} \\
\hline \multicolumn{5}{|c|}{ Panel B: Long-Run Estimates } \\
\hline $\ln \mathrm{EX}$ & $-1.18(1.58)$ & & $-1.05(0.86)$ & \\
\hline POS & & $-0.42(0.32)$ & & $1.42(0.77)$ \\
\hline NEG & & $-1.26(1.12)$ & & $-2.22(1.53)$ \\
\hline $\ln$ IPI & $2.89(2.60)^{* *}$ & $2.85(2.25)^{* *}$ & $5.40(3.30)^{* *}$ & $6.34(3.73)^{* *}$ \\
\hline $\ln \mathrm{CPI}$ & $-5.73(1.52)$ & $-6.78(1.25)$ & $-16.05(2.27)^{* *}$ & $-17.31(2.54)^{* *}$ \\
\hline $\ln \mathrm{M} 2$ & $2.57(1.99)^{* *}$ & $2.00(1.20)$ & $5.29(2.14)^{* *}$ & $1.09(0.34)$ \\
\hline Constant & $-50.38(2.13)^{* *}$ & $-36.20(0.78)$ & $-98.04(2.36)^{* *}$ & $13.50(0.17)$ \\
\hline \multicolumn{5}{|c|}{ Panel C: Diagnostic Statistics } \\
\hline $\mathrm{F}$ & $3.46^{*}$ & 2.83 & $3.55^{*}$ & $3.43^{*}$ \\
\hline $\mathrm{ECM}_{\mathrm{t}-1}$ & $-.07(4.06)^{* *}$ & $-.07(4.05)^{*}$ & $-.10(4.18)^{* *}$ & $-.10(4.45)^{* *}$ \\
\hline LM & 13.62 & 13.45 & 5.44 & 4.04 \\
\hline RESET & $4.23 * *$ & 2.08 & 1.69 & 1.31 \\
\hline AdjustedR $^{2}$ & 0.07 & 0.08 & 0.07 & 0.07 \\
\hline $\mathrm{CS}\left(\mathrm{CS}^{2}\right)$ & $\mathrm{S}(\mathrm{U})$ & S (S) & $\mathrm{S}(\mathrm{U})$ & $\mathrm{S}(\mathrm{U})$ \\
\hline
\end{tabular}

Notes:

a. Numbers inside the parentheses next to coefficient estimates are absolute value of t-ratios. *, ** indicate significance at the $10 \%$ and $5 \%$ levels respectively.

b. The upper bound critical value of the F-test for cointegration in the linear model where there are four exogenous variables is $3.52(4.01)$ at the $10 \%(5 \%)$ level of significance. Comparable figure for the nonlinear model where there are five exogenous variables are 3.35 and 3.79 respectively. These come from Pesaran et al. (2001, Table CI, Case III, p. 300).

c. The critical value for significance of $\mathrm{ECM}_{\mathrm{t}-1}$ is $-3.67(-4.03)$ at the $10 \%(5 \%)$ level when $\mathrm{k}=4$. The comparable figures when $\mathrm{k}=5$ are -3.85 and -4.30 respectively. These come from Banerjee et al. (1998, Table 1).

d. LM is the Lagrange Multiplier statistic to test for autocorrelation. It is distributed as $\chi^{2}$ with 12 degrees of freedom. The critical value is 21.03 .

e. RESET is Ramsey's test for misspecification. It is distributed as $\chi^{2}$ with one degree of freedom. The critical value is 3.84 .

f. In this sector, in order to make sure the models are not misspecified, some additional lags of the dependent variable were included. 
Figure 1: CUSUSM and CUSUSM Square plots for the multivariate model

\begin{tabular}{|c|c|c|}
\hline \multicolumn{2}{|c|}{ Linear ARDL } & \begin{tabular}{c} 
BRAZIL \\
Residuals \\
\hline
\end{tabular} Plot of Cumulative Sum of Recursive \\
Residuals
\end{tabular}

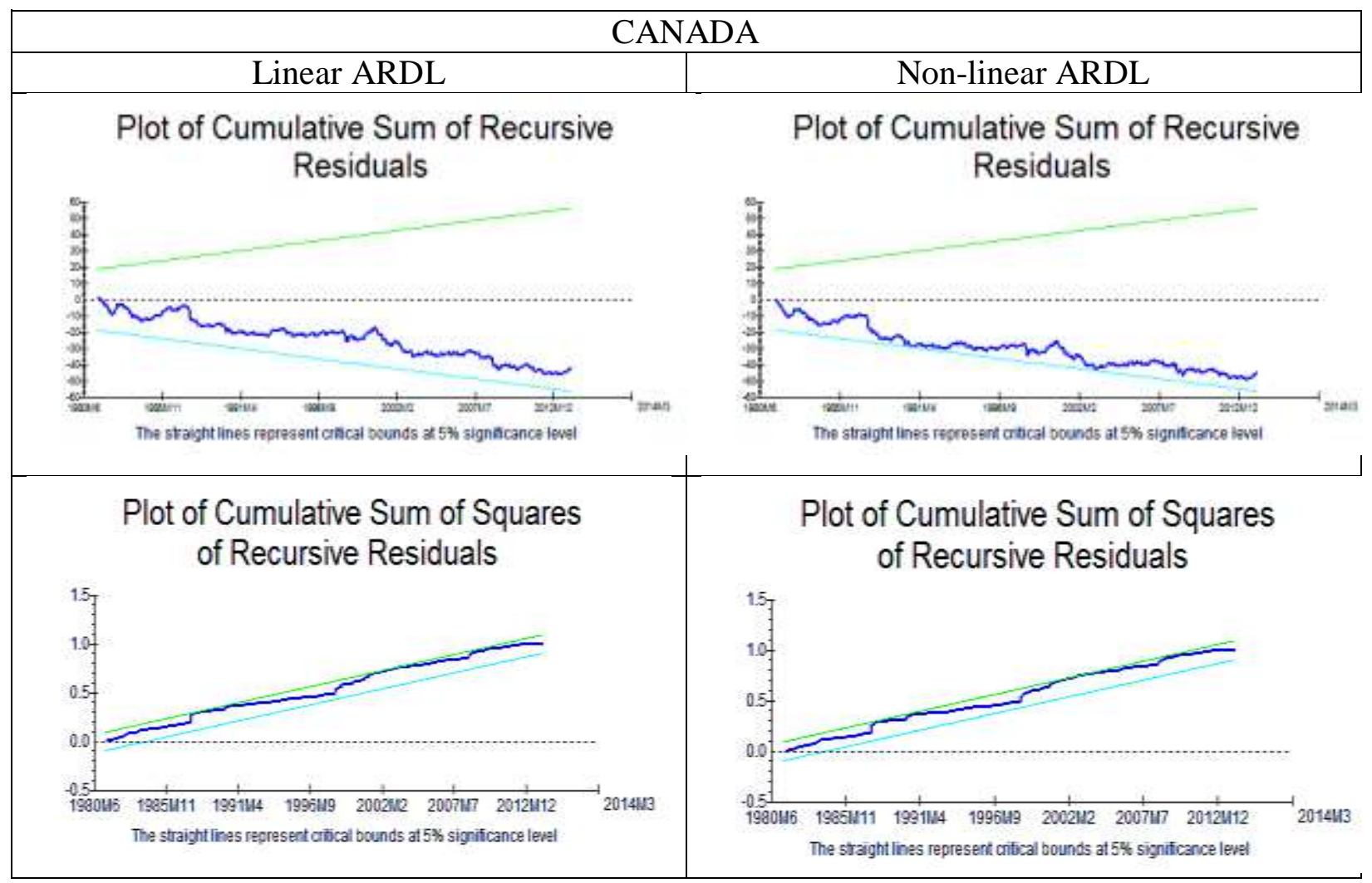


Figure 1: CUSUSM and CUSUSM Square plots for the multivariate model (cont'd)

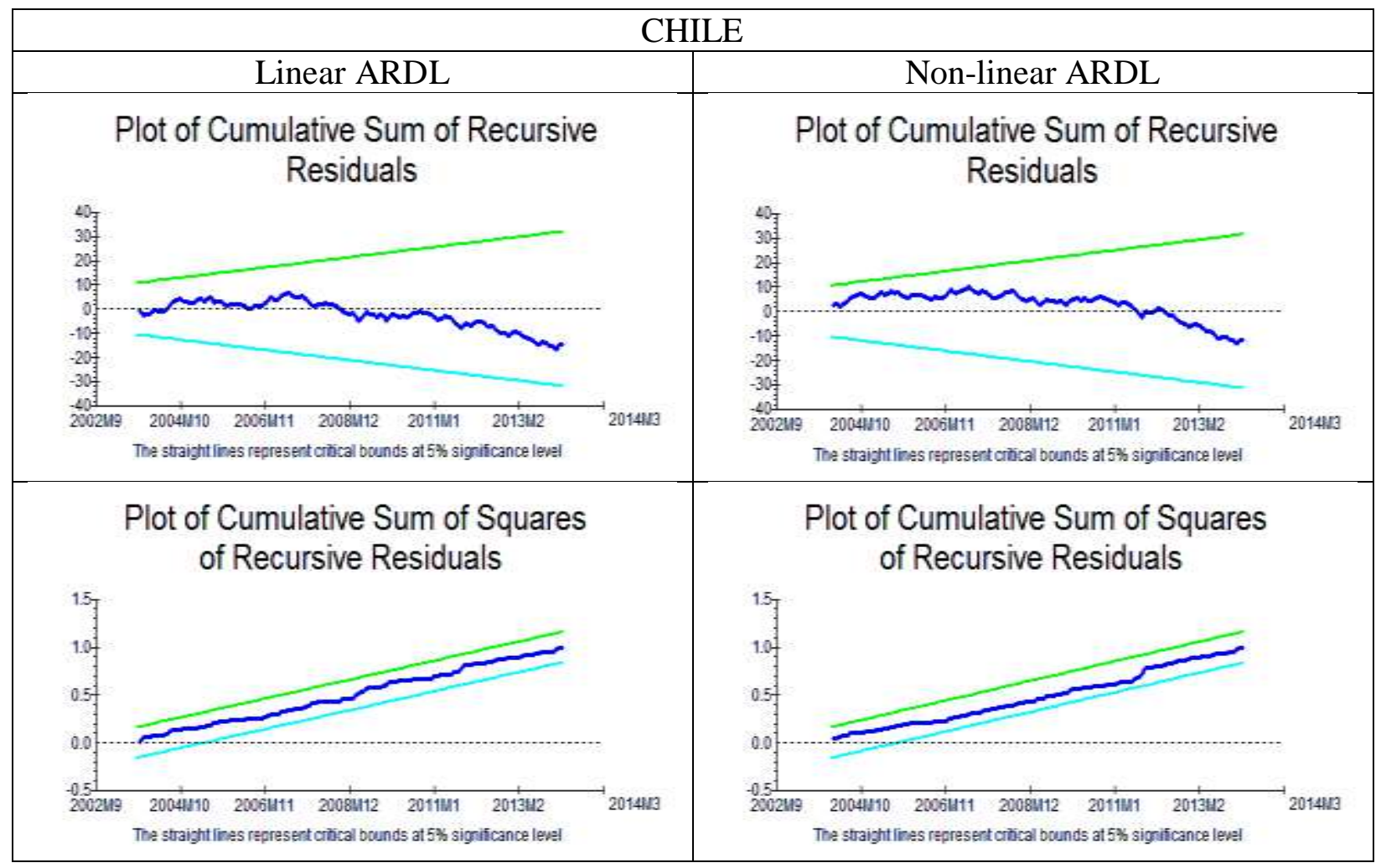

\begin{tabular}{|c|c|c|}
\hline \multicolumn{2}{|c|}{ INDONESIA } \\
\hline $\begin{array}{c}\text { Linear ARDL } \\
\text { Residuals } \\
\text { Rlot of Cumulative Sum of Recursive }\end{array}$ & Pot of Cumulative Sum of Recursive \\
Residuals
\end{tabular}


Figure 1: CUSUSM and CUSUSM Square plots for the multivariate model (cont'd)

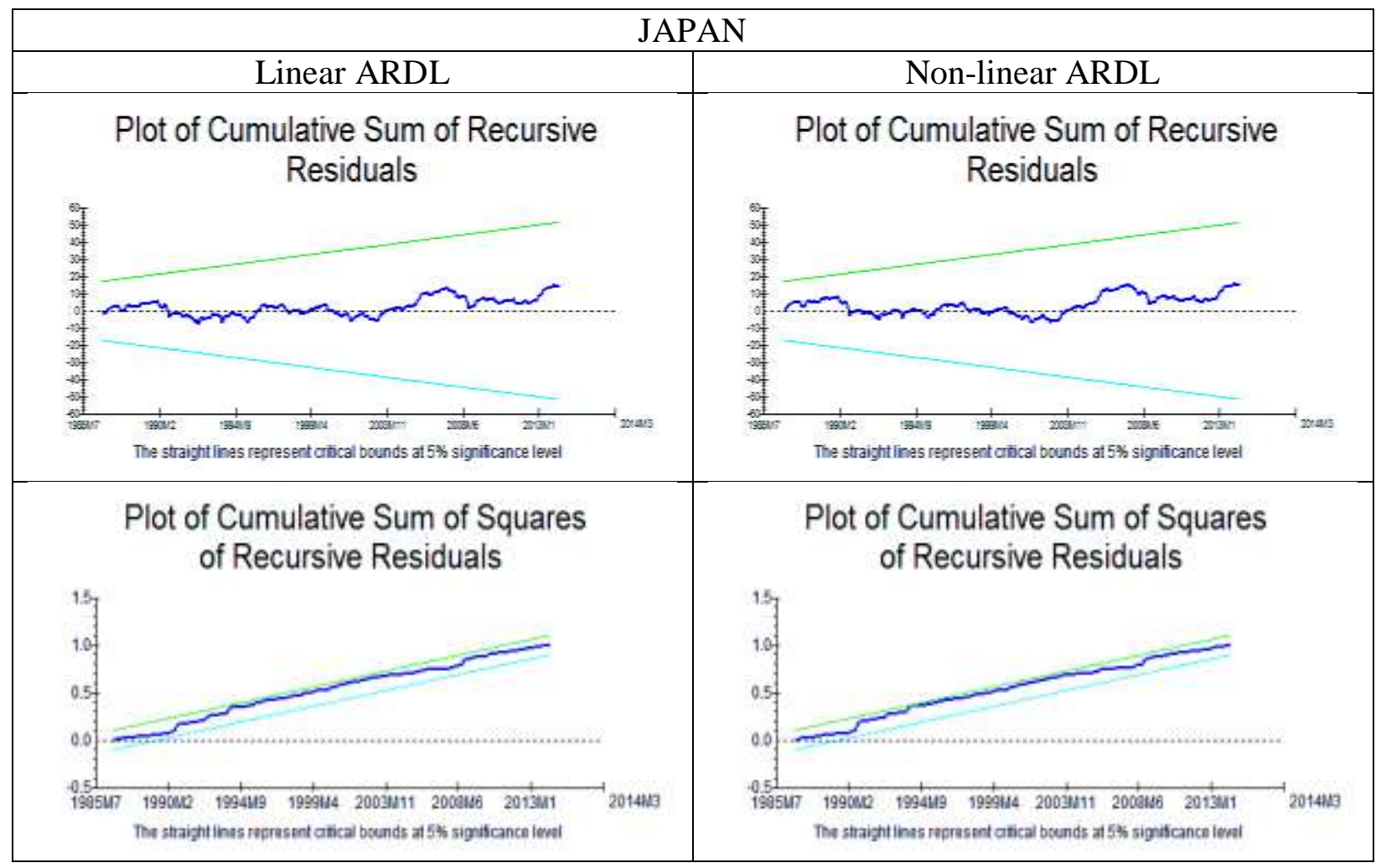

\begin{tabular}{|c|c|c|}
\hline \multicolumn{2}{|c|}{ LOREA } \\
\hline $\begin{array}{c}\text { Linear ARDL } \\
\text { Residuals }\end{array}$ \\
\hline \multicolumn{2}{|c|}{$\begin{array}{c}\text { Not of Cumulative Sum of Recursive } \\
\text { Plot of Cumulative Sum of Recursive } \\
\text { Residuals }\end{array}$} \\
\hline Plot of Cumulative Sum of Squares \\
of Recursive Residuals
\end{tabular}


Figure 1: CUSUSM and CUSUSM Square plots for the multivariate model (cont'd)

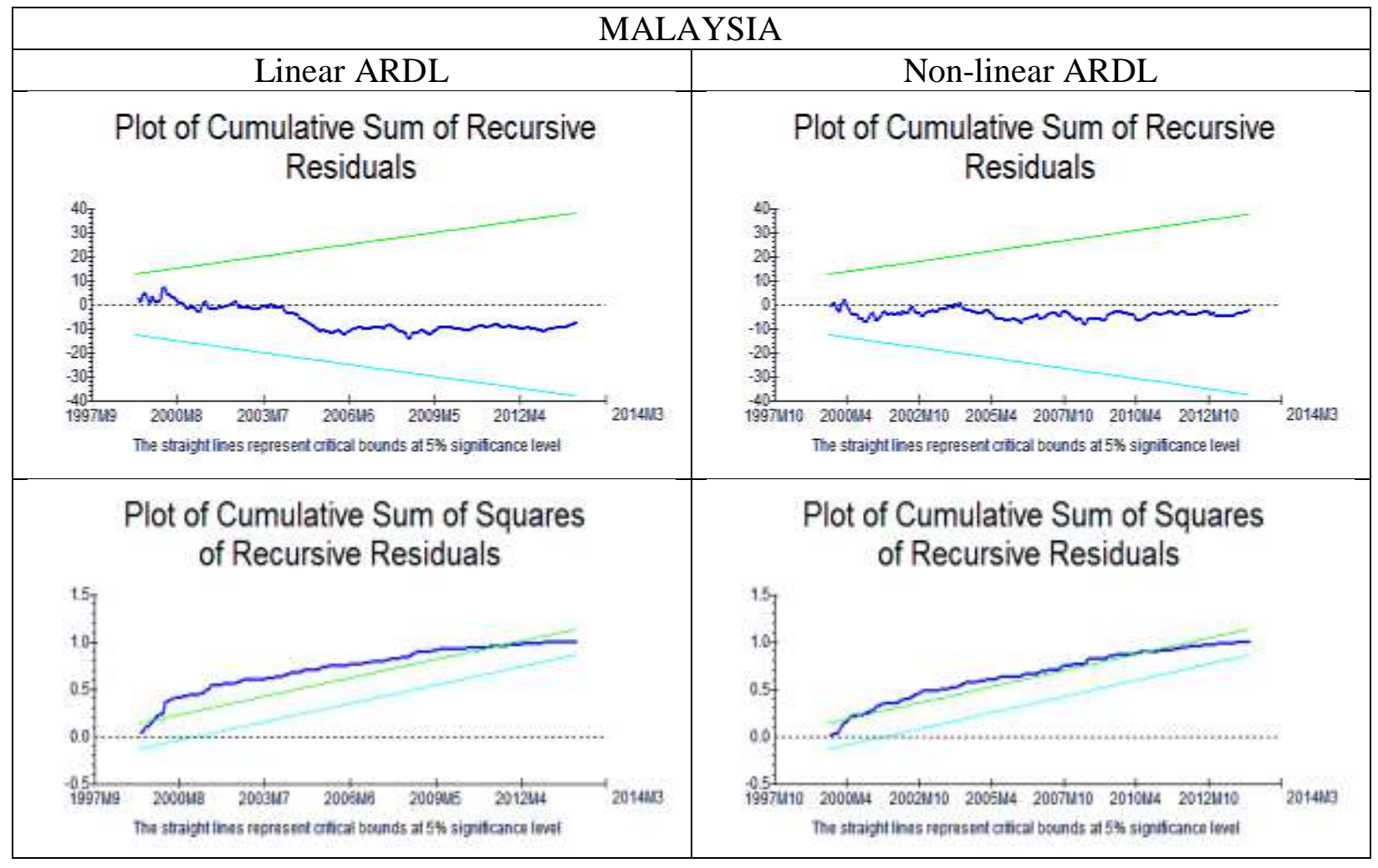

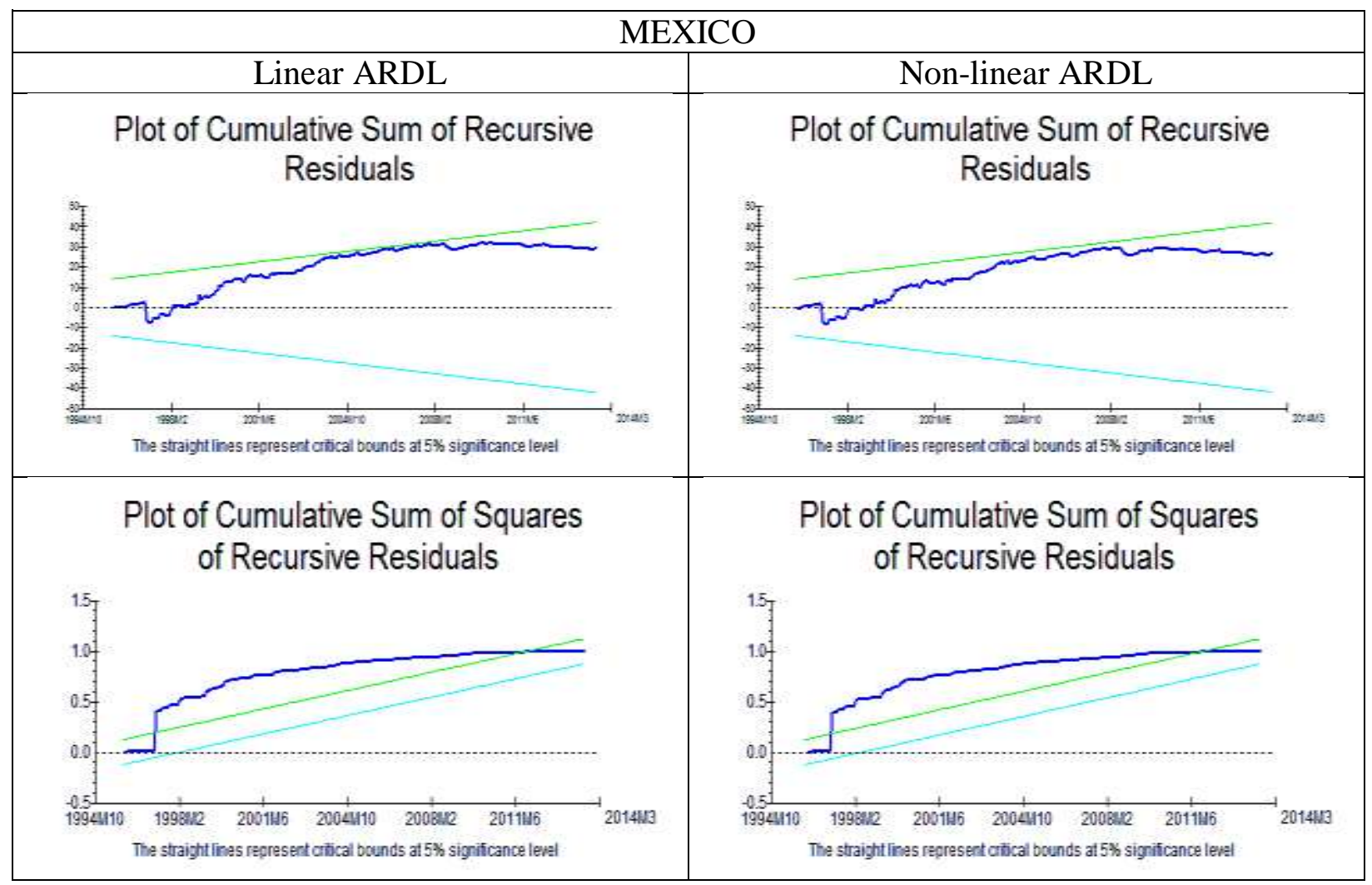


Figure 1: CUSUSM and CUSUSM Square plots for the multivariate model (cont'd)

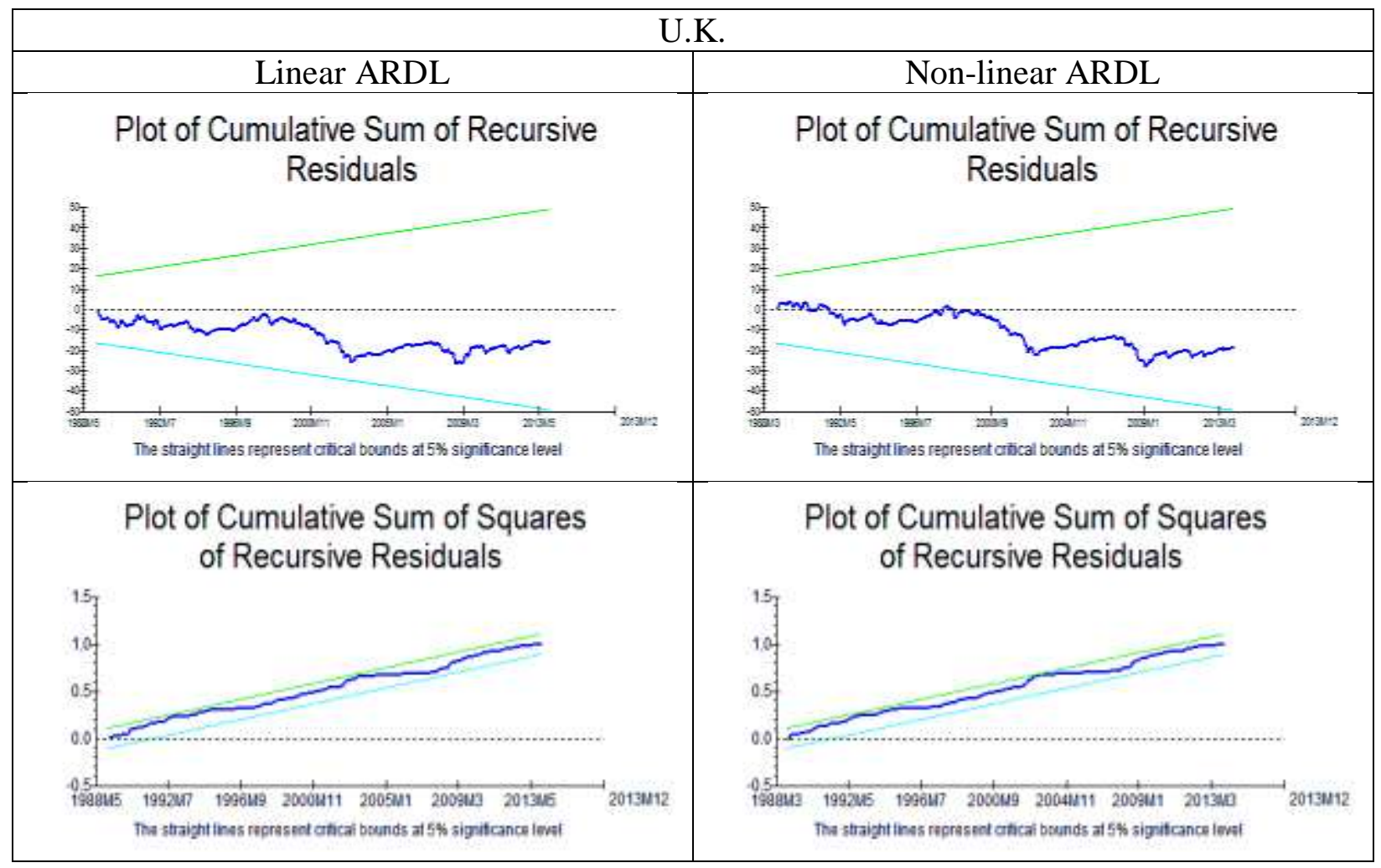

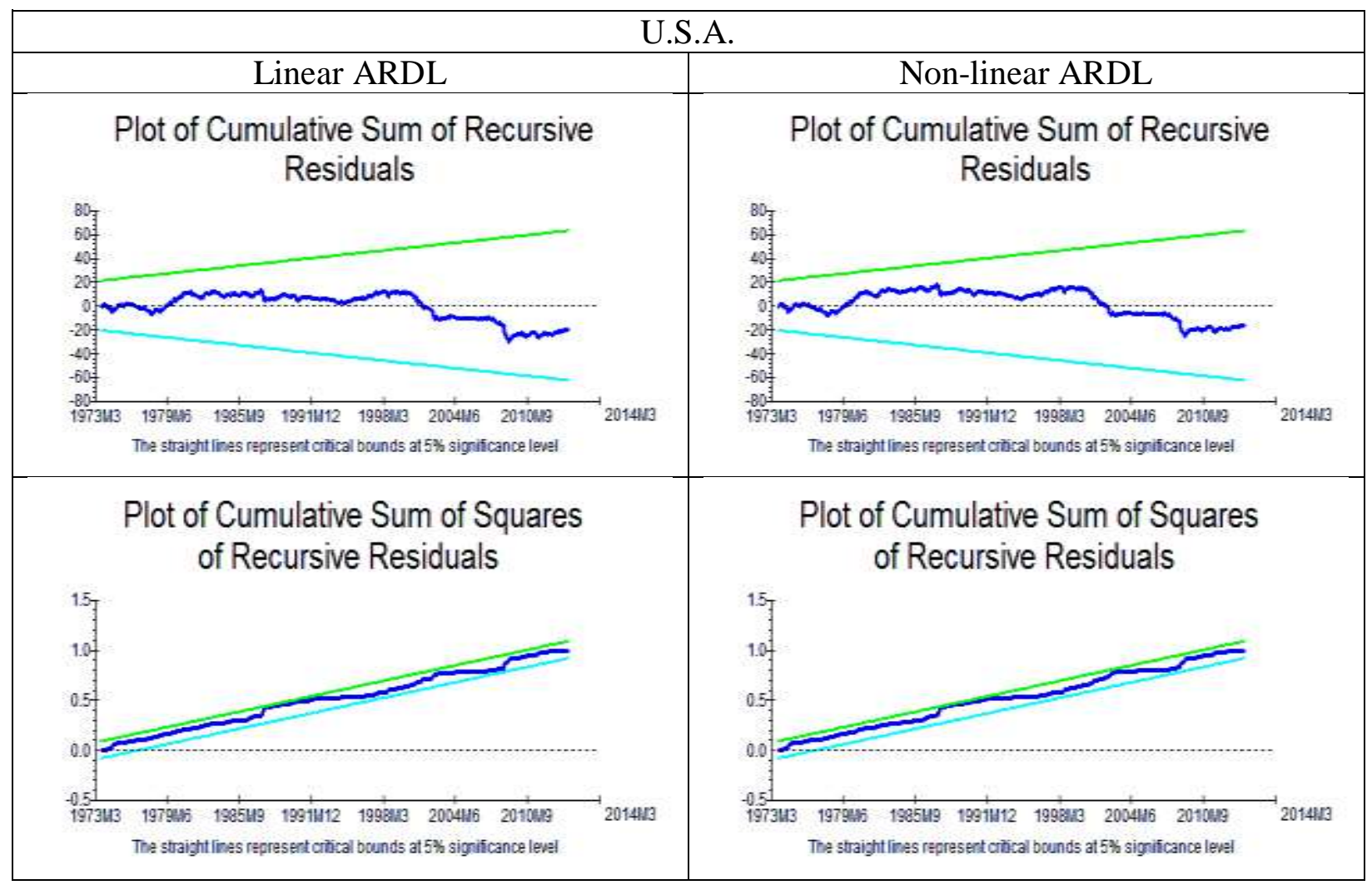


Figure 2: CUSUSM and CUSUSM Square plots for the sectoral analysis
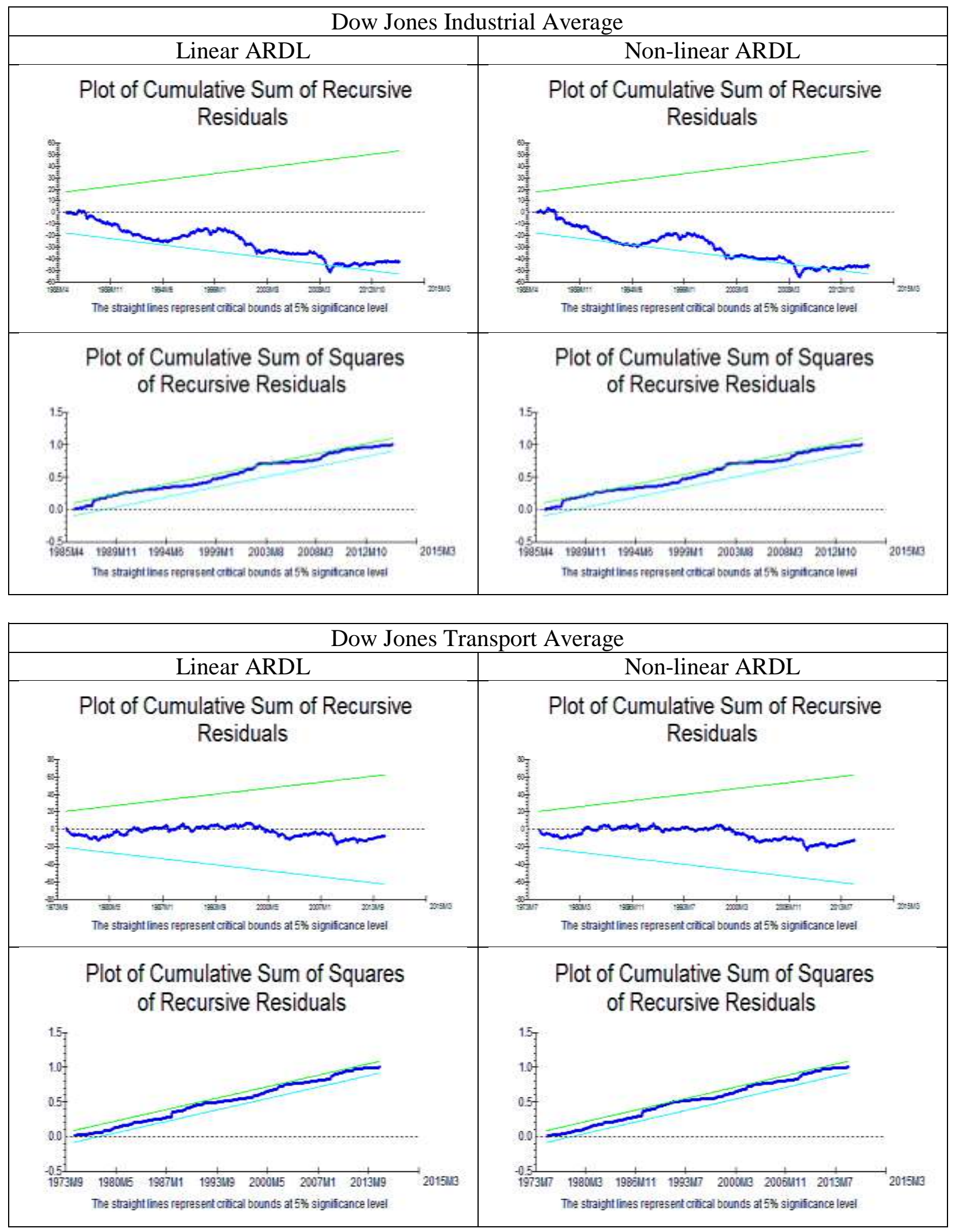
Figure 2: CUSUSM and CUSUSM Square plots for the sectoral analysis (cont'd)

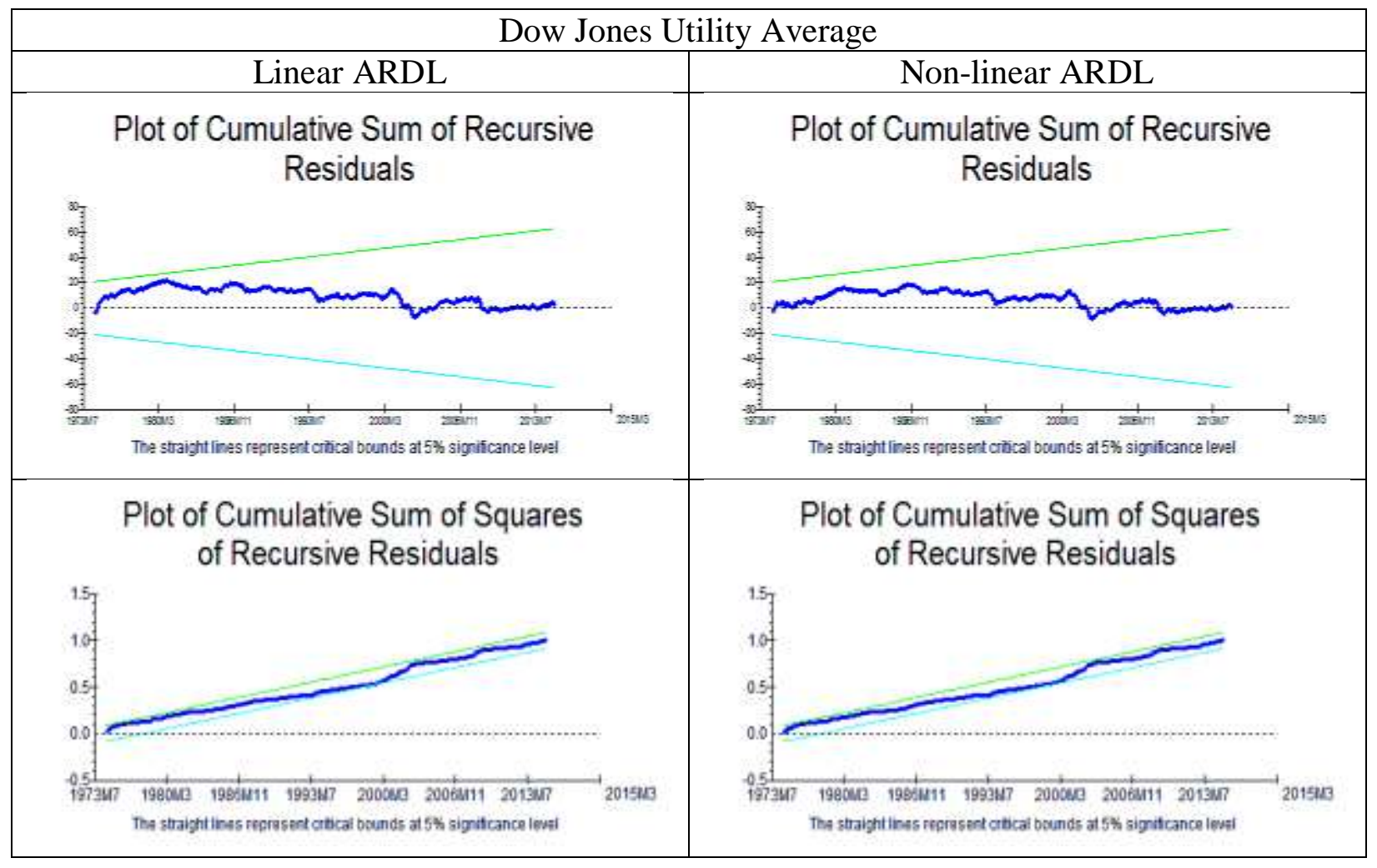

\begin{tabular}{|c|c|c|}
\hline \multicolumn{2}{|c|}{ Linear ARDL } & $\begin{array}{c}\text { NASDAQ Bank } \\
\text { Residuals }\end{array}$ \\
\hline $\begin{array}{c}\text { Plot of Cumulative Sum of Recursive } \\
\text { Plot of Cumulative Sum of Recursive } \\
\text { Residuals }\end{array}$ \\
\hline Plot of Cumulative Sum of Squares \\
of Recursive Residuals
\end{tabular}


Figure 2: CUSUSM and CUSUSM Square plots for the sectoral analysis (cont'd)

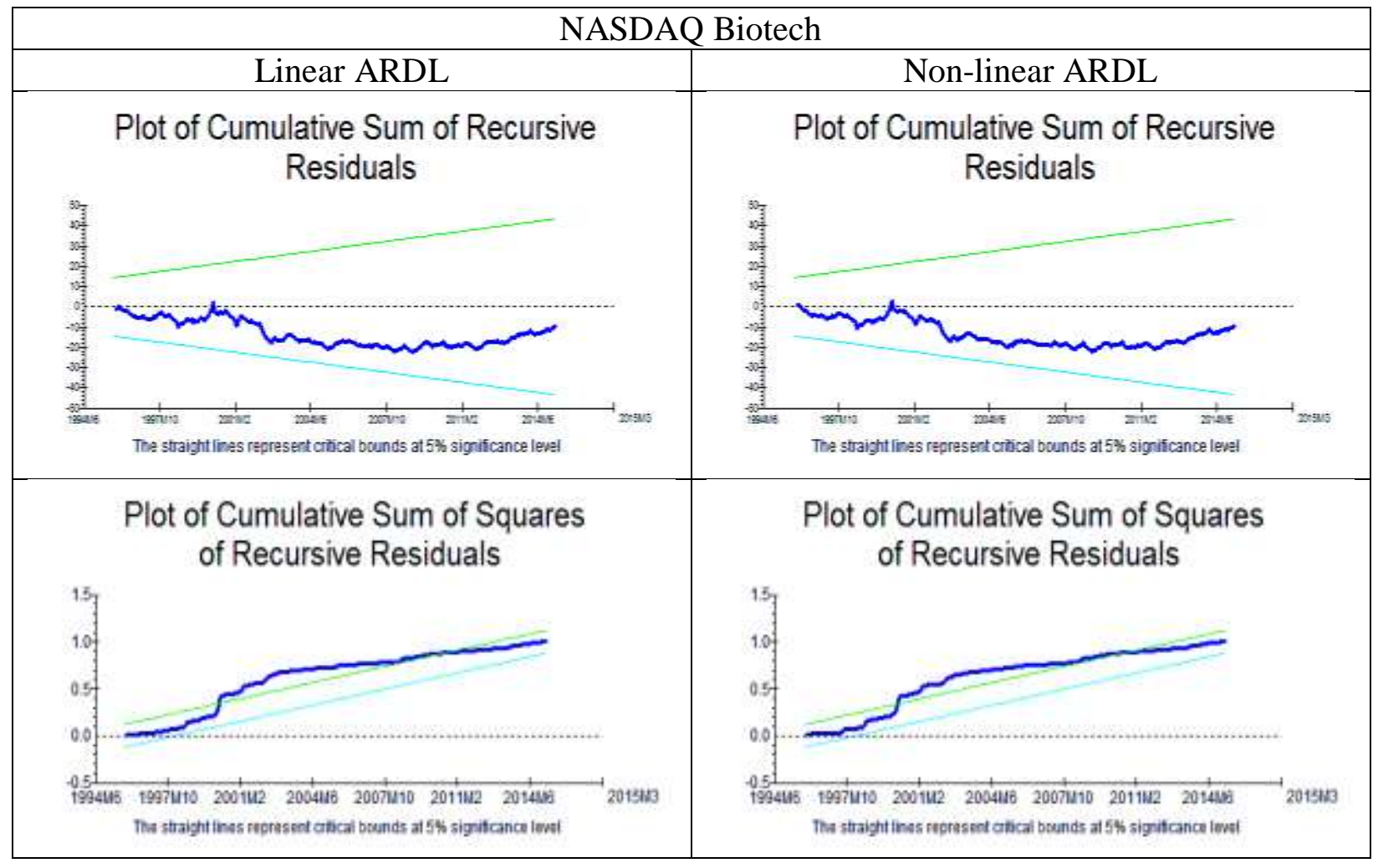

\begin{tabular}{|c|c|c|}
\hline \multicolumn{2}{|c|}{ NASDAQ Computer } & \begin{tabular}{c} 
Linear ARDL \\
Residuals \\
\hline
\end{tabular} $\begin{array}{c}\text { Plot of Cumulative Sum of Recursive } \\
\text { Residuals }\end{array}$ \\
\hline
\end{tabular}


Figure 2: CUSUSM and CUSUSM Square plots for the sectoral analysis (cont'd)

\begin{tabular}{|c|c|}
\hline \multicolumn{2}{|c|}{ NASDAQ Industrial } \\
\hline \multicolumn{2}{|c|}{$\begin{array}{c}\text { Linear ARDL } \\
\text { Residuals of Cumulative Sum of Recursive } \\
\text { Resive }\end{array}$} \\
\hline Plot of Cumulative Sum of Squares \\
of Recursive Residuals
\end{tabular}

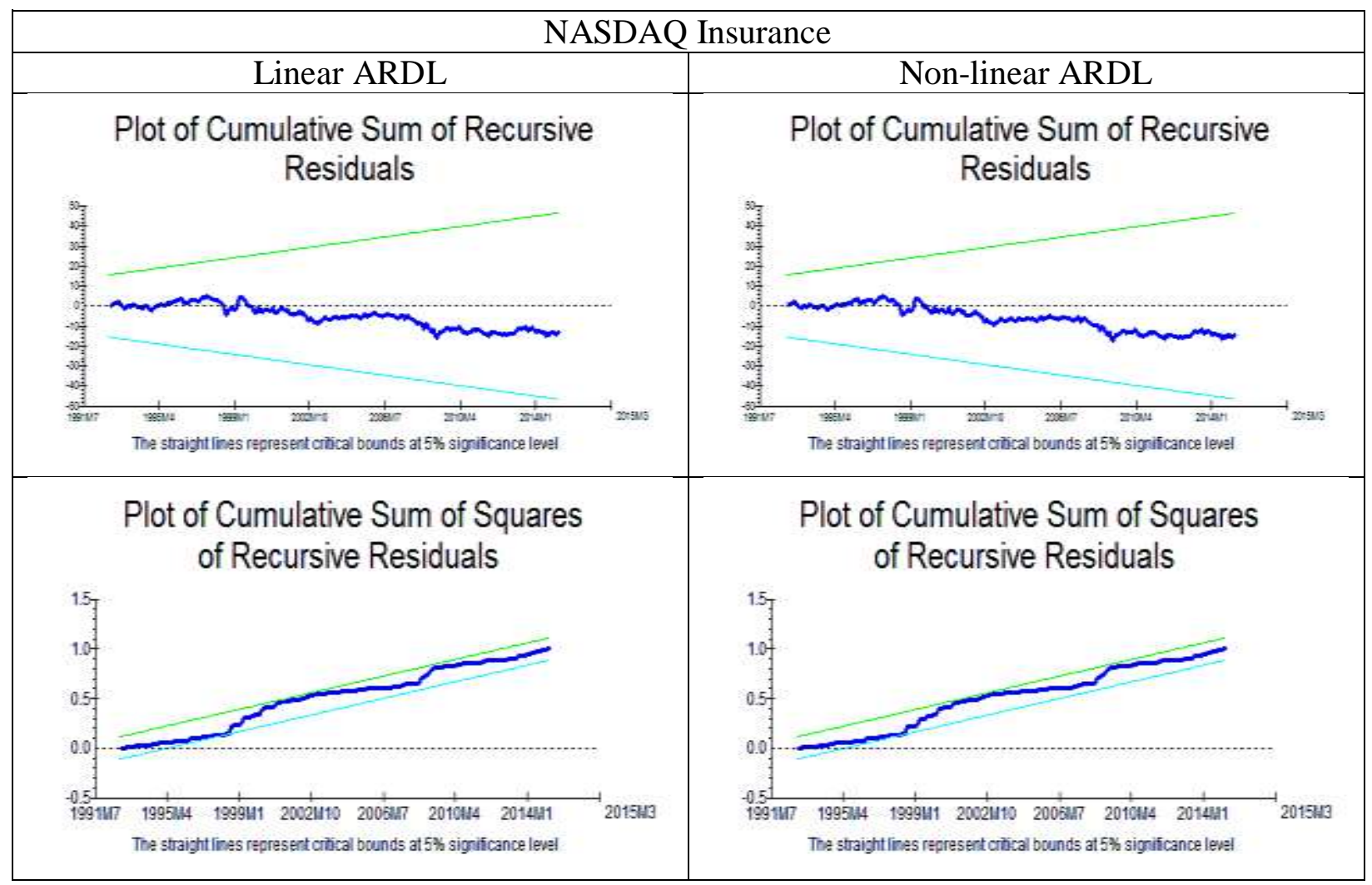


Figure 2: CUSUSM and CUSUSM Square plots for the sectoral analysis (cont'd)
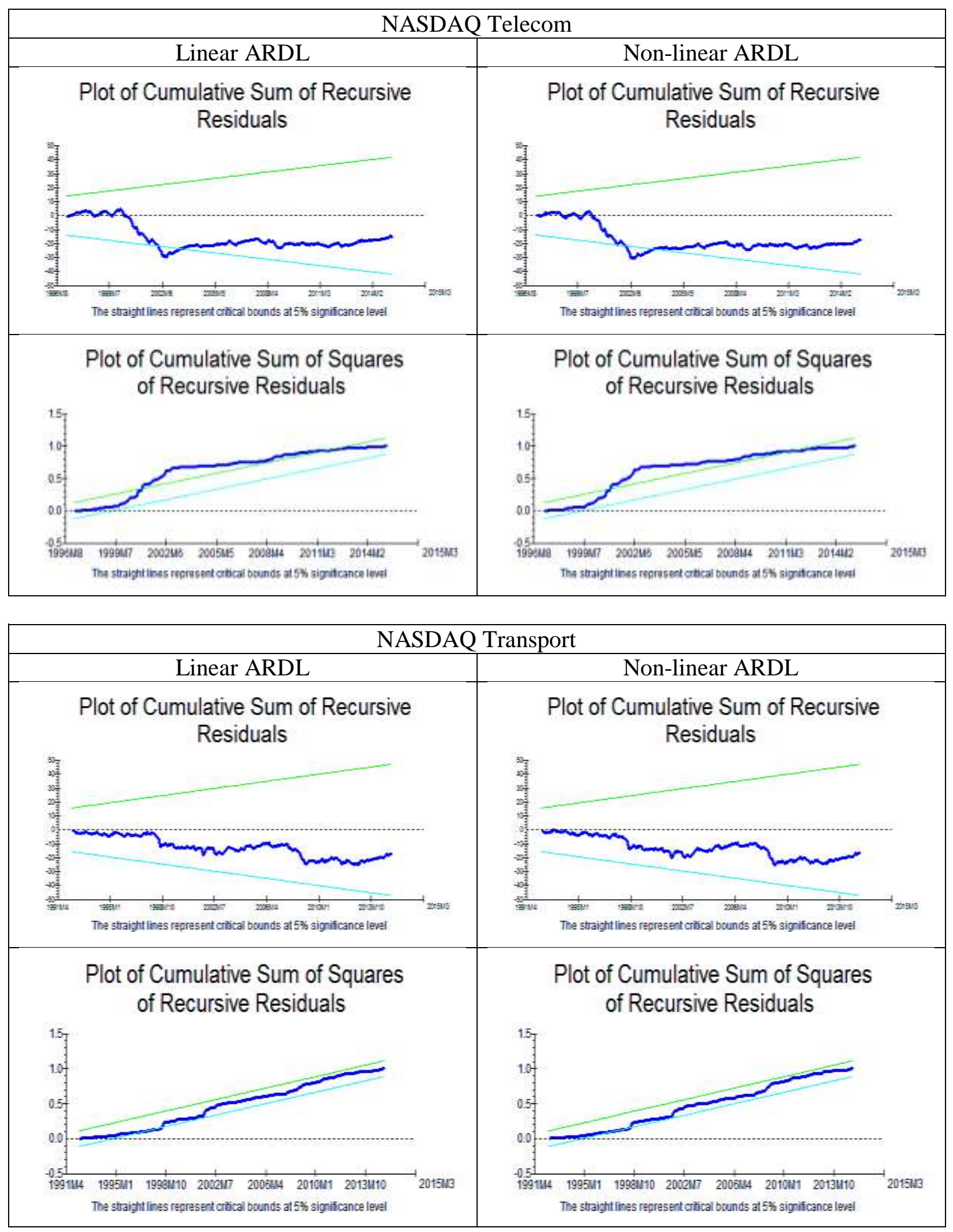
Figure 2: CUSUSM and CUSUSM Square plots for the sectoral analysis (cont'd)

\begin{tabular}{|c|c|c|}
\hline \multicolumn{2}{|c|}{ PHLX Semi-Conductor } \\
\hline $\begin{array}{c}\text { Linear ARDL } \\
\text { Residuals } \\
\text { Rot of Cumulative Sum of Recursive }\end{array}$ \\
$\begin{array}{c}\text { Plot of Cumulative Sum of Recursive } \\
\text { Residuals }\end{array}$ \\
\hline
\end{tabular}




\section{References}

Abidin, S. (2013). Cointegration between stock prices and exchange rates in Asia-Pacific countries. Investment Management \& Financial Innovations, 10(2), 142-146.

Aggarwal, R. (1981). Exchange rates and stock prices: A study of the U.S. capital markets under floating exchange rates. Akron Business and Economic Review, 12(3), 7-12.

Alagidede, P., Panagiotidis, T. \& Zhang, X. (2011). Causal relationship between stock prices and exchange rates. The Journal of International Trade \& Economic Development: An International and Comparative Review, 20(1), 67-86.

Akinlo, A. E. (2006). The stability of money demand in Nigeria: An autoregressive distributed lag approach. Journal of Policy Modeling, (28), 445-452.

Anari, A. \& Kolari, J. (2001). Stock prices and inflation. The Journal of Financial Research, 24 (4), 587-602.

Apergis, N. \& Miller S. (2006). Consumption asymmetry and the stock market: Empirical Evidence. Economics Letters, 93, 337-342.

Aslam, M.T. \& Ramzan, M. (2013). Impact of consumer price index, real effective exchange rate index, per capita income and discount rate on Pakistan's stock market index. International Journal of Research in Commerce, Economics and Management, 3(5), 10-14.

Bahmani-Oskooee, M. \& Ardalani, Z. (2006). Exchange rate sensitivity of U.S. trade flows: Evidence from industry data. Southern Economic Journal, 72, 542-559.

Bahmani-Oskooee, M. \& Bahmani, S. (2015). Nonlinear ARDL approach and the demand for money in Iran. Economics Bulletin, 35, 381-391.

Bahmani-Oskooee, M. \& Fariditavana, H. (2014). Do exchange rate changes have Symmetric Effect on the S-Curve?. Economics Bulletin, 34, 164-173.

Bahmani-Oskooee, M. \& Ghodsi, H. (2016). Do Changes in the Fundamentals have Symmetric or Asymmetric Effects on House Prices? Evidence from 52 States of the U.S. Applied Economics, 48, 2912-2936.

Bahmani-Oskooee, M. \& Sohrabian, A. (1992). Stock prices and the effective exchange rate of the dollar. Applied Economics, 24, 459-464.

Bahmani-Oskooee, M. \& Tanku, A. (2008). Black market exchange rate vs. official rate in testing the PPP: Which rate fosters the adjustment process. Economics Letters, 99, 40-43. 
Banerjee, A., Dolado, J.J. \& Mestre, R. (1998). Error-correction mechanism tests for cointegration in a single-equation framework. Journal of the Time Series Analysis, 19(3), 267-283.

Basher, S.A., Haug, A.A. \& Sadorsky, P. (2012). Oil prices, exchange rates and emerging stock markets. Energy Economics, 34(1), 227-240.

Boonyanam, N. (2014). Relationship of stock price and monetary variables of Asian small open emerging economy: Evidence from Thailand. International Journal of Financial Research, 5(1), 52-63.

Buberkoku, O. (2013). The relationship between stock prices and exchange rates: Evidence from developed and developing countries. ISE Review, 13(52), 1-16.

Brown, R.L., Durbin, J. \& Evans, J.M (1975). Techniques for testing the constancy of regression relationships over time. Journal of the Royal Statistical Society, Series B,37(2), 149 - 192.

Caporale, G. M., Hunter, J. \& Ali, F. M. (2014). On the linkages between stock prices and exchange rates: Evidence from the banking crisis of 2007-2010. International Review of Financial Analysis, 33, 87-103.

Chen, N.F., Roll, R \& Ross, S.A. (1986). Economic forces and the stock market. The Journal of Business, 59(3), 383-403.

Chortareas, G., Cipollini, A. \& Eissa, M.A. (2011). Exchange rates and stock prices in the MENA countries: What role for oil?. Review of Development Economics, 15(4), 758-774.

Delatte, A-L \& Villavicencio, A. L. (2012). Asymmetry exchange rate pass-through: Evidence from major countries. Journal of Macroeconomics, 34, 833-844.

Engle R. F, \& Granger C. W. J. (1987). Cointegration and error correction: Representation, estimation, and testing. Econometrica, 55(2), 251-276.

Eita, J.H. (2012). Modelling macroeconomic determinants of stock market prices: Evidence from Namibia. Journal of Applied Business Research, 871-884.

Fama, E. F. (1981). Stock returns, real activity, inflation and money. The American Economic Review, 71 (4), 545-565.

Granger, C.W.J., Huang, B.N. \& Yang, C.W. (2000). A bivariate causality between stock prices and exchange rates: Evidence from recent Asian flu. The Quarterly Review of Economics and Finance, 40(3), 337-354.

Groenewold, N. \& Paterson, J.E.H. (2013). Stock prices and exchange rates in Australia: Are commodity prices the missing link? Australian Economic Papers, 52(3-4) 150-170. 
Harjito, D.A. \& McGowan, Jr. C. B. (2011). Stock price and exchange rate causality: The case of four ASEAN countries. Southwestern Economic Review, 103-114.

Inegbedion, H.E. (2012). Macroeconomic determinants of stock price changes: Empirical evidence from Nigeria. Indian Journal of Finance, 6(2), 19-23.

Ismail, M.T. \& Isa, Z.B. (2009). Modeling the interactions of stock price and exchange rate in Malaysia. The Singapore Economic Review, 54(4), 605-619.

Johansen, S \& K. Juselius (1990). Maximum likelihood estimation and inference on cointegration: With application to the Demand for Money. Oxford Bulletin of Economics and Statistics, 52(2), 169-210.

Katechos,G. (2011). On the relationship between exchange rates and equity returns: A new approach. Journal of International Financial Markets, Institutions and Money, 21(4), 550-559.

Khan, F., Muneer, S. \& Anuar, M.A. (2013). Relationship between stock prices and economic variables: Sectoral analysis. Actual Problems of Economics, 143(5), 544-553.

Kollias, C., Mylonidis, N. \& Paleologou, S.M. (2012). The nexus between exchange rates and stock markets: Evidence from the euro-dollar rate and composite European stock indices using rolling analysis. Journal of Economics and Finance, 36, 136-147.

Kutty, G. (2010). The Relationship between exchange rates and stock prices: The case of Mexico. North American Journal of Finance and Banking Research, 4(4), 1-12.

Lean, H.H., Halim, M. \& Wong, W.K. (2005). Bivariate causality between exchange rates and stock prices on major Asian countries. Monash Economics Working Papers, Discussion Paper $10 / 05$.

Lean, H. H., Narayan, P. \& Smyth, R. (2011). Exchange rate and stock prices interaction in major Asian markets: Evidence for individual countries and panels allowing for structural breaks. The Singapore Economic Review, 56(2), 255-277.

Lee, C.H., Doong, S.C. \& Chou, P.I. (2011). Dynamic correlation between stock prices and exchange rates. Applied Financial Economics, 21(11), 789-800.

Lin, C.H. (2012). The co-movement between exchange rates and stock prices in the Asian emerging markets. International Review of Economics and Finance, 22(1), 161-172.

Liu, H.H. \& Tu, T.T. (2011). Mean-reverting and asymmetric volatility switching properties of stock price index, exchange rate and foreign capital in Taiwan. Asian Economic Journal, 25(4), 375-395. 
Moore, T. \& Wang, P. (2014). Dynamic linkage between real exchange rates and stock prices: Evidence from developed and emerging Asian markets. International Review of Economics and Finance, 29, 1-11.

Mukherjee, T. K. \& Naka, A. (1995). Dynamic relations between macroeconomic variables and the Japanese stock market: An application of a vector error correction model. The Journal of Financial Research, 18 (2), 223-237.

Nieh, C.C., Lee, C.F. (2001). Dynamic relationship between stock prices and exchange rates for G-7 countries. The Quarterly Review of Economics and Finance, 41(4), 477-490.

Obben, J., Pech, A. \& Shakur, S. (2006). Analysis of the relationship between the share market performance and exchange rates in New Zealand: A cointegrating VAR approach. New Zealand Economic Papers, 40(2), 147-180 .

Pan, M.S., Fok, R. C.W. \& Liu, Y. A. (2007). Dynamic linkages between exchange rates and stock prices: Evidence from East Asian markets. International Review of Economics \& Finance, 16(4), 503-520.

Parsva, P. \& Lean, H.H. (2011). The analysis of relationship between stock prices and exchange rates: Evidence from six Middle Eastern financial markets. International Research Journal of Finance and Economics, ISSN 1450-2887, (66), 157-171.

Pesaran, M. H., Y. Shin \& R. J. Smith (2001). Bounds testing approaches to the analysis of level relationships. Journal of Applied Econometrics, 16, 289-326.

Phylaktis, K. \& Ravazzolo, F. (2005). Stock prices and exchange rate dynamics. Journal of International Money and Finance, 24(7), 1031-1053.

Rahman, Md. L. \& Uddin, J. (2009). Dynamic relationship between stock prices and exchange rates: Evidence from three South Asian countries. International Business Research, 2(2), 167-174.

Richards, N.D., Simpson, J. \& Evans, J. (2009). The interaction between exchange rates and stock prices: An Australian context. International Journal of Economics and Finance, 1(1), 3-23.

Shin, Y., Yu, B. \& Greenwood-Nimmo, M. (2014). Modelling asymmetric cointegration and dynamic multipliers in a non-linear ARDL framework. Feestschrift in Honor of Peter Schmidt: econometric Methods and Applications, Springer Science \& Business Media, New York (NY), pp. 281-314.

Smyth, R. \& Nandha, M. (2003). Bivariate causality between exchange rates and stock prices in South Asia. Applied Economics Letters, 10(11), 699-704.

Soenen, L.A. \& Hennigar, E.S. (1988). An analysis of exchange rates and stock prices: the US experience between 1980 and 1986. Akron Business and Economic Review, 19 (4), 7-16. 
Tian, G.G. \& Ma, S. (2010). The relationship between stock returns and the foreign exchange rate: the ARDL approach. Journal of the Asia Pacific Economy, 15(4), 490-508.

Tsagkanos, A. \& Siriopoulos, C. (2013). A long-run relationship between stock price index and exchange rate: A structural nonparametric cointegrating regression approach. Journal of International Financial Markets, Institutions and Money, 25, 106-18.

Tsai, I.C. (2012). The relationship between stock price index and exchange rate in Asian markets: A quantile regression approach. Journal of International Financial Markets, Institutions and Money, 22(3), 609-621.

Tuncer, I. \& Turaboglu, T.T. (2014). Relationship between Stock Prices and Economic Activity in Turkish Economy. Actual Problems of Economics, Volume 152, Issue 2, pp. 111-121.

Unlu, U. (2013). Oil price, exchange rate and stock market in ASEAN-5 countries. The Empirical Economics Letter: A Monthly International Journal of Economics, 12(5), 551-557.

Verheyen, F. (2013). Interest rate pass-through in the EMU- new evidence using Nonlinear ARDL framework. Economics Bulletin, 33, 729-739.

Wickremasinghe, G.B. (2012). Stock prices and exchange rates in Sri Lanka: Some empirical evidence. Investment Management \& Financial Innovations, 9(4), 8-14.

Yang, Z., Tu, A.H. \& Zeng, Y. (2014). Dynamic linkages between Asian stock prices and exchange rates: New evidence from causality in quantiles. Applied Economics, 46(11), 1184-1201.

Yau, H.Y. \& Nieh, C.C. (2006). Interrelationships among stock prices of Taiwan and Japan and NTD/Yen exchange rate. Journal of Asian Economics, 17(3), 535-552.

Yau, H.Y. \& Nieh, C.C. (2009). Testing for cointegration with threshold effect between stock prices and exchange rates in Japan and Taiwan. Japan and the World Economy, 21(3), 292-300.

Zhao, H. (2010). Dynamic relationship between exchange rate and stock price: Evidence from China. Research in International Business and Finance, 24(2), 103-112. 


\section{Appendix A: Definition of the Variables}

- $\boldsymbol{S P}=$ Stock Price Index of the country.

- $\quad \boldsymbol{S P}^{\boldsymbol{i}}=$ Stock Price Index of sectors of U.S.

- $\boldsymbol{E} \boldsymbol{X}=$ Nominal Effective Exchange Rate of the country.

- $\quad \boldsymbol{P O S}=$ Appreciation of home currency.

- $\quad \boldsymbol{N E G}=$ Depreciation of home currency.

- IPI = Industrial Production Index of the country (measure of economic activity), base year $=2010$.

- $\quad \boldsymbol{C P I}=$ Consumer Price Index of the country, base year $=2010$.

- $\quad M 2=$ Nominal Money Supply of the country, in national currency. 


\section{Appendix B: Data Sources}

1. Stock Price Indices: Yahoo Finance

(http://finance.yahoo.com/stock-center/)

2. Nominal Effective Exchange Rates: Bank for International Settlements

(http://www.bis.org/statistics/eer/index.htm)

3. Industrial Production Index, Consumer Price Index, Money Supply: IFS, OECD, FRED.

- IFS - International Financial Statistics database of International Monetary Fund (IMF)

- OECD - Organization for Economic Co-operation and Development Statistics database

- $\quad$ FRED - Federal Reserve Economics Data, St. Louis Fed 
Appendix C.1: Data period for the Multivariate Model

\begin{tabular}{|c|c|c|}
\hline Serial No & Countries & Data Period \\
\hline 1 & Brazil & $1994 \mathrm{M} 8-2014 \mathrm{M} 3$ \\
\hline 2 & Canada & $1980 \mathrm{M} 1-2014 \mathrm{M} 3$ \\
\hline 3 & Chile & $2002 \mathrm{M} 5-2014 \mathrm{M} 3$ \\
\hline 4 & Indonesia & $1998 \mathrm{M} 1-2014 \mathrm{M} 3$ \\
\hline 5 & Japan & $1985 \mathrm{M} 1-2014 \mathrm{M} 3$ \\
\hline 6 & Korea & $1997 \mathrm{M} 9-2014 \mathrm{M} 3$ \\
\hline 7 & Malaysia & $1997 \mathrm{M} 4-2014 \mathrm{M} 3$ \\
\hline 8 & Mexico & $1994 \mathrm{M} 5-2014 \mathrm{M} 3$ \\
\hline 9 & U.K. & $1988 \mathrm{M} 1-2014 \mathrm{M} 3$ \\
\hline 10 & U.S.A. & $1971 \mathrm{M} 4-2014 \mathrm{M} 3$ \\
\hline
\end{tabular}




\section{Appendix C.2: Data period for the Bivariate Model}

\begin{tabular}{|c|c|c|c|}
\hline Serial No & Country & Data Period & Index Name \\
\hline 1 & Argentina & $1996 \mathrm{M} 12$ to $2014 \mathrm{M} 3$ & MERVAL BUENOS AIRES \\
\hline 2 & Australia & $1984 \mathrm{M} 10$ to $2014 \mathrm{M} 3$ & ALL ORDINARIES \\
\hline 3 & Austria & $1993 \mathrm{M} 4$ to $2014 \mathrm{M} 3$ & ATX \\
\hline 4 & Belgium & $1991 \mathrm{M} 6$ to $2014 \mathrm{M} 3$ & EURONEXT BEL-20 \\
\hline 5 & Brazil & $1994 \mathrm{M} 8$ to $2014 \mathrm{M} 3$ & IBOVESPA \\
\hline 6 & Canada & $1979 \mathrm{M} 8$ to $2014 \mathrm{M} 3$ & S\&P/TSX Compostite Index \\
\hline 7 & Chile & $2002 \mathrm{M} 5$ to $2014 \mathrm{M} 3$ & IPSA SANTIAGO DE CHILE \\
\hline 8 & China_Shanghai & $1995 \mathrm{M} 5$ to $2014 \mathrm{M} 3$ & SSE Composite Index \\
\hline 9 & France & $1990 \mathrm{M} 5$ to $2014 \mathrm{M} 3$ & CAC 40 \\
\hline 10 & Germany & 1991M1 to 2014M3 & DAX \\
\hline 11 & Greece & $1990 \mathrm{M} 6$ to $2014 \mathrm{M} 3$ & ATHEN INDEX COMPOS \\
\hline 12 & Hong Kong & 1987M6 to $2014 \mathrm{M} 3$ & HANG SENG INDEX \\
\hline 13 & India & $1997 \mathrm{M} 9$ to $2014 \mathrm{M} 3$ & S\&P BSE SENSEX \\
\hline 14 & Indonesia & $1997 \mathrm{M} 11$ to $2014 \mathrm{M} 3$ & JKSE \\
\hline 15 & Japan & $1984 \mathrm{M} 3$ to $2014 \mathrm{M} 3$ & Nikkei 225 \\
\hline 16 & Korea & 1997M9 to 2014M3 & KOSPI Composite Index \\
\hline 17 & Malaysia & $1997 \mathrm{M} 4$ to $2014 \mathrm{M} 3$ & FTSE Bursa Malaysia KLCI \\
\hline 18 & Mexico & $1994 \mathrm{M} 5$ to $2014 \mathrm{M} 3$ & IPC \\
\hline 19 & Netherlands & $1992 \mathrm{M} 12$ to $2014 \mathrm{M} 3$ & AEX \\
\hline 20 & New Zealand & $2003 \mathrm{M} 3$ to $2014 \mathrm{M} 3$ & NZX 50 INDEX GROSS \\
\hline 21 & Singapore & $1988 \mathrm{M} 2$ to $2014 \mathrm{M} 3$ & STI Index \\
\hline 22 & Switzerland & $1991 \mathrm{M} 1$ to $2014 \mathrm{M} 3$ & SMI \\
\hline 23 & UK & $1984 \mathrm{M} 5$ to $2014 \mathrm{M} 3$ & FTSE 100 \\
\hline 24 & USA & $1971 \mathrm{M} 4$ to $2014 \mathrm{M} 3$ & S\&P 500 \\
\hline
\end{tabular}




\section{Appendix C.3: Data period for the Sectoral Analysis for the U.S.}

\begin{tabular}{|c|c|c|c|}
\hline & Indices & Description & Data Period \\
\hline 1 & $\begin{array}{l}\text { Dow Jones Industrial } \\
\text { Average }\end{array}$ & $\begin{array}{l}\text { Comprises of } 30 \text { large publicly owned } \\
\text { companies based in the U.S. }\end{array}$ & 1985: M1 - 2015:M5 \\
\hline 2 & $\begin{array}{c}\text { Dow Jones } \\
\text { Transportation Average }\end{array}$ & $\begin{array}{l}\text { An average of the stock prices of twenty } \\
\text { transportation corporations. }\end{array}$ & 1973: M1 - 2015:M5 \\
\hline 3 & $\begin{array}{l}\text { Dow Jones } \\
\text { Utility Average }\end{array}$ & $\begin{array}{l}\text { Tracks the performance of } 15 \text { prominent } \\
\text { utility companies. }\end{array}$ & 1973: M1 - 215:M5 \\
\hline 4 & NASDAQ Bank & $\begin{array}{l}\text { Includes banks providing financial } \\
\text { services such as retail banking, loans and } \\
\text { money transmissions. }\end{array}$ & 1990: M10 - 2015:M5 \\
\hline 5 & $\begin{array}{c}\text { NASDAQ } \\
\text { Biotechnology }\end{array}$ & $\begin{array}{l}\text { Includes biotechnology and } \\
\text { pharmaceutical equities. }\end{array}$ & 1993: M10 - 2015:M5 \\
\hline 6 & NASDAQ Computer & $\begin{array}{l}\text { Includes companies involved in various } \\
\text { phases of the computer industry }\end{array}$ & 1995: M7 - 2015:M5 \\
\hline 7 & NASDAQ Industrial & Includes around 950 companies & 1990: M10 - 2015:M5 \\
\hline 8 & NASDAQ Insurance & Includes around 46 insurance companies & 1990: M10 - 2015:M5 \\
\hline 9 & $\begin{array}{c}\text { NASDAQ } \\
\text { Telecommunications }\end{array}$ & Includes around 118 telecom companies & 1996: M5 - 2015:M5 \\
\hline 10 & $\begin{array}{c}\text { NASDAQ } \\
\text { Transportation }\end{array}$ & $\begin{array}{l}\text { Tracks performance of around } 50 \\
\text { transportation companies }\end{array}$ & 1990: M10 - 2015:M5 \\
\hline 11 & PHLX Semiconductors & $\begin{array}{l}\text { Tracks } 30 \text { companies which are mainly } \\
\text { involved in manufacture and sale of } \\
\text { semiconductors }\end{array}$ & 1994: M5 - 2015:M5 \\
\hline
\end{tabular}




\section{Appendix D: ARDL Model Equations}

Derivation of the equations (Pesaran et al. (2001)):

- $\ln \mathrm{SP}_{\mathrm{t}}=\mathrm{c}_{1}+\mathrm{c}_{2} \ln \mathrm{EX}_{\mathrm{t}}+\mathrm{c}_{3} \ln \mathrm{IPI}_{\mathrm{t}}+\mathrm{c}_{4} \ln \mathrm{CPI}_{\mathrm{t}}+\mathrm{c}_{5} \ln \mathrm{M} 2_{\mathrm{t}}+\varepsilon_{\mathrm{t}}$

- $\Delta \ln \mathrm{SP}_{\mathrm{t}}=\alpha_{0}+\sum_{\mathrm{k}=1}^{\mathrm{n} 1} \alpha_{1, \mathrm{k}} \Delta \ln \mathrm{SP}_{\mathrm{t}-\mathrm{k}}+\sum_{\mathrm{k}=0}^{\mathrm{n} 2} \alpha_{2, \mathrm{k}} \Delta \ln \mathrm{EX}_{\mathrm{t}-\mathrm{k}}+\sum_{\mathrm{k}=0}^{\mathrm{n} 3} \alpha_{3, \mathrm{k}} \Delta \ln \operatorname{IPI}_{\mathrm{t}-\mathrm{k}}+$

$$
\sum_{\mathrm{k}=0}^{\mathrm{n} 4} \alpha_{4, \mathrm{k}} \Delta \ln \mathrm{CPI}_{\mathrm{t}-\mathrm{k}}+\sum_{\mathrm{k}=0}^{\mathrm{n} 5} \alpha_{5, \mathrm{k}} \Delta \ln \mathrm{M} 2_{\mathrm{t}-\mathrm{k}}+\lambda \varepsilon_{\mathrm{t}-1}+\mathrm{U}_{\mathrm{t}}
$$

- $\Delta \ln \mathrm{SP}_{\mathrm{t}}=\alpha_{0}+\sum_{\mathrm{k}=1}^{\mathrm{n} 1} \alpha_{1, \mathrm{k}} \Delta \ln \mathrm{SP}_{\mathrm{t}-\mathrm{k}}+\sum_{\mathrm{k}=0}^{\mathrm{n} 2} \alpha_{2, \mathrm{k}} \Delta \ln \mathrm{EX}_{\mathrm{t}-\mathrm{k}}+\sum_{\mathrm{k}=0}^{\mathrm{n} 3} \alpha_{3, \mathrm{k}} \Delta \ln \mathrm{IPI}_{\mathrm{t}-\mathrm{k}}+$ $\sum_{\mathrm{k}=0}^{\mathrm{n} 4} \alpha_{4, \mathrm{k}} \Delta \ln \mathrm{CPI}_{\mathrm{t}-\mathrm{k}}+\sum_{\mathrm{k}=0}^{\mathrm{n} 5} \alpha_{5, \mathrm{k}} \Delta \ln \mathrm{M} 2_{\mathrm{t}-\mathrm{k}}+\beta_{1} \ln \mathrm{SP}_{\mathrm{t}-1}+\beta_{2} \ln \mathrm{EX}_{\mathrm{t}-1}+$

$\beta_{3} \ln \mathrm{IPI}_{\mathrm{t}-1}+\beta_{4} \ln _{\mathrm{CPI}} \mathrm{t}_{\mathrm{t}-1}+\beta_{5} \ln \mathrm{M} 2_{\mathrm{t}-1}+\mathrm{U}_{\mathrm{t}}$

LR effects are inferred by estimates of $\beta_{2}-\beta_{5}$ normalized on estimate of $\beta_{1}$. So the linear lagged combination is set to zero:

- $\widehat{\beta_{1}} \ln \mathrm{SP}_{\mathrm{t}-1}+\widehat{\beta_{2}} \ln \mathrm{EX}_{\mathrm{t}-1}+\widehat{\beta_{3}} \ln \mathrm{IPI}_{\mathrm{t}-1}+\widehat{\beta_{4}} \ln \mathrm{CPI}_{\mathrm{t}-1}+\widehat{\beta_{5}} \ln \mathrm{M} 2_{\mathrm{t}-1}=0$

- $\quad \ln \mathrm{SP}_{\mathrm{t}-1}=-\frac{\widehat{\beta}_{2}}{\widehat{\hat{\beta}}_{1}} \ln \mathrm{EX}_{\mathrm{t}-1}-\frac{\widehat{\beta}_{3}}{\widehat{\beta}_{1}} \ln \mathrm{IPI}_{\mathrm{t}-1}-\frac{\widehat{\beta}_{4}}{\widehat{\beta}_{1}} \ln \mathrm{CPI} \mathrm{t}_{\mathrm{t}-1}-\frac{\widehat{\beta}_{5}}{\widehat{\beta}_{1}} \ln \mathrm{M} 2_{\mathrm{t}-1}$

- $E C_{\mathrm{t}-1}=\ln \mathrm{SP}_{\mathrm{t}-1}+\frac{\widehat{\beta}_{2}}{\widehat{\beta}_{1}} \ln \mathrm{EX}_{\mathrm{t}-1}+\frac{\widehat{\beta}_{3}}{\widehat{\hat{\beta}}_{1}} \ln \mathrm{IPI}_{\mathrm{t}-1}+\frac{\widehat{\beta}_{4}}{\widehat{\hat{\beta}}_{1}} \ln \mathrm{CPI} \mathrm{t}_{\mathrm{t}-1}+\frac{\widehat{\beta}_{5}}{\widehat{\beta}_{1}} \ln \mathrm{M} 2_{\mathrm{t}-1}$

Replace lagged level variables in (3) by $E C_{\mathrm{t}-1}$ :

- $\Delta \ln \mathrm{SP}_{\mathrm{t}}=\alpha_{0}+\sum_{\mathrm{k}=1}^{\mathrm{n} 1} \alpha_{1, \mathrm{k}} \Delta \ln \mathrm{SP}_{\mathrm{t}-\mathrm{k}}+\sum_{\mathrm{k}=0}^{\mathrm{n} 2} \alpha_{2, \mathrm{k}} \Delta \ln \mathrm{EX}_{\mathrm{t}-\mathrm{k}}+\sum_{\mathrm{k}=0}^{\mathrm{n} 3} \alpha_{3, \mathrm{k}} \Delta \ln \mathrm{IPI}_{\mathrm{t}-\mathrm{k}}+$

$$
\sum_{\mathrm{k}=0}^{\mathrm{n} 4} \alpha_{4, \mathrm{k}} \Delta \ln \mathrm{CPI}_{\mathrm{t}-\mathrm{k}}+\sum_{\mathrm{k}=0}^{\mathrm{n} 5} \alpha_{5, \mathrm{k}} \Delta \ln \mathrm{M} 2_{\mathrm{t}-\mathrm{k}}+\gamma E C_{t-1}+U_{t}
$$




\section{Appendix E: Critical Values}

Critical Values for F test- from Pesaran et al. (2001): Table CI (iii), Case III, pp. 300

\begin{tabular}{|c|c|c|}
\hline \multicolumn{3}{|c|}{ For FOUR Exogenous Variables } \\
\hline Significance Level & Lower Bound Critical Value & Upper Bound Critical Value \\
\hline $1 \%$ & 3.74 & 5.06 \\
\hline $2.5 \%$ & 3.25 & 4.49 \\
\hline $5 \%$ & 2.86 & 4.01 \\
\hline $10 \%$ & 2.45 & 3.52 \\
\hline
\end{tabular}




\section{Appendix F: Natural Log of LEX, POS, NEG, LIPI, LCPI, LM2 and LSP Graphs}

\section{Brazil}

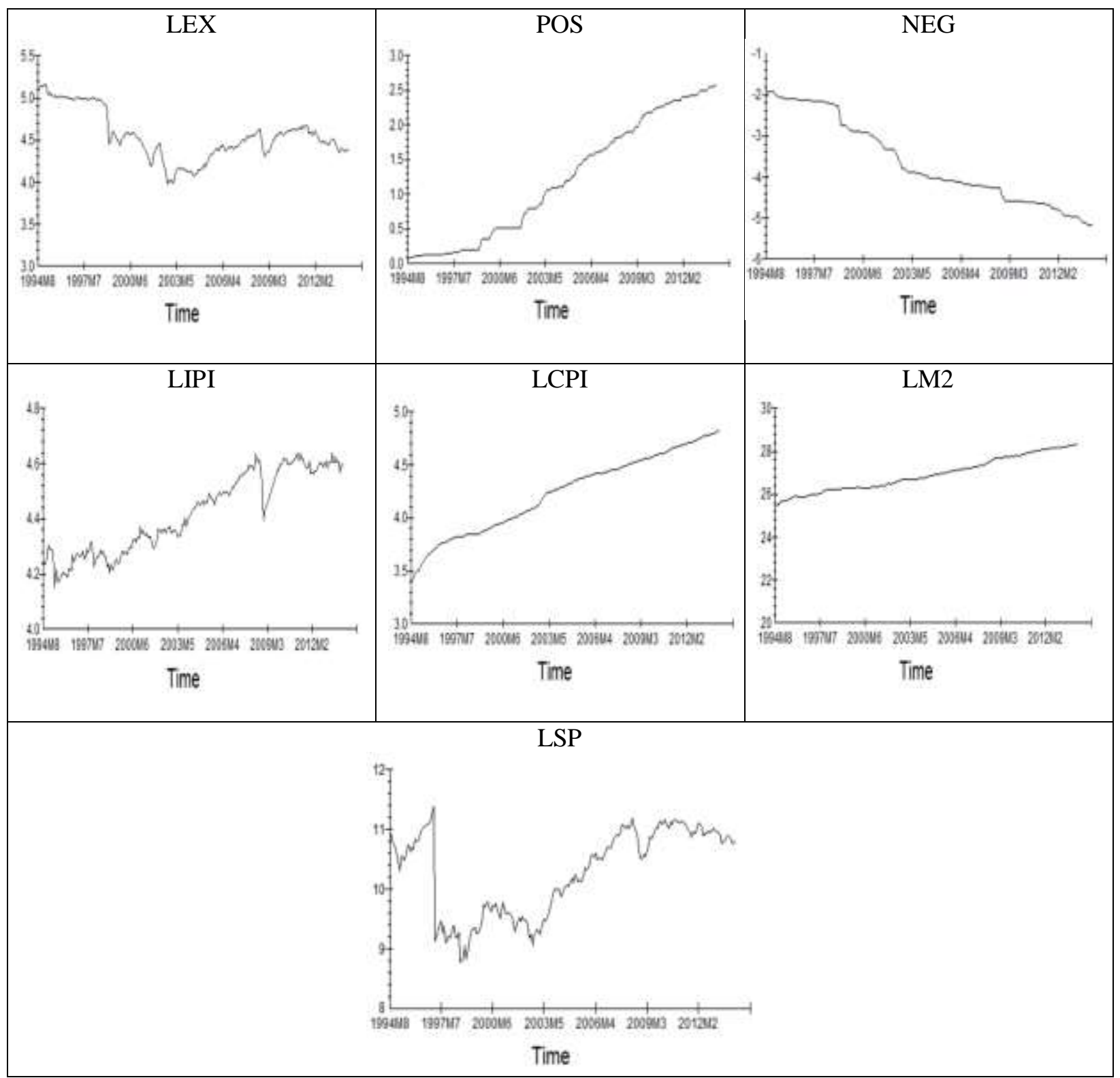

Note:

- LEX: Log (Nominal Effective Exchange Rate)

- POS: Appreciation of home currency

- NEG: Depreciation of home currency

- LIPI: Log (Industrial Production Index)

- LCPI: Log (Consumer Price Index)

- LM2: Log (Nominal Money Supply)

- LSP: Log (Stock Price Index) 


\section{Canada}

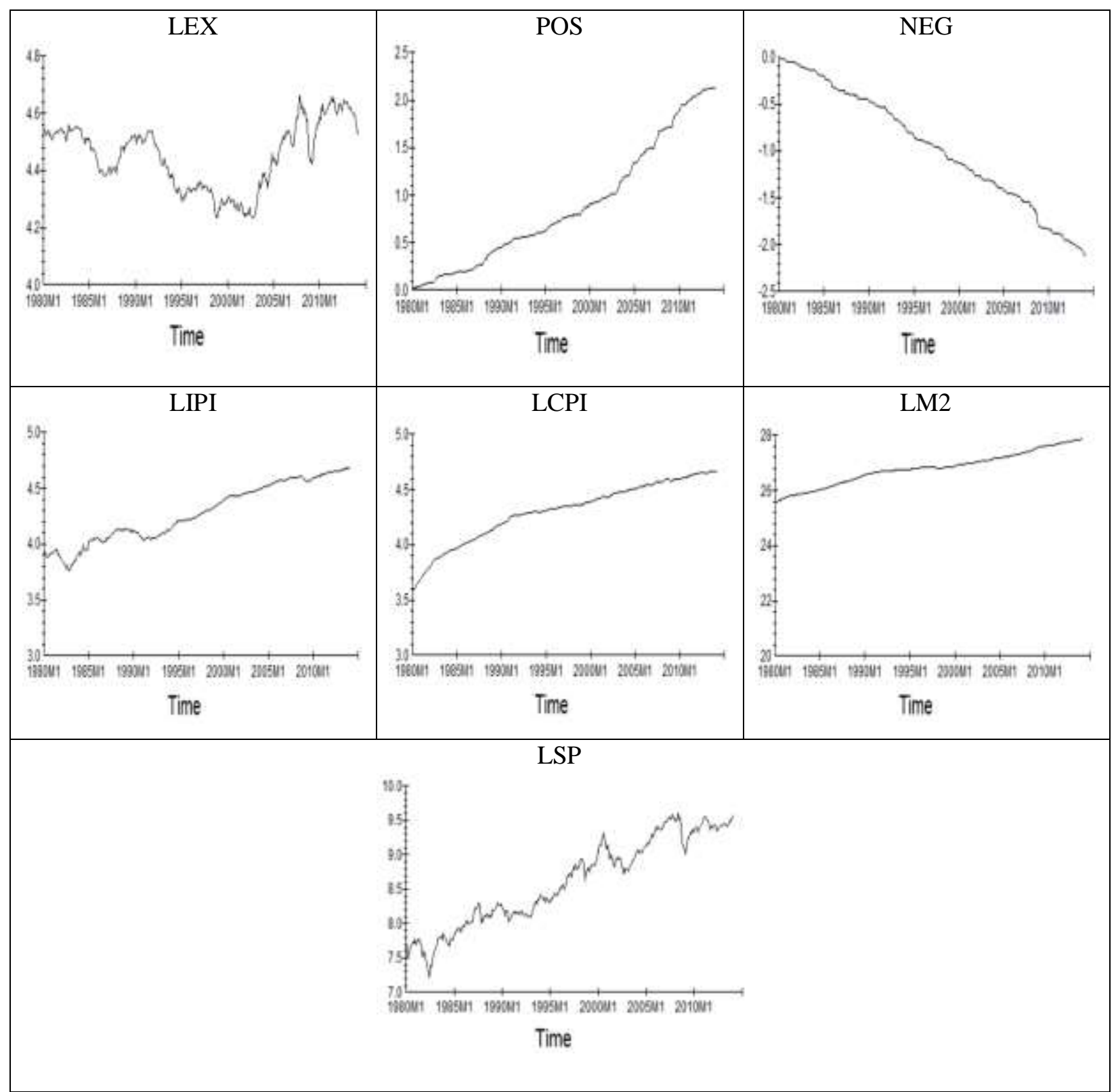

Note:

- LEX: Log (Nominal Effective Exchange Rate)

- POS: Appreciation of home currency

- NEG: Depreciation of home currency

- LIPI: Log (Industrial Production Index)

- LCPI: Log (Consumer Price Index)

- LM2: Log (Nominal Money Supply)

- LSP: Log (Stock Price Index) 


\section{Chile}

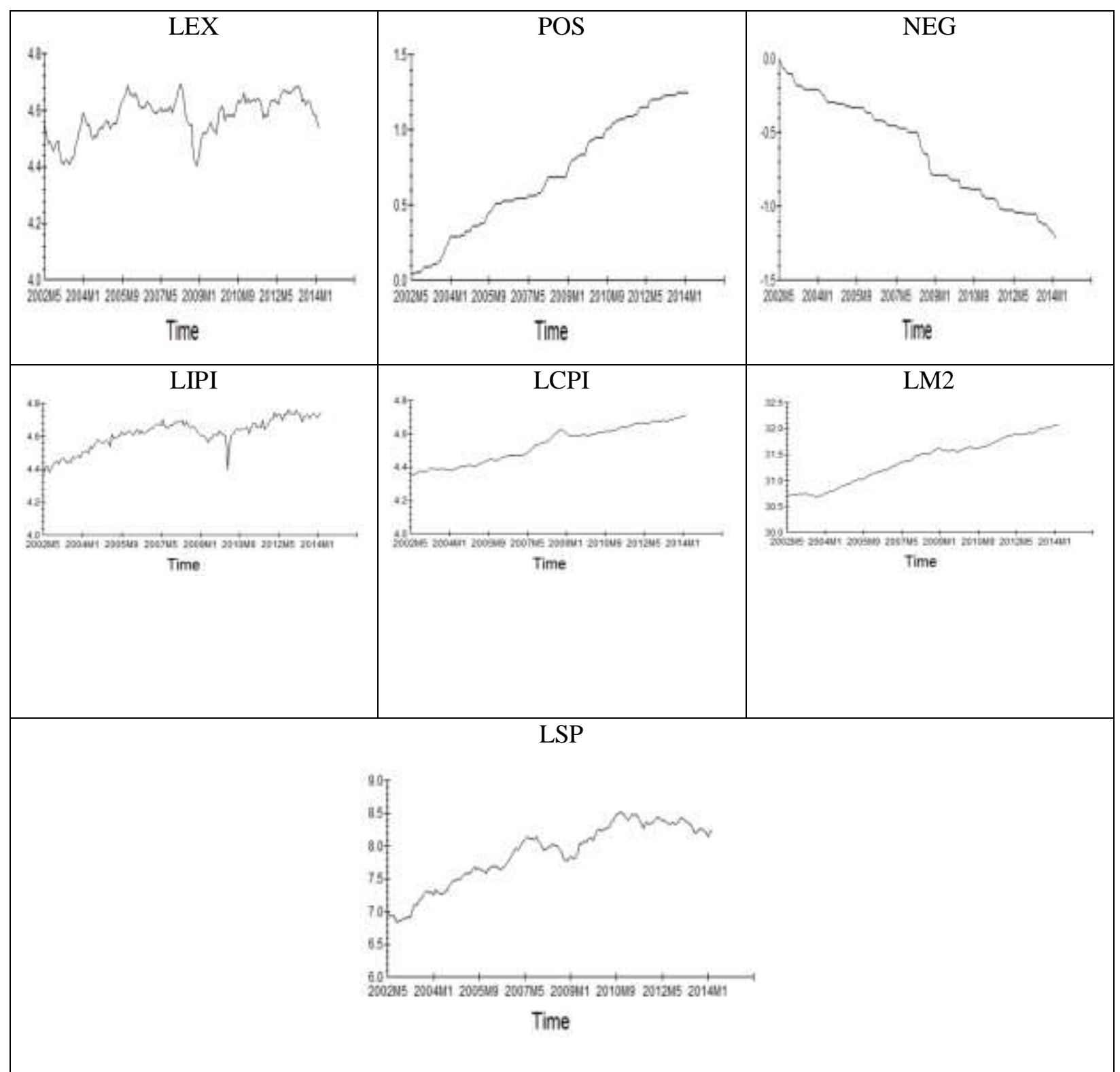

Note:

- LEX: Log (Nominal Effective Exchange Rate)

- POS: Appreciation of home currency

- NEG: Depreciation of home currency

- LIPI: Log (Industrial Production Index)

- LCPI: Log (Consumer Price Index)

- LM2: Log (Nominal Money Supply)

- LSP: Log (Stock Price Index) 


\section{Indonesia}

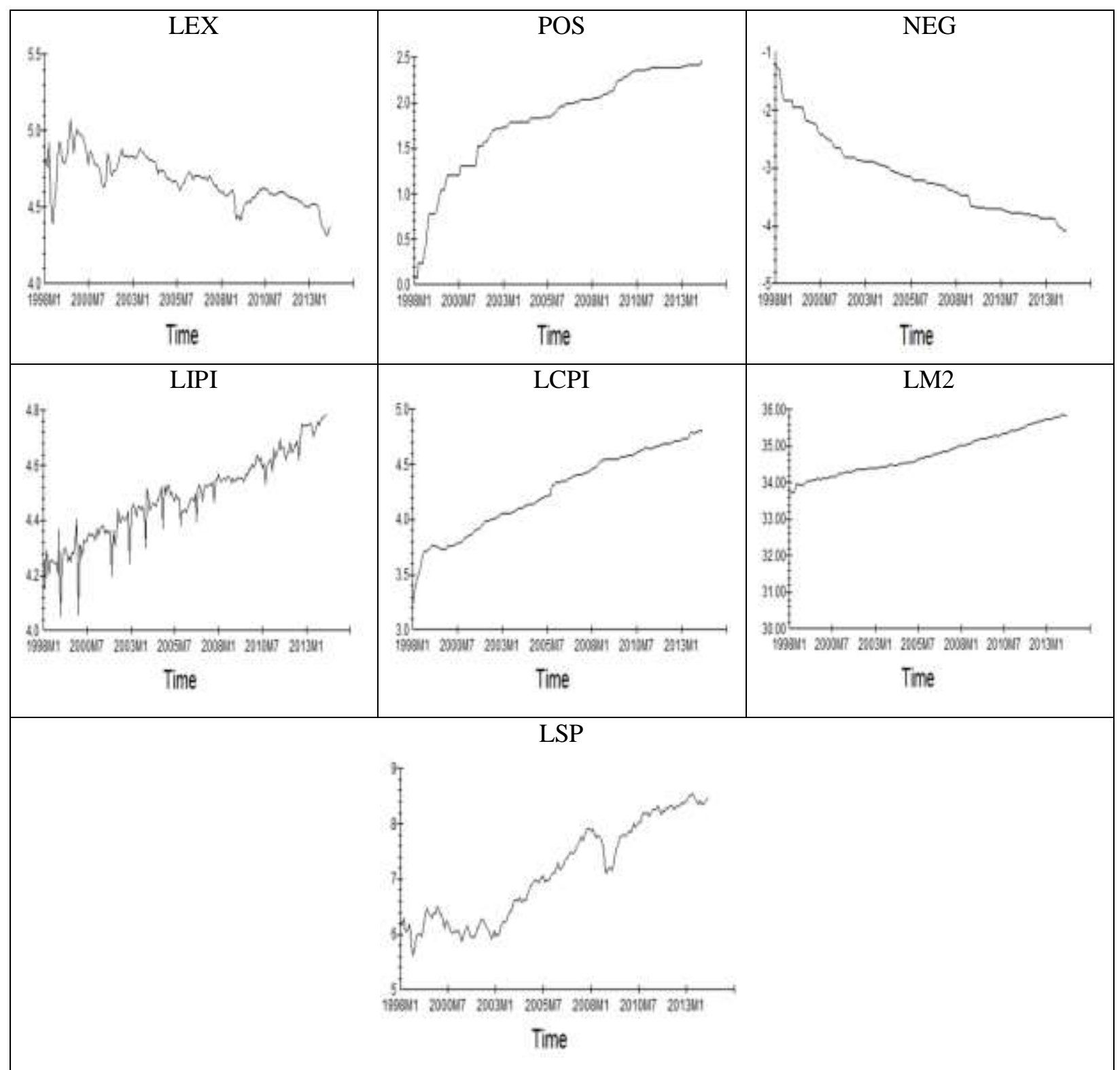

Note:

- LEX: Log (Nominal Effective Exchange Rate)

- POS: Appreciation of home currency

- NEG: Depreciation of home currency

- LIPI: Log (Industrial Production Index)

- LCPI: Log (Consumer Price Index)

- LM2: Log (Nominal Money Supply)

- LSP: Log (Stock Price Index) 


\section{Japan}

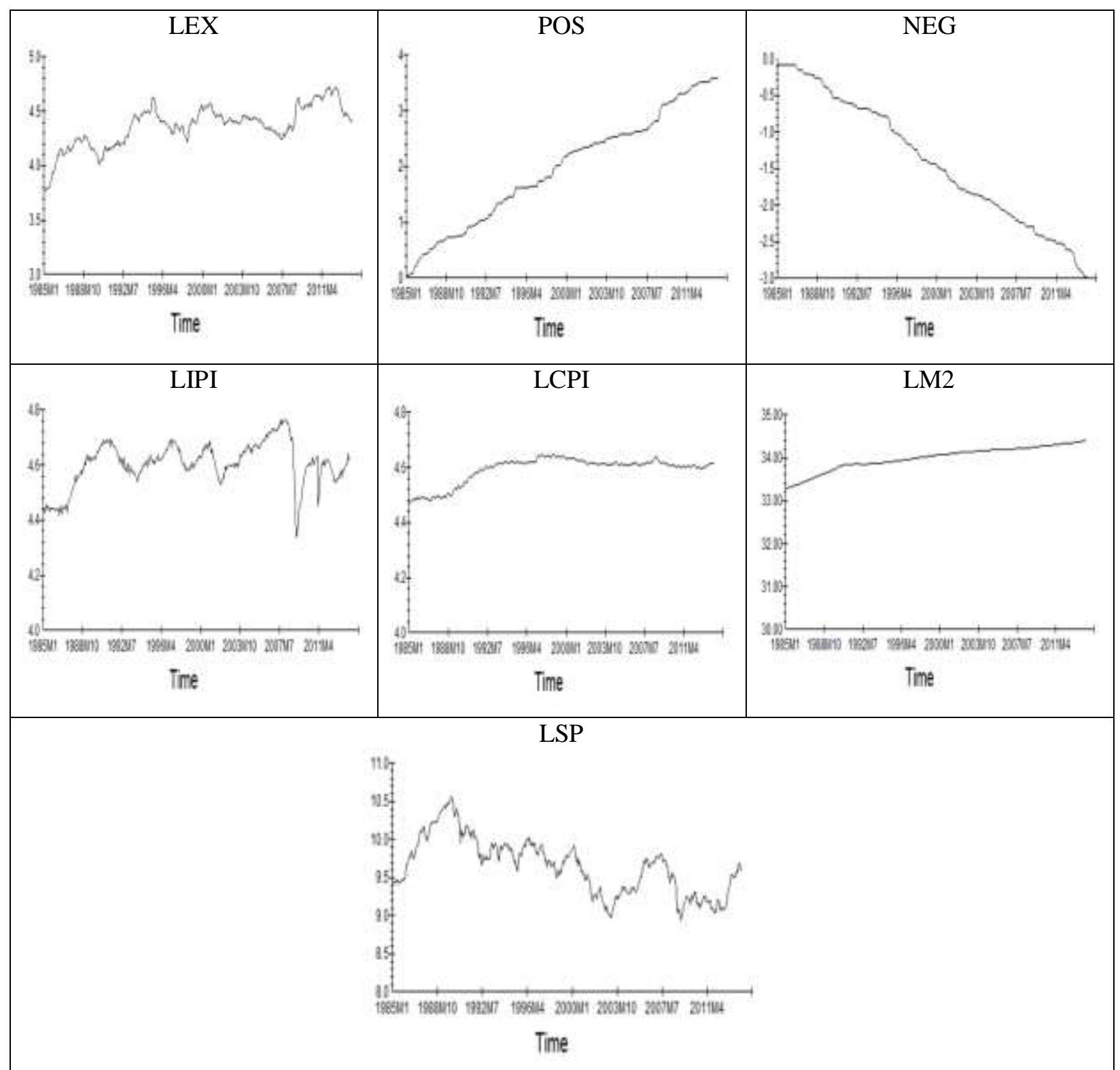

Note:

- LEX: Log (Nominal Effective Exchange Rate)

- POS: Appreciation of home currency

- NEG: Depreciation of home currency

- LIPI: Log (Industrial Production Index)

- LCPI: Log (Consumer Price Index)

- LM2: Log (Nominal Money Supply)

- LSP: Log (Stock Price Index) 


\section{Korea}

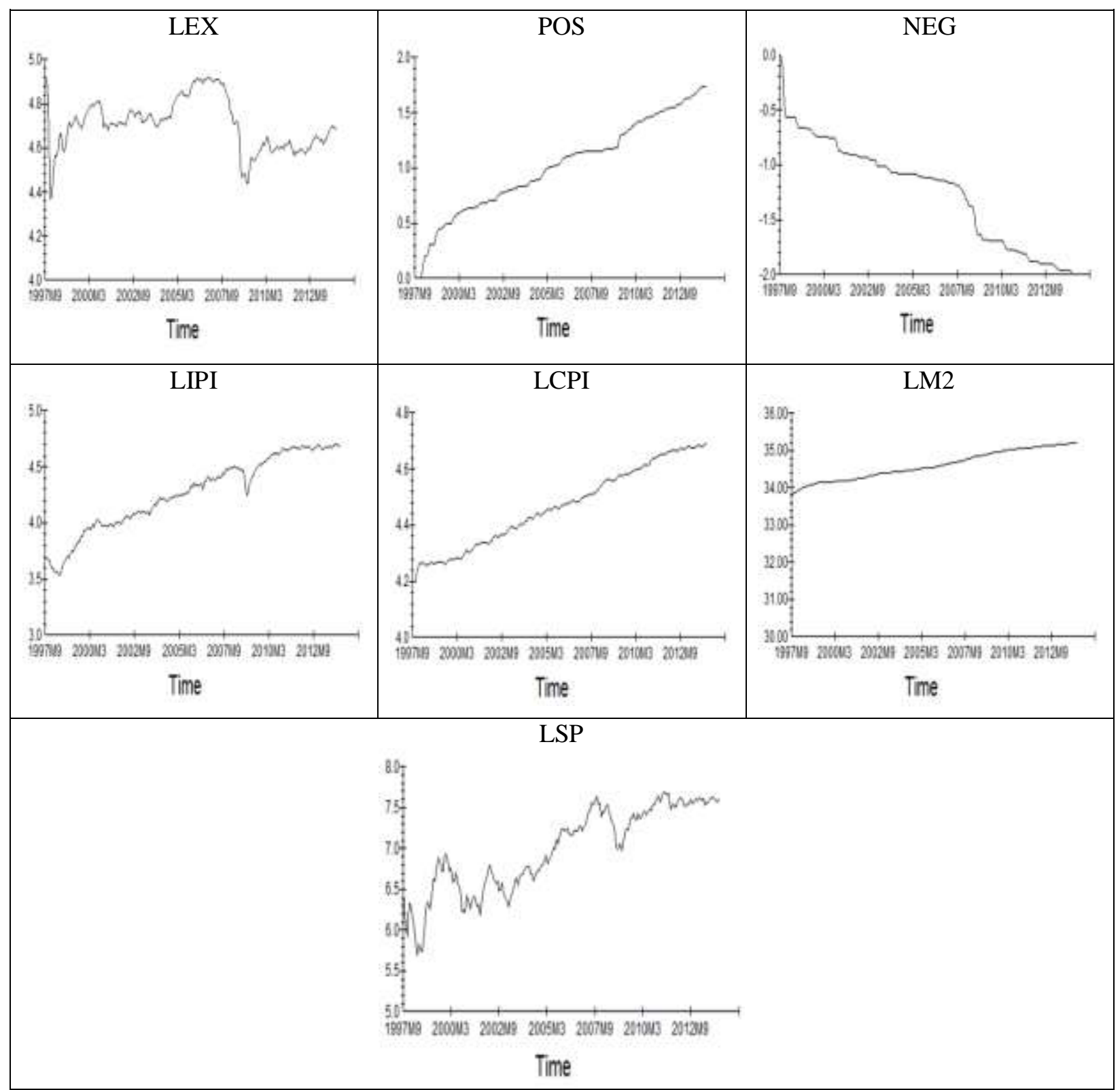

Note:

- LEX: Log (Nominal Effective Exchange Rate)

- POS: Appreciation of home currency

- NEG: Depreciation of home currency

- LIPI: Log (Industrial Production Index)

- LCPI: Log (Consumer Price Index)

- LM2: Log (Nominal Money Supply)

- LSP: Log (Stock Price Index) 


\section{Malaysia}

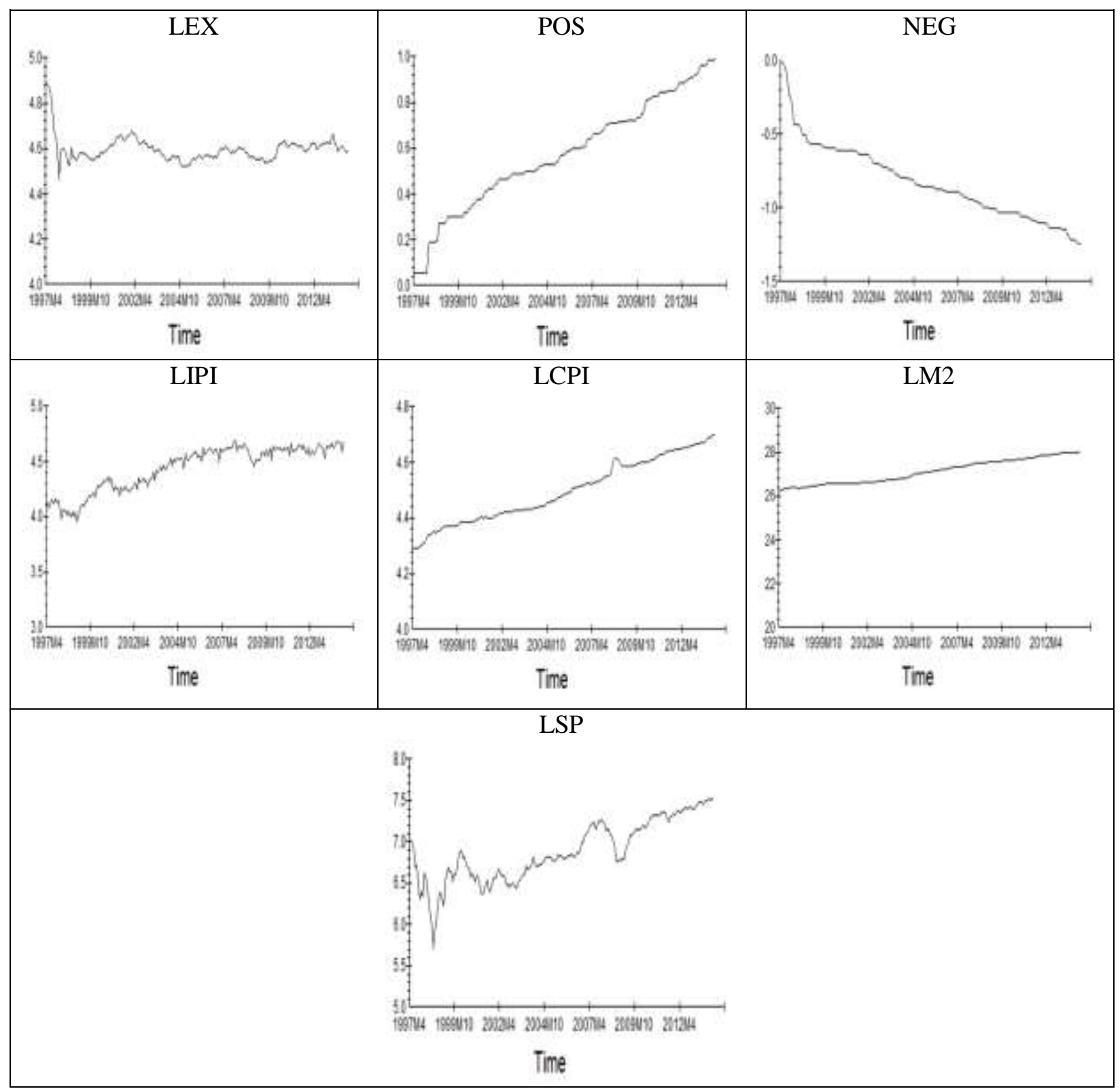

Note:

- LEX: Log (Nominal Effective Exchange Rate)

- POS: Appreciation of home currency

- NEG: Depreciation of home currency

- LIPI: Log (Industrial Production Index)

- LCPI: Log (Consumer Price Index)

- LM2: Log (Nominal Money Supply)

- LSP: Log (Stock Price Index) 


\section{Mexico}

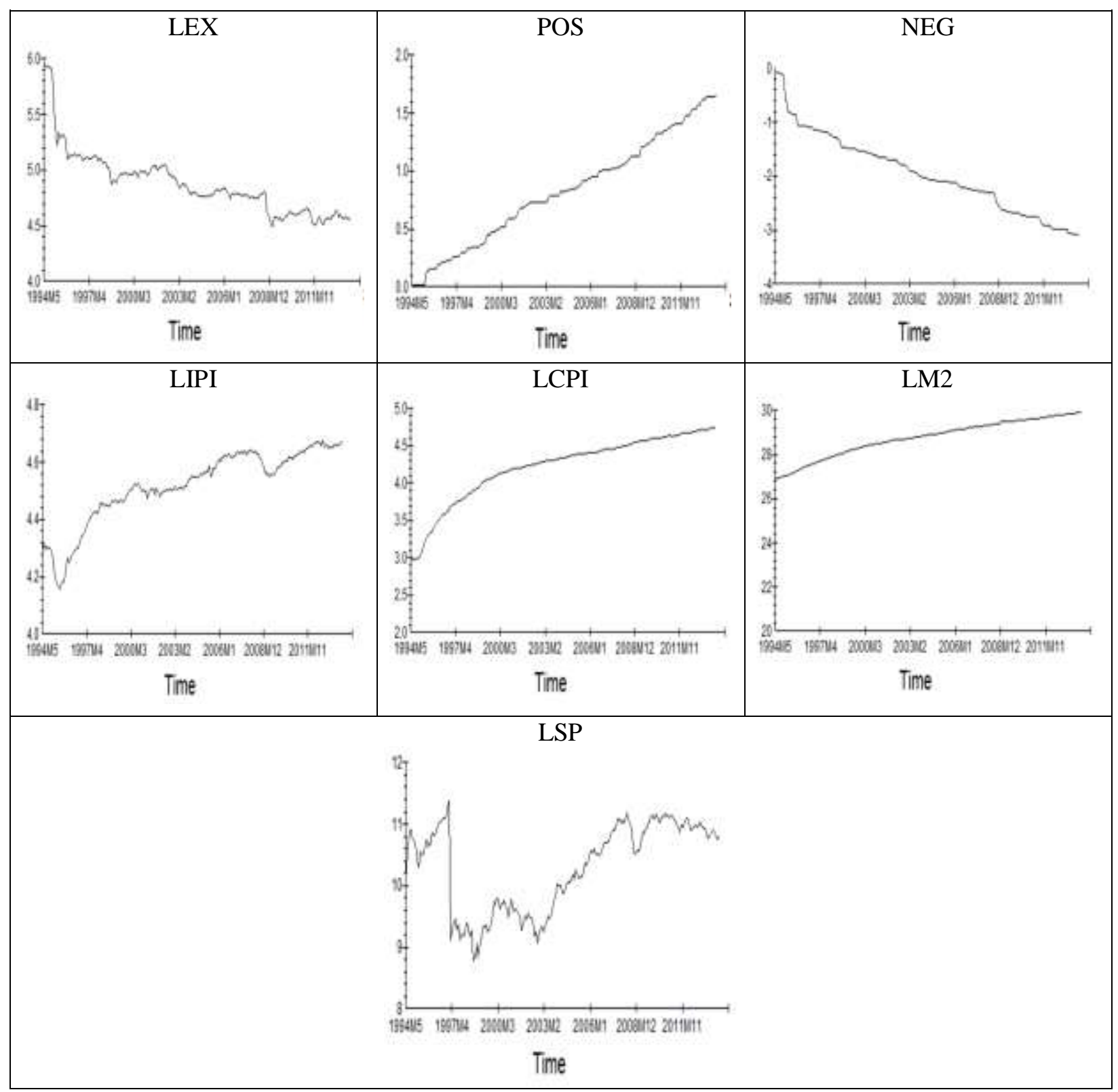

Note:

- LEX: Log (Nominal Effective Exchange Rate)

- POS: Appreciation of home currency

- NEG: Depreciation of home currency

- LIPI: Log (Industrial Production Index)

- LCPI: Log (Consumer Price Index)

- LM2: Log (Nominal Money Supply)

- LSP: Log (Stock Price Index) 


\section{U.K.}

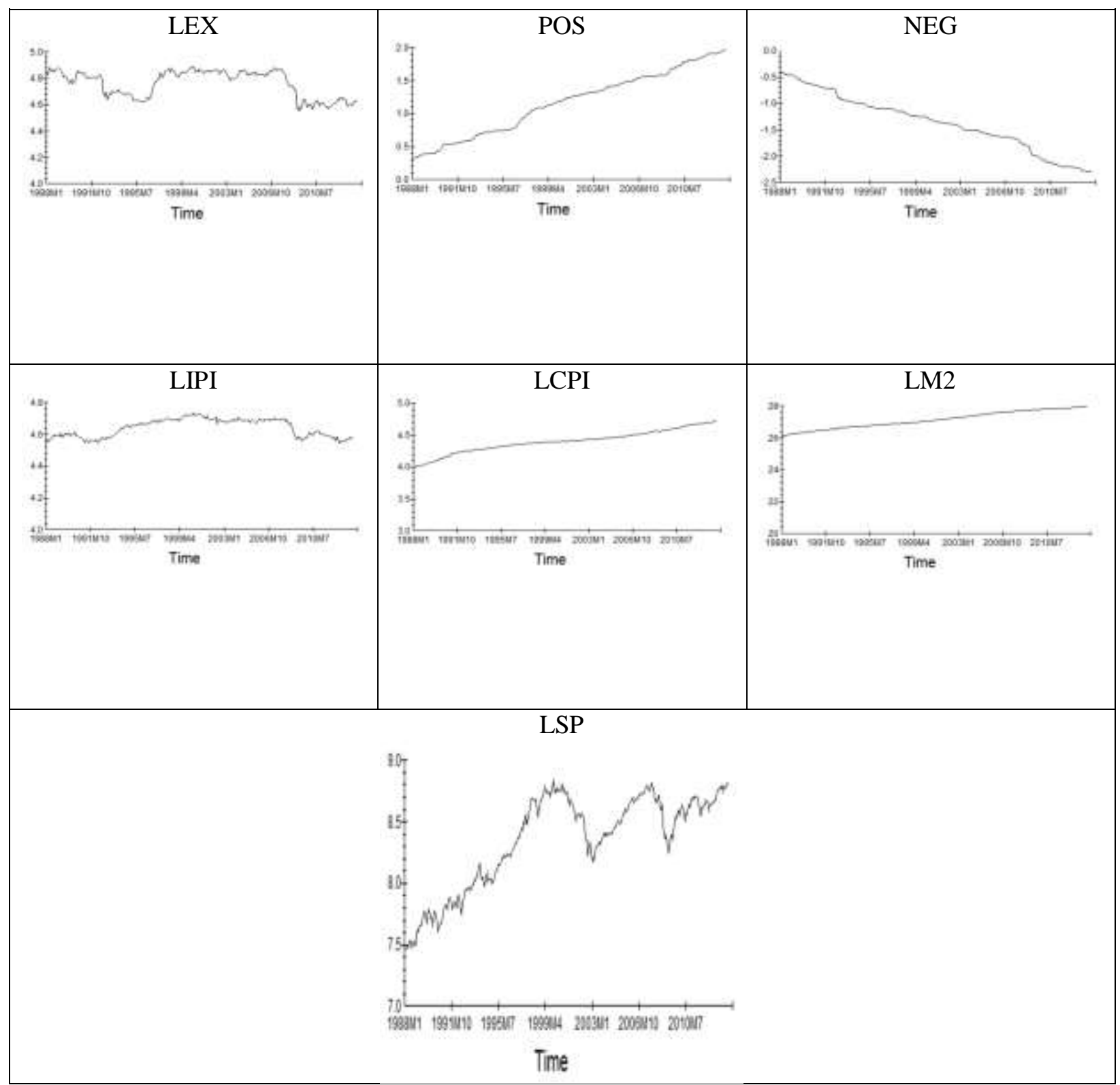

Note:

- LEX: Log (Nominal Effective Exchange Rate)

- POS: Appreciation of home currency

- NEG: Depreciation of home currency

- LIPI: Log (Industrial Production Index)

- LCPI: Log (Consumer Price Index)

- LM2: Log (Nominal Money Supply)

- LSP: Log (Stock Price Index) 


\section{U.S.A.}

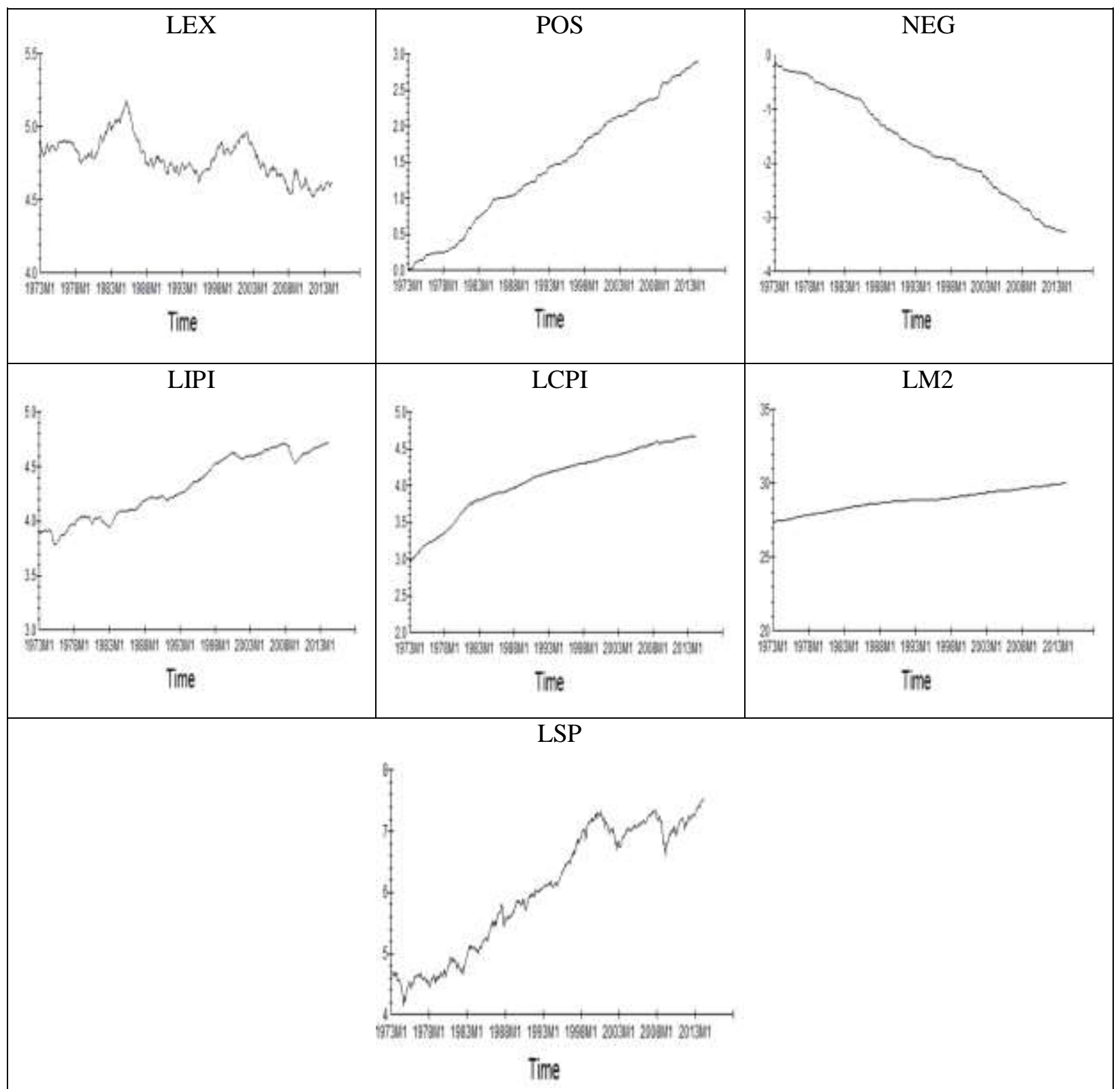

Note:

- LEX: Log (Nominal Effective Exchange Rate)

- POS: Appreciation of home currency

- NEG: Depreciation of home currency

- LIPI: Log (Industrial Production Index)

- LCPI: Log (Consumer Price Index)

- LM2: Log (Nominal Money Supply)

- LSP: Log (Stock Price Index) 


\section{Curriculum Vitae}

\section{SUJATA SAHA}

May, 2017

\section{Education}

- University of Wisconsin - Milwaukee, U.S.A., PhD in Economics, 2012 - 2017

- University of Calcutta, India, Master of Science in Economics, 2008

- University of Calcutta (Serampore College), India, Bachelor of Science in Economics, 2006

\section{Research Interests}

International Finance and Trade, Open Economy Macroeconomics, Econometrics

\section{Honors and Awards}

- William L. Holahan Prize for Outstanding Teaching by a Graduate Student (2016)

- Graduate Teaching Assistantship Award, University of Wisconsin - Milwaukee

- Ranked $1^{\text {st }}$ in Serampore College and $3^{\text {rd }}$ in University of Calcutta (Bachelor of Science, Economics)

- $\quad$ Ranked $5^{\text {th }}$ in University of Calcutta (Master of Science, Economics)

\section{Current Position}

- Lecturer, University of Wisconsin-Whitewater, Department of Economics.

\section{Future Position}

- Assistant Professor of Economics, Wabash College (Start Date: July, 2017).

\section{Publications}

1. "On the Relation between Stock Prices and Exchange Rates: A Review Article", 2015, Journal of Economic Studies, Vol. 42, No 4, pp. 707-732. (with Mohsen Bahmani-Oskooee)

2. "Asymmetry Cointegration between the Value of the Dollar and Sectoral Stock Indices in the U.S.”, 2016, International Review of Economics and Finance, Vol. 46, pp. 78-86. (with Mohsen Bahmani-Oskooee)

3. "Do exchange rate changes have symmetric or asymmetric effects on stock prices", 2016, Global Finance Journal, Vol. 31, pp.57-72. (with Mohsen Bahmani-Oskooee)

4. "Commodity Trade between the U.S. and Korea and the J-Curve Effect", New Zealand Economic Papers, forthcoming. (with Mohsen Bahmani-Oskooee and Jia Xu) 
5. "Non-Linear ARDL Approach and Bilateral J-Curve: India vs. Her Trading Partners", Contemporary Economic Policy, forthcoming. (with Mohsen Bahmani-Oskooee)

6. "On the Relation between Exchange Rates and Stock Prices: A Non-Linear ARDL Approach", Revised and resubmitted to Journal of Economics and Finance. (with Mohsen Bahmani-Oskooee)

7. "Asymmetric Response of the U.S.-India Trade Balance to Exchange Rate Changes: Evidence from 68 Industries", Revised and resubmitted to The World Economy. (with Mohsen Bahmani-Oskooee)

\section{Work in Progress}

“On the Impact of Policy Uncertainty on Stock Prices". (with Mohsen Bahmani-Oskooee)

\section{Teaching Experience}

\section{University of Wisconsin - Whitewater, Department of Economics}

- Lecturer

- Business Statistics: Fall 2016

- $\quad$ Principles of Macroeconomics: Spring 2017

University of Wisconsin - Milwaukee, Department of Economics

- Instructor

- $\quad$ Money and Banking: Spring 2015, Fall 2015, Spring 2016

- Principles of Macroeconomics : Fall 2013, Spring 2014, Fall 2014

- Economics of Personal Finance (online and in-person): Summer 2014, Fall 2014, Spring 2015, Fall 2015, Spring 2016

- Teaching Assistant

- Principles of Macroeconomics: Fall 2013, Spring 2014

- Grader

- Economics of Personal Finance: Spring 2014, Spring 2015

- Introduction to International Economic Relations: Spring 2015, Summer 2016

\section{Professional Activities}

- Financial Literacy Instructor, UW-Milwaukee Student Support Services Summer B ridge Program: Summer 2014, Summer 2015, Summer 2016.

- Math Tutor, Upward Bound, University of Wisconsin-Milwaukee: Summer 2016, Fall 2016, Spring 2017.

- Adult Tutor at Milwaukee Public Library, Volunteer: February 2012 - August 2012

- Undergraduate Student Tutor, India: 2005-2009, 2010-2011

- Volunteer, Make A Difference - Wisconsin: 2015-present

- Speaker at the UW-Milwaukee Department of Economics TA Training: 2015, 2016

- Speaker at the STEM-Inspire WiscAMP Boot Camp, Financial Literacy: January 2015

\section{Presentations}

Midwest Business Administration Association (MBAA) International Conference, April 2016. "On the Relation between Exchange Rates and Stock Prices: A Non-Linear ARDL Approach" 


\section{Language and Computer Skills}

- Language: English (fluent), Hindi (fluent), Bengali (native).

- Computer: Microfit, EViews, GAUSS, STATA, MATLAB, MS-Office.

\section{Professional Association}

American Economic Association, Golden Key International Honor Society. 